Aus der Poliklinik für Zahnärztliche Prothetik

Prof. Dr. med. dent. R. Bürgers

im Zentrum Zahn-, Mund- und Kieferheilkunde

der Medizinischen Fakultät der Universität Göttingen

\title{
Die DDR-1-knockout-Maus - ein neues \\ Tiermodell für Osteoarthritis im Kiefergelenk
}

\author{
INAUGURAL - DISSERTATION \\ zur Erlangung des Doktorgrades \\ der Medizinischen Fakultät der \\ Georg-August-Universität zu Göttingen
}

vorgelegt von

Gerhard Georg Leonard Hoene

aus

Hamburg

Göttingen 2018 
Dekan: $\quad$ Prof. Dr. rer. nat. H. K. Kroemer

Referent Prof. Dr. med. N. Miosge

Ko-Referent: $\quad$ Prof. Dr. med. Dr. med. dent. H. Schliephake

Drittreferent: $\quad$ Prof. Dr. med. dent. R. Mausberg

Datum der mündlichen Prüfung: 
Hiermit erkläre ich, die Dissertation mit dem Titel "Die DDR-1-knockout-Maus - ein neues Tiermodell für Osteoarthritis im Kiefergelenk" eigenständig angefertigt und keine anderen als die von mir angegebenen Quellen und Hilfsmittel verwendet zu haben.

Göttingen, den

(Unterschrift) 


\section{Inhaltsverzeichnis}



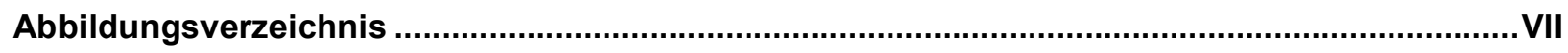

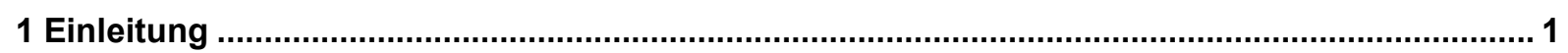

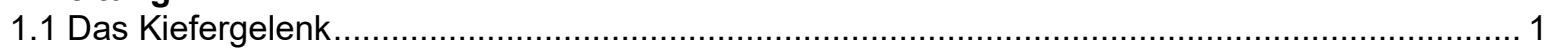

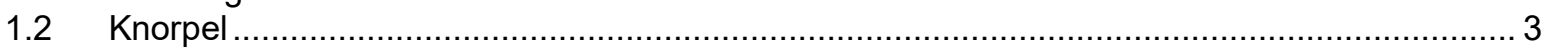

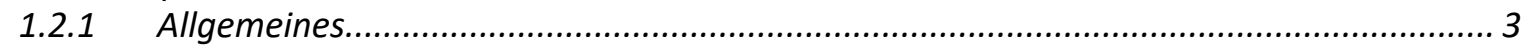

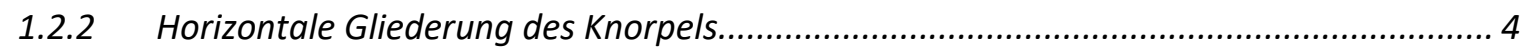

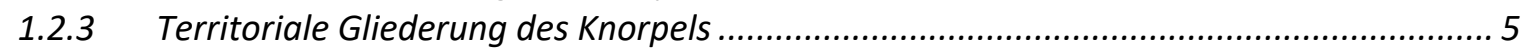

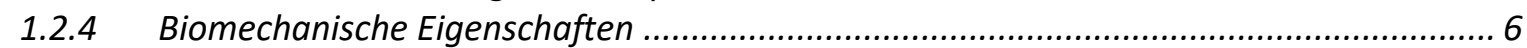



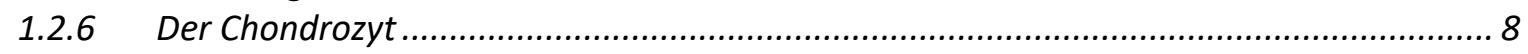

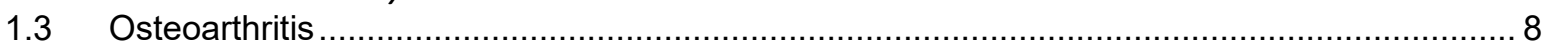

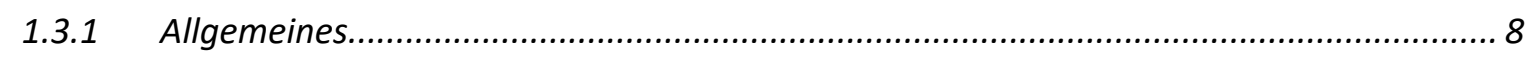

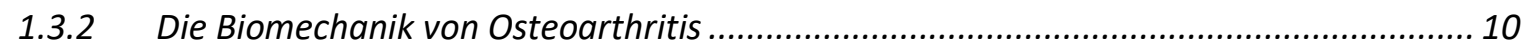

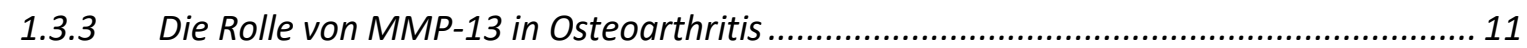

1.3.4 Nidogene und die perizelluläre Matrix in Osteoarthritis ............................................ 12

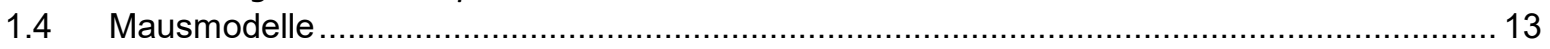

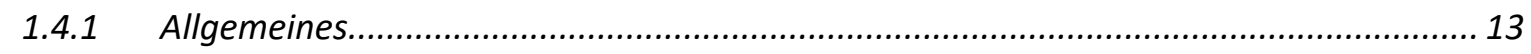

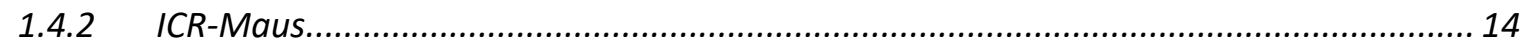

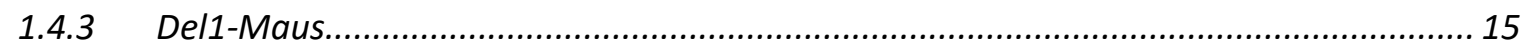

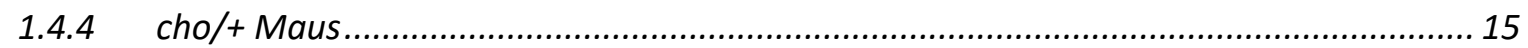

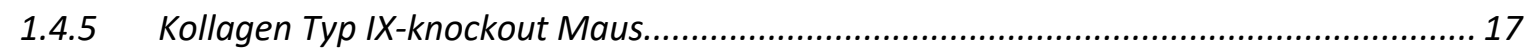

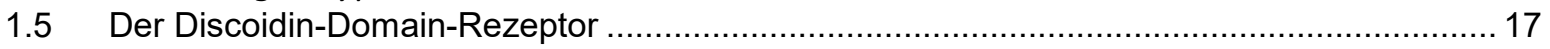

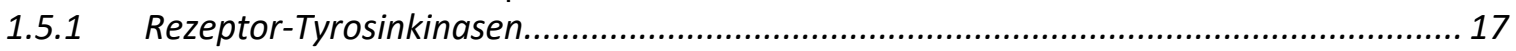

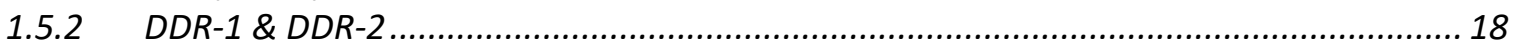

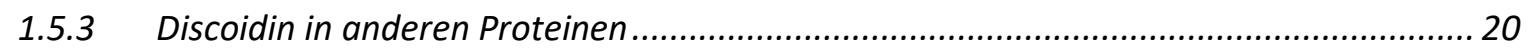

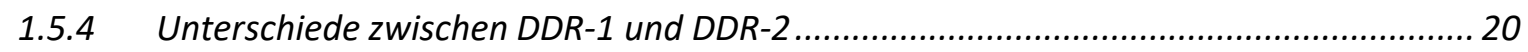



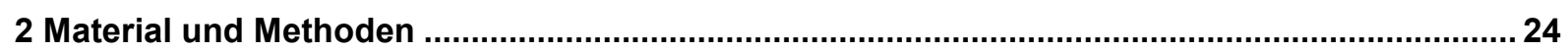

2.1 Lichtmikroskopische Immunhistochemie am Kiefergelenk der Maus von Kollagen Typ 1,

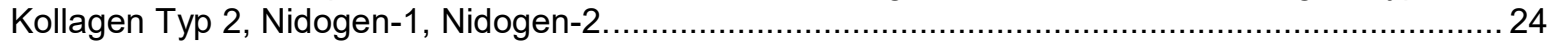

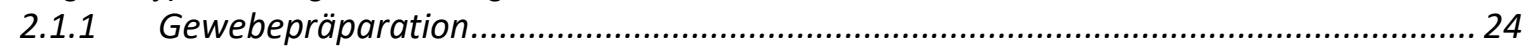

2.1.2 Protokoll zur Herstellung der histologischen Präparate .............................................. 26



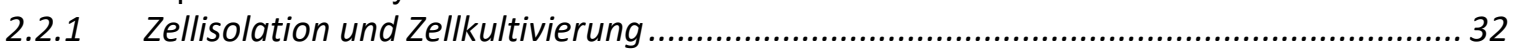

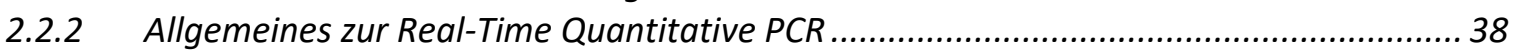

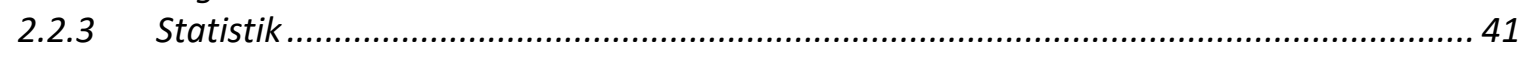

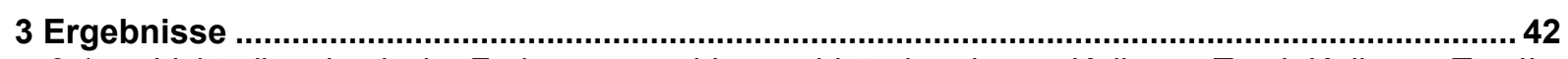

3.1 Lichtmikroskopische Färbungen und Immunhistochemie von Kollagen Typ I, Kollagen Typ II,

Nidogen 1 und Nidogen 2 im Kiefergelenksknorpel der DDR-1-knockout-Maus ............................. 42

3.2 Vergleichende Genexpressionsanalyse von Chondrozyten in Monolayer-Kultur und 3D-

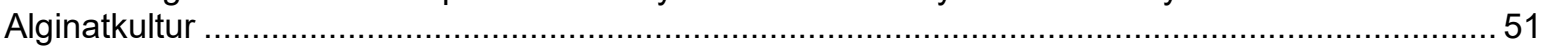



4.1 Diskussion der Ergebnisse der Genexpressionsanalyse und der immunhistochemischen

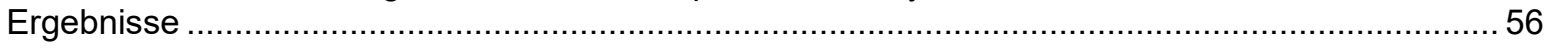

4.1.1 Veränderung des Chondrozyten und seiner perizellulären Matrix bei Osteoarthritis ..... 56

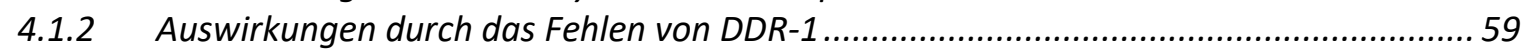

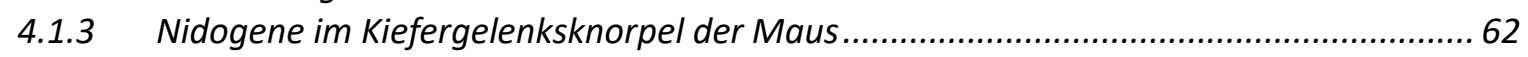

4.1.4 Osteoarthritis im Kiefergelenk - ein weit verbreitetes Krankheitsbild ............................ 64






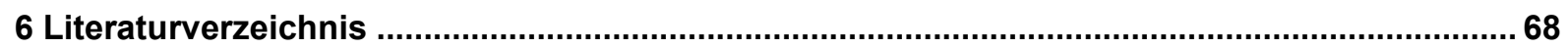

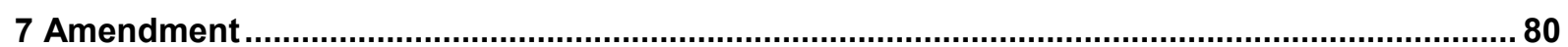




\section{Abkürzungsverzeichnis}

AK
ATM
aqua dest.
BLAST
cDNA
DAB
DDR
dNTP
DMEM
g
GAG
ml
HCl
HE-Färbung
HPRT
HRP
I
Lsg.
MPa
min
mRNA
NCBI
NSAP
PAP
PBS
PCR

Antikörper

Articulatio temporomandibularis

destilliertes Wasser

Basic Local Alignment Search Tool

komplementäre Desoxyribonukleinsäure

3,3'-Diaminobenzidin

Discoidin Domain-Rezeptor

Desoxyribonukleosidtriphosphate

Dulbecco's Modified Eagle Medium

Gramm

Glykosaminoglykane

Milliliter

Salzsäure

Hämalaun-Eosin-Färbung

Hypoxanthin-Phosphoribosyltransferase

Meerrettichperoxidase (horseraddish peroxidase)

Liter

Lösung

Megapascal

Minuten

messenger-Ribonukleinsäure

National Center for Biotechnology Information

nicht-steroidale Antiphloghistika

Peroxidase-Anti-Peroxidase

Phosphate-Buffered Saline

Polymerase-Chain-Reaction 


\section{Abbildungsverzeichnis}

Abbildung 1: Das knöcherne Kiefergelenk. 1

Abbildung 2: Schematische Darstellung der Proteine DDR-1 und DDR-2. ........................19

Abbildung 3: Dreidimensionales Modell der Discoidin-Domäne von DDR-1.

Abbildung 4: A Lichtmikroskopische Übersicht in HE- und Toluidinblaufärbung Färbung am Kiefergelenk der Maus.

Abbildung 5: Immunhistochemie: Kollagen Typ I am Kiefergelenk der Maus....................................45

Abbildung 6: Immunhistochemie: Kollagen Typ II am Kiefergelenk der Maus.....................................46

Abbildung 7: Immunhistochemie: Nidogen 1 am Kiefergelenk der Maus. ........................................ 47

Abbildung 8: Immunhistochemie: Nidogen 1 am Kiefergelenk der Maus. ..........................................48

Abbildung 9: Darstellung der Kiefergelenke von DDR-1-knockout-Mäusen in Toluidinblaufärbung und Immunhistochemie mit Kollagen Typ I.

Abbildung 10: Imunhistochemie für Nidogen 1 und für Nidogen 2 an Kiefergelenken DDR-1-



Abbildung 11: Relative mRNA-Level für Sox-9 und Runx-2 der q-PCR............................................52

Abbildung 12: Relative mRNA-Level für Aggrecan und Kollagen Typ I der q-PCR.........................53

Abbildung 13: Relative mRNA-Level für Sox-9 und Runx-2 der q-PCR..........................................5 54

Abbildung 14: Relative mRNA-Level für Aggrecan und Kollagen Typ I der q-PCR..........................55

Dabei entsprechen folgende Abbildungen jeweils Abbildungen aus der Publikation Schminke, Muhammad et al. (2013): A discoidin domain receptor 1 knock-out mouse as a novel model for osteoarthritis of the temporomandibular joint. Cell Mol Life Sci. 71(6):1081-96). Diese Publikation ist gemeint, wenn im folgenden Abschnitt auf die Publikation verwiesen wird. Eine weiterführende Erklärung findet sich im Amendment am Ende dieser Arbeit.

Auf Seite 43 entsprechen Abbildung 4A der Fig. 3b aus der Publikation, die Abbildung 4B der Fig. 1I aus der Publikation, der vergrößerte Ausschnitt der Abb. 4B der Fig. 1m aus der Publikation, die Abbildung 4C der Fig. 1j sowie der vergrößerte Ausschnitt der Abbildung 4C der Fig. 1k.

Auf Seite 46 entsprechen Abbildung 6B der Fig. 2e aus der Publikation, der vergrößerte Ausschnitt der Abb. 6B der Fig. $2 g$ aus der Publikation, Abbildung 6A der Fig. $2 f$ aus der Publikation und der vergrößerte Ausschnitt der Abbildung 6A der Fig. 2h aus der Publikation.

Auf Seite 47 entsprechen Abbildung 7B der Fig. 2i aus der Publikation und der vergrößerte Ausschnitt der Abb. 7B der Fig. 2k aus der Publikation.

Auf Seite 48 entsprechen Abbildung 8A der Fig. 2n aus der Publikation und der vergrößerte Ausschnitt der Abb. 8A der Fig. 2p aus der Publikation.

Auf Seite 49 entspricht Abbildung 9B der Fig. 2a aus der Publikation.

Auf Seite 50 entspricht Abbildung 10B der Fig. 2m aus der Publikation.

Auf Seite 52 entspricht die Abbildung 11A der Fig. 4d aus der Publikation.

Auf Seite 52 entspricht die Abbildung 11B der Fig. 4e aus der Publikation.

Auf Seite 53 entspricht die Abbildung 12A der Fig. 4g aus der Publikation.

Auf Seite 53 entspricht die Abbildung 12B der Fig. 4f aus der Publikation.

Auf Seite 54 entspricht die Abbildung 13A der Fig. 6c aus der Publikation. 
Auf Seite 54 entspricht die Abbildung 13B der Fig. 6a aus der Publikation.

Auf Seite 55 entspricht die Abbildung 14A der Fig. 6d aus der Publikation.

Auf Seite 55 entspricht die Abbildung 14B der Fig. 6b aus der Publikation. 


\section{Einleitung}

\subsection{Das Kiefergelenk}

Die folgende anatomische Beschreibung des menschlichen Kiefergelenks beruft sich auf dessen Darstellung in Benninghoffs Anatomie (Schmidt 2008).

Das Kiefergelenk (Articulatio temporomandibularis, ATM) gehört zu den echten Gelenken des Körpers. In echten Gelenken sind die beiden miteinander artikulierenden Knochen durch einen Gelenkspalt voneinander getrennt. Einer der beiden artikulierenden Knochen ist der walzenförmige Unterkieferkopf, das Caput mandibulae oder Condylus. Dieser sitzt antevertiert auf dem Kieferhals, dem Collum mandibulae. Der Condylus liegt in der Gelenkpfanne, der Fossa mandibularis, die wiederum eine Verbindung der unteren Außenseite des Schläfenbeins mit dem äußeren Gehörgang darstellt. Direkt ventral der Fossa mandibularis liegt ein Knochenwulst, das Tuberculum articulare.

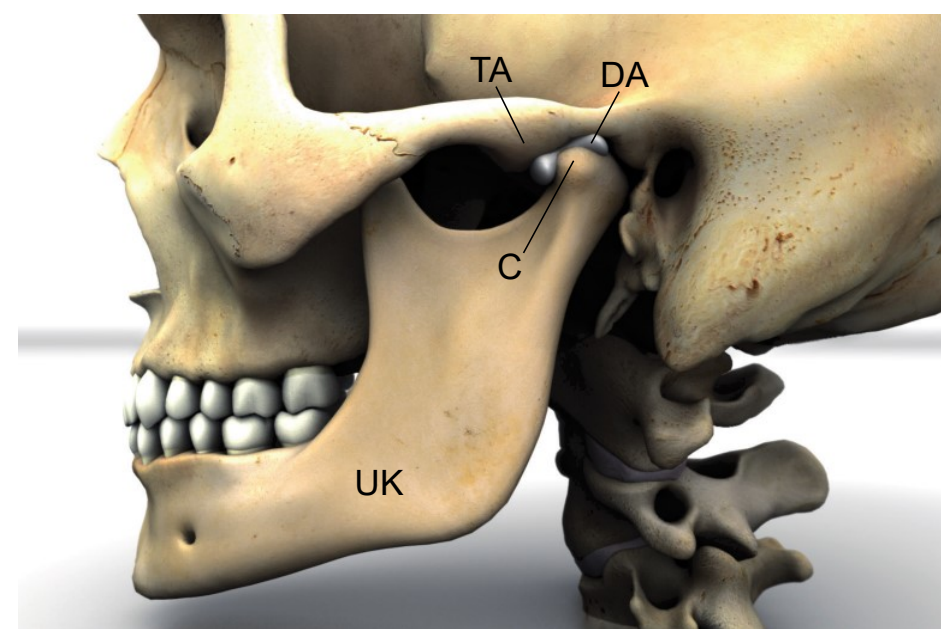

Abbildung 1: Seitliche Ansicht auf das knöcherne Kiefergelenk; unter freundlicher Bereitstellung der Abteilung Prothetik, UMG

Gut zu erkennen ist der helle Discus articularis (DA) zwischen Condylus (C) und Gelenkgrube, die nach ventral hin durch das Tuberculum articulare (TA) abgegrenzt wird.

UK: Unterkiefer, C: Condylus, DA: Discus articularis, TA: Tuberculum articulare 
Die Gelenkfläche (Facies articularis) wird von dem vorderen Teil der Fossa mandibularis und dem Tuberculum articulare gebildet. Beide sind beim Menschen überwiegend mit Faserknorpel überzogen. Auch der Kopf des Condylus besteht weitestgehend aus Faserknorpel. Es finden sich jedoch auch Anteile hyalinen Knorpels auf dem Condylus.

Das ATM ist von einer dünnen, relativ schlaffen Gelenkkapsel (Capsula articularis) umschlossen. Sie bildet die Gelenkflüssigkeit (Synovia) und ist so weit, dass der Condylus nach ventral vor das Tuberculum articulare luxieren kann, ohne dass die Gelenkkapsel reißt. Funktionell gehört zum ATM noch ein Bandapparat, der hauptsächlich aus drei verschiedenen Bändern besteht. Diese sind die Ligamenta stylomandibulare, sphenomandibulare und laterale, wobei nur letzteres eine direkte Verbindung mit der Gelenkkapsel besitzt. Der Bandapparat begrenzt die funktionelle Bewegung des ATM.

Das Kiefergelenk hat spezifische Charakteristika, durch welche es sich von den übrigen Gelenken des menschlichen Körpers unterscheidet. So haben die beiden Knochen keine direkte Verbindung zueinander, sondern stehen über eine faserknorpelige Scheibe, den Discus articularis, indirekt in Kontakt. Der Discus articularis kann mit den Menisci in den Kniegelenken verglichen werden. Er ist nötig, da die artikulierenden Gelenkflächen inkongruent zueinander sind, d. h., sie passen nicht optimal ineinander, wie es bei anderen Gelenken der Fall ist. Der Gelenkkopf ist, relativ zur Gelenkgrube gesehen, zu klein. Durch den Discus wird diese Inkongruenz ausgeglichen.

Der Discus wird durch unterschiedliche Gewebe gebildet. In seiner Mitte findet sich die dünne intermediäre Zone, die aus straffem Bindegewebe aufgebaut und gefäßfrei ist. Die verdickten Randzonen bestehen aus Faserknorpel. Diese Verdickungen heften sich rundherum an die Gelenkkapsel und teilen das Gelenk in zwei Kammern (Spatium articulare superius bzw. inferius). Nach lateral und medial ist der Discus direkt mit der Gelenkkapsel verwachsen. Nach dorsal löst er sich in ein bindegewebiges Balkenwerk auf, die sog. bilaminäre Zone, welche reichlich elastische Fasern, Nerven und Blutgefäße enthält. Sie grenzt den Gelenkraum nach dorsal hin ab.

Der Musculus pterygoideus lateralis hat seinen Ursprung teilweise am Discus articularis, in den seine Muskelfasern von ventral einstrahlen, und ist folglich maßgeblich für dessen Verlagerung bei Abduktion des Unterkiefers verantwortlich. Zusätzlich sind auch der Musculus masseter, der Musculus temporalis und der 
Musculus pterygoideus medialis an der Steuerung der Kiefergelenksbewegungen beteiligt.

Das ATM ist das einzige Gelenk des Körpers, das physiologisch eine Rotation und gleichzeitig eine Translation durchführen kann. Bei der Translationsbewegung tritt der Condylus aus der Fossa mandibularis heraus. Beide Bewegungsarten können zu einem gewissen Grad auch unabhängig voneinander vollzogen werden. Dabei ist das einzelne ATM nicht isoliert $z u$ betrachten, da es nur eine Komponente eines funktionellen Systems darstellt, welches neben der Kaumuskulatur (und somit auch neben dem Nervensystem), die Okklusionsflächen der Zähne sowie das kontralaterale Kiefergelenk miteinschließt. Aus diesem Grund müssen stets beide Kiefergelenke gleichzeitig tätig sein.

Die Hauptbewegung ist das Öffnen und Schließen der Zahnreihen. Während des Öffnens beschreibt der Condylus mitsamt dem Diskus eine Bewegung nach vorne unten. Für einen physiologischen Ablauf ist es dabei wichtig, dass sich die gefäßfreie, intermediäre Zone des Discus articularis immer zwischen Condylus und Rückseite des Tuberculum articulare befindet. Dort entsteht der stärkste Druck zwischen den Knochen. Der Diskus kann dem Condylus jedoch nicht in seinem vollen Umfang folgen, weil er durch die gedehnten elastischen Fasern der bilaminären Zone gebremst wird. Damit der Diskus nicht vollständig abrutscht und so den Kontakt zum Condylus verliert, kontrahiert der Musculus pterygoideus lateralis und hält den Diskus in seiner optimalen Position. Auch beim Schließen des Mundes sorgt der Musculus pterygoideus lateralis dafür, dass der Discus articularis nicht zu schnell zurückgleitet.

\subsection{Knorpel}

\subsubsection{Allgemeines}

Knorpel ist ein Stützgewebe, welches sich an verschiedenen Stellen im Körper findet. Die Konsistenz des Knorpelgewebes ergibt sich aus dem Zusammenschluss von extrazellulärer Matrix (EZM) und den darin eingeschlossenen spezialisierten Zellen, den Chondrozyten. Das Grundgerüst der EZM bilden verschiedene Kollagene und Proteoglykane. Die Proteoglykane sind mit sulfatisierten Glykosaminoglykanen (GAG, Chondroitinsulfate und Keratinsulfate) und nicht-sulfatisierten GAG verbunden. Dazu kommen verschiedene Kollagenfibrillen, die sich in Typ und Menge unterscheiden. 
Es existieren drei Haupttypen des Knorpelgewebes: hyaliner Knorpel, elastischer Knorpel und Faserknorpel (Kirkham und Samarainghe 2009). Diese Arten von Knorpelgewebe sind im Körper an verschiedenen Stellen lokalisiert und haben jeweils eine spezielle Architektur, die den jeweiligen funktionellen Eigenschaften entspricht. Hyaliner Knorpel formt die Wachstumsfuge der langen Röhrenknochen während des Heranwachsens (Sugiki et al. 2007). Zudem ist er in den meisten Diarthrosen vorhanden, wo er die miteinander artikulierenden Gelenkflächen überzieht. Elastischer Knorpel findet sich im menschlichen Körper an der Epiglottis, der Eustachi-Röhre des Ohres und in den kleinen Bronchien. Faserknorpel bildet sich zeitweise an Frakturen aus (Adams et al. 1996). Ansonsten ist er vorwiegend in drei Regionen des Körpers zu finden: in den intervertebralen Bandscheiben, in den Menisci der Kniegelenke und im ATM.

Diese Arbeit befasst sich insbesondere mit dem Kiefergelenk. Wie oben beschrieben, kommen im Kiefergelenk des Menschen zwei Knorpelarten vor: Faserknorpel und hyaliner Knorpel. Das Kiefergelenk der Maus unterscheidet sich von dem des Menschen in der mengenmäßigen Verteilung der Knorpelarten. So besteht der Kiefergelenksknorpel bei der Maus aus hyalinem Knorpel. Der Anteil von Faserknorpel ist hingegen nur sehr gering, wenn überhaupt vorhanden.

Diese Arbeit stellt ein neues Mausmodell vor, welches Osteoarthritis im Kiefergelenk, folglich im hyalinen Knorpel, entwickelt. Deswegen beziehen sich die folgenden Beschreibungen auf den hyalinen Gelenkknorpel (Cartilagines articulares).

\subsubsection{Horizontale Gliederung des Knorpels}

Hyaliner Gelenkknorpel lässt sich in verschiedene horizontale Zonen einteilen. Betrachtet man den Knorpel zunächst in einem sagittalen Schnitt, lässt sich zwischen dem kalzifizierten Knorpel und dem darüberliegenden nicht kalzifizierten Knorpel unterscheiden. Diese beiden Zonen werde durch die sog. Tide Mark abgegrenzt. Die Tide Mark ist eine Grenzlinie, die parallel zur Gelenkoberfläche verläuft und in histologischen Präparaten erkennbar ist. Der oberflächliche, nicht kalzifizierte Knorpel wird in drei weitere Zonen gegliedert: Die Superfizialzone, die Intermediärzone und die Basalzone. In der Nomenklatur gibt es hier Unterschiede, so dass die drei Zonen auch Tangential-, Transitional- und Radiärzone genannt werden. Letztere Einteilung bezieht sich dabei auf die Faserzugrichtug der Kollagenfibrillen (Rudert und Wirth 1998). Im 
hyalinen Knorpel dominiert Kollagen Typ II, während der Faserknorpel einen höheren Gehalt an Kollagen Typ I aufweist (Erye und Muir 1975).

Von der Tangentialzone bis zur Radiärzone verdoppelt sich das Zellvolumen der Chondrozyten ebenso wie ihre Oberfläche (Wong et al. 1996). Die Zellen, die in den verschiedenen Zonen vorkommen, unterscheiden sich nicht nur in Größe, Form und Anordnung, sondern auch in ihrer Stoffwechselaktivität (Aydelotte et al. 1988).

Die Zonen variieren zusätzlich noch in der Zusammensetzung und Ausrichtung der Kollagenfibrillen. In der Tangentialzone findet sich ein dichtes Kollagennetzwerk, in dem die einzelnen Fibrillen parallel zur Knorpeloberfläche liegen. Der Zweck dieser Zone scheint in erster Linie die Absorption von Scherkräften zu sein, die auf den Knorpel einwirken (Clark 1991). In der Transitionalzone liegen die Kollagenfibrillen weniger dicht gepackt. Hier ziehen sie arkadenförmig in Richtung Oberfläche. In der tiefen Radiärzone stehen die Kollagenfibrillen fast orthogonal zur Knorpeloberfläche und verankern das Knorpelgewebe im subchondralen Knochen (Gannon et al. 2012).

\subsubsection{Territoriale Gliederung des Knorpels}

Der Knorpel bzw. seine EZM lässt sich topografisch zusätzlich zu der horizontalen Gliederung auch in verschiedene Territorien einteilen. Diese verlaufen konzentrisch um die Chondrozyten und bilden dessen Mikroumgebung (Poole et al. 1984). Man unterscheidet die perizelluläre, territoriale und interterritoriale Matrix.

Dabei stellt letztere die eigentliche Knorpelmatrix dar. Die perizelluläre und territoriale Matrix machen zusammen nur ca. 10\% der Biomasse der gesamten EZM aus. Der Hauptbestandteil des hyalinen Knorpels ist ein dichtes Netzwerk aus verschiedenen Kollagenen. Hauptsächlich kommen Kollagen Typ II, VI, IX, X und XI vor.

In der perizellulären Matrix finden sich Kollagen Typ IX (Duance et al. 1982) und Kollagen Typ VI (Poole et al. 1992), welches das Chondron, die morphologische Grundeinheit des Knorpels, einkapselt. Die perizelluläre Matrix wird von der territorialen Matrix umschlossen, welche wiederum an die interterritoriale Matrix grenzt. In dieser liegen die Kollagenfasern dichter gepackt als in der territorialen Matrix (Poole et al. 1984, Paukkonen und Helminen 1987). Für die biomechanische Funktion des Knorpels ist auch die Ausrichtung der Kollagenfilamente von Bedeutung. Die Grundstruktur bilden Typ-II-Kollagenfibrillen. Sie ziehen ausgehend vom subchondralen Knochen arkadenartig durch den Knorpel. In der mineralisierten Zone und in der Radiärzone liegen sie dabei nahezu orthogonal zur Knorpeloberfläche. In 
der Tangentialzone und der Superfizialzone beschreiben sie dann einen Bogen, der sie wieder zurück in Richtung des subchondralen Knochens ziehen lässt. In diesem Grundgerüst aus Kollagen Typ II-Fibrillen gibt es weitere Quervernetzungen, die hauptsächlich wiederum aus Kollagen Typ II (Wu und Eyre 1989) und Kollagen Typ XI (Bruckner et al. 1992) bestehen. Hypertrophe Chondrozyten, die häufig im frühen Stadium von Osteoarthritis auftreten, synthetisieren zudem noch Kollagen Typ X in der metabolisch aktiven Zone des kalzifizierten Knorpels (Eavey et al. 1987).

\subsubsection{Biomechanische Eigenschaften}

Neben dem Kollagennetz wird das Hauptgerüst der EZM von Hyaluron, einem Polysaccharid, gebildet. Hyaluron ist mit dem Chondrozyten über CD44-Rezeptoren verbunden (Knudsen und Knudsen 2004). An das Hyaluron sind über das kleine Linkerprotein Hyaluronektin Proteoglykane geheftet. Im hyalinen Knorpel ist der Hauptvertreter der Proteoglykane das Aggrecan. Von den Proteoglykanen ragen flaschenbürstenartig die GAG ab. Die biomechanischen Eigenschaften des Knorpels hängen mit der Interaktion zwischen den einzelnen Komponenten der EZM zusammen: Die Seitenketten der GAG stoßen sich durch ihre nach außen gerichteten negativen Ladungen voneinander ab und besitzen aufgrund ihrer Polarität gleichzeitig eine hohe Wasserbindungskapazität. Durch diese sind sie maßgeblich an der Verteilung von Flüssigkeit im Knorpelgewebe beteiligt, was grundlegend für die Fähigkeit des Knorpels ist, extremen mechanischen Belastungen standzuhalten. Das hydrophile Verhalten der GAG lässt einen hohen endosmotischen Quellungsdruck entstehen. Die Kollagenfibrillen haben hierauf eine limitierende Wirkung. Ohne sie würde das Quellungsvolumen bis auf das Fünffache ansteigen. Entsprechend diesem Verhältnis setzt sie der Quellungsdruck unter eine Zugspannung von 0,2 MPa (Maroudas et al. 1980).

Das viskoelastische Verhalten des Knorpels lässt sich gut anhand des biphasischen Modells darstellen (Mobasheri 1998). Das biphasische Modell besteht aus einer festen Phase, zu welcher Zellen und andere feste Bestandteile der EZM gehören. Die bewegliche Phase besteht aus der interstitiellen Flüssigkeit. Das Modell nimmt an, dass, sobald ein Druck auf den Knorpel ausgeübt wird, dieser von der festen Phase absorbiert wird. Das Gerüst aus Zellen, Kollagen und Proteoglykanen wird zusammengepresst und die bewegliche Phase kann zu den Seiten austreten. Dadurch steigt der relative Gehalt der festen Phase an. Bei anhaltender Belastung kommt es 
zu einer erhöhten Reibung, da die Flüssigkeit den immer stärker werdenden Widerstand der Poren überwinden muss, die sich zwischen den Bestandteilen der festen Phase bilden (Mow et al. 1984). Der Flüssigkeitsausstrom endet erst, wenn der hydrostatische Druck der Kraft entspricht, die der Knorpel von außen erfährt.

\subsubsection{Chondrogenese}

In der frühesten Phase der Skelettentwicklung, der Chondrogenese, werden verschiedene Stadien durchlaufen. Zunächst findet während der Embryonalentwicklung die Migration und Proliferation mesenchymaler Stammzellen statt (Goldring et al. 2006). Danach kommt es zur Kondensation und Aggregatbildung der Zellen (Hall und Miyake 2000). Vor der Kondensation produzieren die mesenchymalen Zellen eine an Hyaluron und Kollagen Typ I reiche Matrix. Die Chondroprogenitorzellen exprimieren zudem Kollagen Typ II A, ein Prokollagen (Sandall et al. 1994). Es folgt die weitere Entwicklung zu Chondroblasten, bei der sowohl die Zellproliferationsrate als auch die Matrixproduktionsrate ansteigen. Kollagen Typ II und Aggrecan werden verstärkt exprimiert und die sog. „LinkerProteine" Kollagen Typ IX und XI können erstmalig nachgewiesen werden (Gebhard et al. 2004). Schließlich differenzieren sich die Chondroblasten zu bestimmten (epiphysären, metaphysären und ruhenden) Chondrozyten aus. Jeder einzelne Schritt in der Chondrogenese wird präzise von diversen Zell-Zell- und Zell-MatrixInteraktionen gesteuert (Goldring et al. 2006). Während der gesamten Proliferation und Differenzierung bis hin zum reifen Chondrozyten ist, neben den Faktoren Sox-5 und Sox-6 (Smits et al. 2004), v. a. Sox-9 ein wichtiger Transkriptionsfaktor (Henry et al. 2012). Das Gewebe, das die proliferierenden Chondrozyten umgibt, verändert sich. Eine Avaskularisierung findet statt, und die beginnende Verknöcherung lässt die Chondrozyten hypertrophieren. An den Gelenkflächen des Knochens findet diese Hypertrophie jedoch nicht statt. Die dort lokalisierten Chondrozyten behalten ihren prähyperthrophen Phänotyp bei und sind so imstande, die artikuläre Knorpelmatrix zu bilden (Goldring et al. 2006). 


\subsubsection{Der Chondrozyt}

Die Chondrozyten sind in der Knorpelmatrix in Chondronen organisiert. Ein Chondron ist die strukturelle Grundeinheit des Knorpels. Die Zahl der Chondrozyten, die sich in jeweils einem Chondron befinden, hängt von ihrer Lage in der Knorpelschicht ab. Jeder Chondrozyt innerhalb seines Chondrons stellt wiederum eine unabhängige funktionelle Einheit dar. Die Chondrozyten sind für die Produktion und Aufrechterhaltung ihrer direkten Umgebung verantwortlich. Da sich die von innen produzierte Matrix zwischen den einzelnen Zellen anlagert, haben die Chondrozyten keine direkte interzelluläre Verbindung (Kuettner et al. 1982). Sie kommunizieren folglich über die EZM miteinander (Kuettner 1992). Auch morphologisch zeigt sich ein dominantes raues endoplasmatisches Retikulum ebenso wie ein ausgeprägter GolgiApparat (Kuettner et al. 1982). Beide Organellen sprechen für die sezernierende Aktivität der Zelle (Mollenhauer et al. 2002). Des Weiteren finden sich im Zytoplasma viele freie Ribosomen und ein meist exzentrisch gelegener Kern.

\subsection{Osteoarthritis}

\subsubsection{Allgemeines}

Osteoarthritis ist eine weit verbreitete, alle Bevölkerungsschichten betreffende degenerative Gelenkerkrankung. Eine hohe Zahl von attestierten körperlichen Behinderungen und Frührenten gehen auf die Folgen einer osteoarthritischen Erkrankung zurück. Allein im Jahr 2007 belastete Osteoarthritis das Gesundheitssystem der USA mit Kosten von über \$185,5 Milliarden (Kotlarz et al. 2009).

Dabei ist Osteoarthritis nicht alleinig als Erkrankung des Gelenkknorpels zu verstehen, sondern eher als eine sich auf das gesamte Gelenk beziehende Erkrankung, bei der neben dem Gelenkknorpel auch der subchondrale Knochen, die Gelenkkapsel und die Synovialflüssigkeit erkrankt sein können (Brandt et al. 2006).

Mit dem Alter steigt die Gefahr, an Osteoarthritis zu erkranken. So weist die Mehrzahl der über 65-Jährigen radiologische oder/und klinische Symptome von Osteoarthritis auf (Felson 2006). Dabei sind die am stärksten belasteten Gelenke, wie z. B. Hüft- und Kniegelenke, am häufigsten betroffen. Jedoch kommt Osteoarthritis auch in kleineren Gelenken, wie denen der Hand und im Kiefergelenk vor. Die Schwere der osteoarthritischen Veränderungen ist nicht nur vom Alter abhängig (Fuerst et al. 2009), 
sondern auch von einigen anderen Faktoren. So sind zusätzlich zum erhöhten Alter auch ein erhöhtes Körpergewicht, das weibliche Geschlecht und biomechanische Instabilität bereits als Risikofaktoren identifiziert worden. Zudem gibt es Hinweise auf eine genetische Beteiligung (Rodriguez-Fontenla et al. 2014). Dies wurde bisher v. a. am Beispiel der Osteoarthritis der Hand gezeigt (Loughlin 2005; Suk et al. 2005; Zhai et al. 2009). Dabei scheint die Wirkung der genetischen Unterschiede u. a. von der Körpergröße und dem Geschlecht abzuhängen (Bukulmez et al. 2006).

Die Initiation des pathologischen Prozesses der Osteoarthritis folgt unabhängig von den auslösenden Faktoren immer einem bestimmten Muster (Hamerman 1989). Der erste Hinweis auf eine pathologische Veränderung ist das Auftreten von sog. Clustern, Ansammlungen von Chondrozyten. Diese Zellhaufen entstehen aufgrund einer erhöhten Zellproliferation und einer generell gesteigerten synthetischen Aktivität, die mit dem Versuch der Selbstreparatur einhergeht.

Es schließt sich der allmähliche Verlust der Proteoglykane an. Zunächst geschieht dies in den oberflächlichen Gelenkregionen, und wird gefolgt von dem Abbau von Kollagen Typ II. Schließlich entstehen an der Gelenkoberfläche Risse. In späteren Stadien wandelt sich hyaliner Knorpel in Faserknorpel um. Wahrscheinlich passiert dies durch den erfolglosen Versuch, die Risse durch Chondrozyten zu füllen. Am Ende entstehen Osteophyten und das Gelenk verknöchert.

Die osteoarthritischen Symptome sind vielfältig. Dazu gehören knackende Geräusche beim Bewegen, funktionelle Einschränkung in der Mobilität und Gelenkschmerzen in Ruhe und unter Belastung (Goldring 2006, Felson 2006, Glasson 2007). Die entzündliche Komponente im osteaoarthritischen Gelenk zeigt sich in der Synovialflüssigkeit anhand von vermehrtem Vorkommen von Entzündungsmediatoren (z. B. IL-6) sowie Proteasen, die die Knorpemartix abbauen. In Osteoarthritis zeigen sich generell jedoch geringere Mengen, als es bei der rheumatoiden Arthritis der Fall ist (Pozgan et al. 2010).

Eine effektive Therapie dieses Krankheitsbildes wäre sowohl primär für die Betroffenen als auch für das Gesundheitssystem sehr vorteilhaft. Bis heute beschränken sich die Therapieansätze jedoch weitestgehend auf die symptomatische Kontrolle der partiell auftretenden Entzündungszeichen und der Schmerzen. Diese werden zurzeit v. a. mit nicht-steroidalen Antiphlogistika und Physiotherapie behandelt (Wang et al. 2015). Ist die Erkrankung schon weiter fortgeschritten und die Funktion der Gelenke zu stark eingeschränkt, ist die letzte Option der operative Ersatz der Gelenke durch Prothesen. 
Diese limitierten Therapiemöglichkeiten zeigen, wie wichtig es ist, eine Therapie zu entwickeln, die sich möglichst gegen die Ursache und nicht nur gegen die Symptome der Erkrankung richtet. Ein zukünftiges Ziel könnte eine mögliche regenerative Therapie, z. B. durch sog. tissue engeneering, darstellen (Wang et al. 2015). Für solche Therapieansätze müssen allerdings zunächst die molekulargenetischen Ursachen und pathophysiologischen Mechanismen verstanden werden, die der Osteoarthritis zugrunde liegen.

\subsubsection{Die Biomechanik von Osteoarthritis}

Die der Osteoarthritis als Grundlage dienende Problematik lässt sich anhand von zwei Szenarien erklären. Es lässt sich unterscheiden zwischen physiologischem Knorpel unter pathologischer Last, hervorgerufen z. B. durch Übergewicht, einerseits, und pathologischem Knorpel unter physiologischer Last andererseits. Dieses im folgenden Absatz erklärte Szenario würde bei Knorpelverschleiß im Alter zutreffen oder bei einer pathologischen Veränderung in der Differenzierung der Chondrozyten bzw. der EZM des Knorpels, welches auch noch andere Ursachen als die des Alterns haben kann. Mit zunehmendem Alter nimmt die Synthese von Link-Proteinen und Proteoglykanen, besonders von Aggrecan, dem Hauptproteoglykan, ab (Bolton et al. 1999). Zusätzlich zeigt sich im höheren Alter auch eine Zunahme von Spaltprodukten von Aggrecan (Lee et al. 2013). Die EZM organisiert sich neu. Die Steifigkeit des Gewebes nimmt zu, da Kollagene vermehrt exprimiert werden und sich vorhandene Kollagenfibrillen stärker untereinander vernetzen. Des Weiteren nimmt die anabolische Aktivität der Chondrozyten mit zunehmendem Alter ab (Aigner und Gerwin 2007). Ihre ohnehin schon limitierte Fähigkeit zur Regeneration nimmt zusehends ab und auch eine weitere Proliferation findet nicht mehr statt. Dies beruht wahrscheinlich auf den im Alter eingeschränkten DNS-Reparatur-Mechanismen und verkürzten Telomerlängen (Martin et al. 2004). Ob apoptotische Chondrozyten Osteoarthritis hervorrufen oder ob sie eine Folge von Osteoarthritis sind, konnte bisher noch nicht geklärt werden (Zamli et Sharif 2011).

Im zweiten Szenario, bei dem der physiologische Knorpel eine externe Überlastung erfährt, zeigen die Chondrozyten eine gesteigerte Synthese von inflammatorischen Zytokinen und eine gesteigerte synthetische Aktivität. In-vitro- Experimente, die mechanische Belastung auf das Knorpelgewebe simulieren, zeigen, dass eine statische Belastung das Knorpelgewebe stärker schädigt, da dadurch ein Abbau von 
Proteoglykanen, eine Schädigung des Kollagennetzwerkes und eine verringerte Synthese von Knorpelmatrixproteinen hervorgerufen wird. Dagegen reagiert das Gewebe unter dynamischer Belastung mit einer verstärkten Synthese von Knorpelmatrixproteinen (Guilak et al. 2004). Kommt es zu einer traumatischen Verletzung des Knorpels, reagiert der Organismus mit einer gesteigerten Genexpression und einer erhöhten Expression von Entzündungsmediatoren (Kurz et al. 2005, Ding et al. 2010). Solche Effekte müssen nicht unbedingt Folge eines Übergewichts sein, sondern können auch durch eine Fehlstellung und die damit einhergehende Fehlbelastung entstehen.

Chondrozyten besitzen Rezeptoren, um mit der sie umgebenden EZM zu kommunizieren (Salter et al. 2004). Durch sie ist es den Chondrozyten möglich, auf mechanische Reize zu reagieren. Werden diese Rezeptoren, zu denen einige Integrine gehören, aktiviert, startet eine Kaskade, an deren Ende die gesteigerte Produktion von inflammatorischen Zytokinen, Chemokinen und Proteinasen, welche die EZM abbauen, stehen. (Pulai et al. 2005). Unter weiteren Rezeptoren finden sich auch der Discoidin-Domain-Rezeptor-1 (DDR-1) und der Discoidin-Domain-Rezeptor2 (DDR-2), der bevorzugt mit Kollagen Typ II interagiert und so ein Enzym, die MatrixMetalloprotease-13 (MMP-13), aktiviert (Xu et al. 2007).

\subsubsection{Die Rolle von MMP-13 in Osteoarthritis}

Da sich diese Arbeit mit den Discoidin Domain-Rezeptoren auseinandersetzt, ist es wichtig, die Rolle von MMP-13 in Osteoarthritis genauer zu betrachten.

Kollagene sind recht stabile Moleküle. Ihre Halbwertszeit im Knorpel wird mit ungefähr 117 Jahre beziffert (Verzijl et al. 2000). Ist Kollagen Typ II jedoch einmal zerstört, können die Chondrozyten nicht genügend Kollagen produzieren, um den Verlust auszugleichen und den Knorpel vollständig zu regenerieren. Die Abnahme von Kollagen Typ II bzw. die Zunahme seiner Fragmente, die bei der Zerlegung der Fibrillen entstehen, ist ein Hinweis für den Progress von Osteoarthritis. MMP-13 nimmt während des Fortschreitens des Krankheitsstadiums eine besonders wichtige Rolle ein, da es die Tripelhelices von Kollagen Typ II effektiver spalten kann als andere Enzyme, wie z. B. Matrix-Matalloprotease-1 (MMP-1) (Mitchell et al. 1996). MMP-13 spaltet die Ketten von Typ-II-Kollagen an den Aminosäuren (AS) „Gly906-Leu907“, wodurch zwei Fragmente entstehen, die ca. $3 / 4$ und 1/4 des ursprünglichen Moleküls entsprechen. Zusätzlich greift das Enzym das kürzere Stück nochmals an und spaltet 
es zwischen den AS „Gly909-GIn910“. MMP-13 wird im physiologischen Gelenkknorpel nur sehr geringfügig exprimiert. In osteoarthritischen Knorpel hingegen ist seine Expressionsrate deutlich erhöht (Reboul et al. 1996, Shlopov et al. 1997, Bau et al. 2002). Dies steht im Einklang mit der Beobachtung, dass bei einer dauerhaften Erhöhung von MMP-13 osteoarthritische Knorpelveränderungen in den Kniegelenken von Mäusen auftreten (Reboul et al. 1996).

Normalerweise ist das Kollagen Typ II-Netzwerk von Proteoglykanen und dem perizellulären Kollagen Typ VI, das kein fibrilläres Kollagen ist, umgeben und dadurch vor Proteasen geschützt. Polur et al. (2010) konnten zeigen, dass eine Serin-Protease aus der Familie der high temperature requirement (HtrA1)-Proteasen in menschlichem osteoarthtritischem Knorpel sowie in osteoarthritischem Korpel von Mäusen die perizelluläre Matrix abbauen und dadurch das Netzwerk aus Kollagen Typ II freilegen und MMP-13 zugänglich machen kann.

Die Expression von MMP-13 wird u. a. von dem Transkriptionsfaktor Runx-2 reguliert (Chen et al. 2012). Neben Runx-2 ist Sox-9 der weitere, wichtige osteogene Transkriptionsfaktor (Henry et al. 2012). Sowohl für die Chondrogenese bei Mäusen (Bi et al. 1999) als auch beim Menschen (Foster et al. 1994) ist Sox-9 ein wichtiger Regulator. Sox-9 nimmt eine Schlüsselrolle bei der chondrogenen Differenzierung ein (Koelling et al. 2009), während Runx-2 bei knorpelabbauenden Prozessen hochreguliert wird. Runx-2 und Sox-9 stellen praktisch direkte Gegenspieler dar (Zhou et al. 2006, Cheng und Genever 2010), was sich auch in ihren entgegengestzten Expressionsraten zeigt (siehe Ergebnisse Abb. 11 und Abb. 13). Auch RNA-bindende Proteine beinflussen die Expressionsraten von MMP-13 und Sox-9 und sind somit wichtig für die Homöostase des Knorpels (McDermott et al. 2016).

\subsubsection{Nidogene und die perizelluläre Matrix in Osteoarthritis}

Zusätzlich zu Transkriptionsfaktoren, wie Sox-9 und Runx-2, spielen spezielle Glykoproteine eine entscheidende Rolle in der Homöostase des Gelenkknorpels. Dies hängt mit seiner besonderen Mikroanatomie zusammen, in der die einzelnen Chondrozyten in keinem direkten Kontakt miteinander stehen (siehe Abschnitt 1.2.6 Der Chondrozyt). Damit es trotzdem zu einem interzellulären Informationsaustausch kommen kann, sind die Chondrozyten auf Zell-Matrix-Interaktionen angewiesen (Kuettner 1992). Dafür exprimieren die Chondrozyten diverse Oberflächenrezeptoren, darunter Integrine (Loeser 2002), aber auch Rezeptor-Tyrosinkinasen (RTKn), zu 
denen die Discoidin-Rezeptoren (Goldring et al. 2011) gehören. Die perizelluläre Matrix ist demnach ein wichtiger Bereich für die zwischenzelluäre Kommunikation. Folglich nimmt eine gestörte perizelluläre Matrix in der Pathogenese von Osteoarthritis eine zentrale Rolle ein (Poole et al. 1991).

Die Glykoproteine Nidogen 1 (Carlin et al. 1981) und Nidogen 2 (Kohfeldt et al. 1998) sind bekannte Bestandteile der Basalmembran, einer spezialisierten EZM, die Zellen umgibt und sie von der interstitiellen - im Falle des Chondrozyten von der interterritorialen - Matrix abgrenzt (Timpl 1996). Neben den Nidogenen gehören einige Isoformen des Laminins, Kollagen Typ IV und Perlecan zu den obligaten Bestandteilen ubiquitär vorkommender Basalmembranen (Timpl 1996, Kvist et al. 2008). Nidogene zeigen perizellulär in späten osteoarthritischen Stadien ein erhöhtes Vorkommen in humanem Knorpelgewebe (Kruegel et al. 2008) und stellen somit einen Biomarker für Osteoarthritis dar.

\subsection{Mausmodelle}

\subsubsection{Allgemeines}

Ein Tiermodell für menschliche Krankheiten kann definiert werden als eine einheitliche Gruppe von Tieren, die eine geerbte, auf natürliche Weise erworbene oder künstlich induzierte Modifikation besitzen, die es zum Verständnis menschlicher Krankheiten wissenschaftlich zu untersuchen gilt (Pritzker 1994).

Ein ideales Tiermodell erfüllt gewisse Kriterien. Es sollte möglichst die gewebespezifischen und die molekulargenetischen Eigenschaften des menschlichen Gewebes aufweisen, folglich ein Wirbeltier sein. Große Tiere lassen sich eventuell besser untersuchen, während kleine Tiere mit weniger Aufwand zu halten sind. Des Weiteren sollte die Pathologie des Krankheitsbildes im gewählten Tier soweit wie möglich mit der des Menschen übereinstimmen. Dies ist bei Osteoarthritis schwierig, da die komplexe Ätiologie und Pathogenese der Osteoarthritis auch beim Menschen noch nicht vollständig verstanden sind. Das Krankheitsbild müsste reproduzierbar sein und alle spezifischen Stadien der Pathogenese darstellen. Schließlich sollten Therapiekonzepte, die für das Tiermodell entwickelt wurden, auf den Menschen übertragbar sein und zu gleichen Ergebnissen führen (Little und Smith 2008).

Es gibt mehrere Gründe, weshalb gerade Mäuse sinnvolle Versuchstiere sind. Sie sind klein und dadurch relativ pflegeleicht. Ihre Züchtung ist einfach, und ihre Haltekosten 
sind bedeutend geringer als bei größeren Tieren. Neben ihrer Körpergröße, die bspw. chirurgische Interventionen schwierig macht, sind weitere Nachteile $u$. a. bekannte molekulare Unterschiede zwischen Gewebe der Mäuse und humanem Gewebe (z. B. das Fehlen von MMP-1) (Balbin et al. 2001).

In Mäusen kann Osteoarthritis durch verschiedene Faktoren hervorgerufen werden. Das Krankheitsbild kann durch angeborene oder erworbene, lokalisierte oder generalisierte Defekte des Knorpels entstehen, z. B. als Folge metabolischer Erkrankungen, die den Kalziumhaushalt betreffen. Ebenso kann Osteoarthritis sekundär aufgrund einer inadäquaten Anatomie oder durch ein (kalkuliertes) Trauma hervorgerufen werden. Beispielsweise ist es Xu et al. (2009) gelungen, Osteoarthritis im TMJ der Maus durch eine partielle Diskektomie herbeizuführen. Diese Methode wurde im Verlauf auch bei Hasen erfolgreich angewendet (Embree et al. 2015). Auch im kontralateralen gesunden Kiefergelenksknorpel kommt es zu osteoarthritischen Veränderungen, nachdem eine partielle einseitige Diskektomie stattgefunden hat (Cohen et al. 2014).

Osteoarthritische Veränderungen kommen in verschiedenen genetisch modifizierten Mäusestämmen vor. Es gibt bereits mehr als 40 knockout-Mäusestämme, die Formen von Osteoarthritis zeigen (Raducanu und Aszódi 2008). Keines dieser Modelle erfüllt die oben genannten Kriterien. Deshalb ist es wichtig, dass das verwendete Tiermodell der Fragestellung angepasst wird. Die knockout-Mäuse sind nicht als globale Modelle für die Entstehung und Behandlung von Osteoarthritis zu sehen. Vielmehr liefern sie Informationen über bestimmte Komponenten und deren Rolle in osteoarthritischen Prozessen.

Da diese Arbeit die DDR-1-knockout-Maus als ein neues Tiermodell für die Forschung von Osteoarthritis am ATM vorstellt, ist es wichtig, einige andere Mausmodelle zu kennen, die Osteoarthritis im ATM beschreiben.

\subsubsection{ICR-Maus}

Das erste Mausmodell, das Osteoarthritis im ATM beschreibt, ist ein Mäusestamm des Institute of Cancer Research (ICR). Die meisten männlichen Mäuse zeigten typische osteoarthritische Veränderungen des Gelenkknorpels nach 7 Monaten (Silbermann und Livne 1979). Die Läsionen korrelierten mit dem Alter der Mäuse und zeigten sich durch verminderte Anfärbung mit Safranin-O, Zellverlust in den oberflächlichen Knorpelzonen und unebenen Gelenkknorpeloberflächen, die teilweise auch Fissuren 
aufwiesen. In höherem Alter wiesen die ICR-Mäuse extreme Befunde von Osteoarthritis auf, bei denen der Knorpel bis hin zur Tidemark dezimiert war. Die Autoren nahmen an, dass die degenerativen Veränderungen in oberflächlichen Regionen begannen und sich in die tieferen Knorpelschichten ausbreiteten (Livne und Silbermann 1986). Später stellte Livne (1994) die Hypothese auf, dass die Kombination aus vermindertem Vorkommen von sulfatisierten GAGn und einer reduzierten Zellzahl in den superfizialen Zellschichten des Kiefergelenkknorpels die Knorpelarchitektur in Bezug auf mechanischen Stress destabilisierte und es dadurch leichter zur Entstehung von Osteoarthritis kam.

\subsubsection{Del1-Maus}

Das zweite Modell für Osteoarthritis im ATM ist das der Del1-Maus. Hier findet sich eine mutierte Variante von Kollagen Typ II a1 (Col2a1). Es kommt u. a. zu einer kleinen Deletion auf Exon 7 und auf Intron 7, die das Kollagen codieren. Die Deletion führt zu einem Verlust der letzten 15 AS am Aminoende der Triplehelix (Metsäranta et al. 1992). Dies beeinträchtigt die Struktur des Kollagengerüstes und prädisponiert die Tiere für früh einsetzende osteoarthritische Vorgänge. Wie auch bei der DDR-1knockout-Maus gehört hier das für die Knorpelstruktur essentielle Kollagen Typ II zu einem der beeinflussten Parameter des experimentellen Ansatzes.

Homozygote Del1-Mäuse zeigen schwere Formen der Chondrodysplasie (siehe Abschnitt 1.4 .4 cho/+ Maus) und versterben perinatal aufgrund von respiratorischen Problemen (Metsäranta et al. 1992). Heterozygote Del1-Mäuse werden etwa $15 \%$ kleiner im Vergleich zum Wildtyp, überleben und entwickeln verschiedene Grade von Osteoarthritis. Erste osteoarthritische Knorpelschäden entstehen ab einem Alter von drei Monaten. Es bilden sich subchondrale Zysten und vereinzelt Fissuren in der Gelenkfläche, die mit dem Alter allmählich fortschreiten (Rintala et al. 1997). Interessanterweise beeinträchtigt das mutierte Kollagen Typ II nicht das Wachstum des condylären Knorpels.

\section{$1.4 .4 \mathrm{cho} /+$ Maus}

Ein Krankheitsbild, welches eng mit Osteoarthritis verknüpft ist, ist die Chondrodysplasie. Daher sind Mausmodelle, die für die Forschung von dieser Krankheit verwendet werden, auch für die Osteoarthritisforschung relevant. 
Chondrodysplasie ist eine autosomal rezessive Erkrankung (Seegmiller et al. 1971). Sie geht mit dem Verlust von Kollagen Typ XI a1-Ketten in der Knorpelmatrix einher. Dieser Verlust resultiert aus einer Deletion eines einzelnen Nukleotides im Gen, welches für Kollagen Typ XI a1 codiert. Diese Deletion führt zu einem frameshift und dadurch zu einem Stopp der Translation von Kollagen Typ XI $\alpha 1$, wobei auch schon die codierende mRNA nur noch stark reduziert vorkommt (Li et al. 1995). Kollagen Typ $\mathrm{XI}$ ist ein fester und wichtiger, wenn auch nicht prominenter, Bestandteil der Knorpelmatrix (Olsen 1995). Aufgrund der Mutation kommt es zur Ausprägung besonders dicken Kollagenfibrillen, die kein optimales Milieu für Proteoglykane und andere Bestandteile der EZM bieten (Xu et al. 2003). Homozygote cho-knockout Mäuse zeigen das Vollbild der Chondrodysplasie. Sie besitzen ein mutiertes, frühzeitiges Stoppcodon ( $\mathrm{Li}$ et al. 1995), haben verkürzte Schnauzen und Abnormalitäten im Knorpel der Rippen, der Extremitäten, des Kiefers und der Trachea, so dass sie aufgrund von Atembeschwerden bei ihrer Geburt sterben (Seegmiller et al. 1971).

Ein im Kollagen Typ XI heterozygtes Mausmodell, auch cho/+ bzw. Col11a1+/genannt, eignet sich als Forschungsobjekt für die degenerative Knorpelerkrankung, die auch als Stickler-Syndrom bekannt ist. Das Stickler-Syndrom ist eine relativ milde Form einer Chondrodysplasie. Es geht mit Mutationen in Genen einher, die bestimmte Kollagen Typ XI-Ketten (Col11a1 und Col11a2) oder Typ-II-Kollagen (Col2a1) kodieren (Snead und Yates 1999). Die cho/+ Maus entwickelt ca. 3 Monate nach Geburt osteoarthritische Veränderungen in Form von Zellhaufen (Clustern) in den Knie- und Kiefergelenken. Damit geschieht dies einige Monate früher, als beim gleichaltrigen Wildtyp (Olsen 1995, Xu et al. 2003). Nach 6 Monaten zeigt sich ein Verlust von Proteoglykanen im Kiefergelenksknorpel. Einen ausgeprägten osteoarthritischen Phänotyp, welcher weiteren Proteoglykanverlust und Fissuren im Gelenkknorpel zeigt, entwickeln die heterozygoten cho/+ Mäuse erst nach 9 bis 12 Monaten (die normale Lebensdauer beträgt ca. 30 Monate) (Xu et al. 2003). Es kommt folglich erst relativ spät zur vollen Ausprägung von Osteoarthritis im ATM. Dennoch ist die cho/+ Maus ein etabliertes Tiermodell in der Forschung an degenerativen Knorpelerkrankungen, speziell der Chondrodysplasie. 


\subsubsection{Kollagen Typ IX-knockout Maus}

Genau wie das Kollagen Typ XI, welches bei der cho/+ Maus betroffen ist, kommt auch das heterotrimere Kollagen Typ IX ( $\alpha 1 \alpha 2 \alpha 3)$ in der Knorpelmatrix vor. Histologische Untersuchungen an Kollagen Typ IX-knockout-Mäusen (Col9a1-/-) zeigen, dass es auch hier nach 3 Monaten zu osteoarthritischen Veränderungen kommt, welche denen im Abschnitt 1.4.4 beschriebenen Veränderungen entsprechen (Hu et al. 2006).

Der osteoarthritische Phänotyp, den die Col9a1-/- Mäuse ausbilden, stellt ein weiteres relevantes Modell für degenerative Knorpelerkrankungen dar, wie sie z. B. bei der Multiplen Epiphysialen Dysplasie (MED) auftreten. MED ist eine heterogene Gruppe erblicher Chondrodysplasien, die sich durch eine früh eintretende Osteoarthritis bemerkbar machen. Betroffene Menschen zeigen zudem eine geringfügig kleinere Körpergröße. MED wird durch Mutationen im Kollagen Typ IX (Col9a1, Col9a2 und Col9a3), im oligomären-Knorpel-Matrix-Protein (COMP) oder im Matrilin 3 ausgelöst (Hecht et al. 1995, Borochowitz et al. 2004).

In beiden zuletzt behandelten Mausmodellen (cho/+ und Col9a1-/-) und wurde eine erhöhte Expression von MMP-13, DDR-2 und ebenso ein erhöhter Gehalt von Kollagen Typ II-Fragmenten nachgewiesen, die anscheinend durch MMP-13 entstanden sind (Xu et al. 2003, Hu et al. 2006, Li et al. 2007). Diese Veränderungen im Milieu des Knorpels, insbesondere die veränderte Expression der DiscoidinDomain-Rezeptoren (DDR-1 und DDR-2), sind auch für das in dieser Arbeit vorgestellte Mausmodell von Relevanz.

\subsection{Der Discoidin-Domain-Rezeptor}

\subsubsection{Rezeptor-Tyrosinkinasen}

Die zelluläre Reaktion, z. B. auf eine Verletzung oder auf einen anderen externalen Stimulus, hängt stark von einem Mechanismus ab, bei dem ein Protein reversibel phosphoryliert wird. Katalysiert wird diese Reaktion von einer Gruppe von Enzymen, die als Protein-Tyrosin-Kinasen (PTKn) bekannt sind. PTKn können in zwei Gruppen klassifiziert werden. Zum einen gibt es solche PTKn, die mit keinem Rezeptor assoziiert sind (Cantley et al. 1991). Zum anderen gibt es PTKn, die direkt oder indirekt mit einem Rezeptor, meistens für Wachstumsfaktoren, in Verbindung stehen. Man bezeichnet sie als RTKn. Bisher konnten 21 verschiedene Tyrosinkinasen, mit und 
ohne Rezeptor, auf genetischer Ebene im humanen Chondrozyten identifiziert werden (Islam et al. 2001). Die Tyrosinkinase selbst kommt als intrazelluläre Untereinheit eines membranständigen Rezeptors vor und besitzt katalytische Aktivität. Die Tyrosinkinase wird aktiv, sobald ein für sie spezifischer Botenstoff an die extrazelluläre Domäne des Rezeptors bindet. Man spricht bei solchen Botenstoffen von Liganden. Im Falle der RTKn entsprechen diese Liganden meist den jeweiligen Wachstumsfaktoren, bspw. EGF, dem „epidermal growth factor“ oder IGF-1, dem „insulin-like growth factor 1“ .

Wie beschrieben, haben Chondrozyten in gesundem Knorpelgewebe kaum bzw. keinen Kontakt zu benachbarten Knorpelzellen. Sie liegen einzeln in durch Kollagen Typ II abgegrenzten Knorpelhöhlen. Dass dennoch eine interzelluläre Kommunikation stattfinden kann, liegt an Signalübertragungswegen, die durch Oberflächenrezeptoren vermittelt werden. Dazu zählen u. a. die schon erwähnten Integrinen (Loeser 2002) und die RTKn.

Kommt es während der interzellulären Kommunikation zur Bindung eines spezifischen Liganden an den Oberflächenrezeptor, ist dies der Start für eine Signaltransduktionskaskade. Die RTK geht in ihre aktive Form über. Dabei phosphoryliert sie Tyrosin-Reste von Proteinen, die an der weiteren Signaltransduktion beteiligt sind. RTKn haben demnach Einfluss auf verschiedene Zellfunktionen wie Wachstum, Differenzierung, Migration, Stoffwechsel und Zellzyklus.

\subsubsection{DDR-1 \& DDR-2}

In Wirbeltieren wurden diverse Gene beschrieben, die für eine große Anzahl von verschiedenen RTKs codieren. Diese wurden je nach Aufbau und Funktion ihrer extrazellulären Domäne in Subfamilien eingeteilt (van der Geer et al. 1996). Eine Subfamilie der RTKn unterscheidet sich von den anderen durch ein ca. 155 AS langes homologes, extrazellulär gelegenes Motiv, das Discoidin-Motiv, welches zuerst bei dem Einzeller Dictyostelium discoideum aus der Klasse der Schleimpilze beschrieben wurde (Rosen et al. 1973).

Zwei Proteine, die an ihrem Aminoende diese spezielle homologe Discoidindomäne $($ DiscD) tragen, wurden in der Wissenschaft schon häufiger beschrieben. Eines von innen wurde u. a. als DDR, NEP, Cak, TrkE, Ptk-3, MCK-10, EDDR1, RTK6 oder NTRK4 benannt. Mittlerweile wird es als Discoidin-Domain-Receptor-1 (DDR-1) bezeichnet. Das andere Protein, Discoidin-Domain-Receptor-2 (DDR-2), war früher auch als CCK-2, Tyro10 oder TKT bekannt (Vogel 1999). 
Wie alle RTKen sind auch die Mitglieder der DDR-Subfamilie transmembrane Proteine, die aus verschiedenen Domänen aufgebaut sind. Es kommt immer eine extrazellulär gelegene DiscD vor. Sie ist sowohl bei DDR-1 als auch bei DDR-2 homolog und ca. 155 AS lang. Sie schließt die Region ein, an der spezifische Kollagene binden können. An die DiscD schließt sich direkt die sog. stalk-Region an. Diese etwa 200 AS lange Domäne ist charakteristisch für Proteine der DDR-Subfamilie. Schließlich folgt ein einzelnes transmembranes Peptid, eine juxtamembranöse intrazelluläre Region und der Abschnitt, der die eigentliche Kinaseaktivität besitzt (Abdulhussein et al. 2004).

Es wurden bisher fünf verschiedene Isoformen des DDR-1 entdeckt. Sie entstehen durch alternatives Splicing und werden als DDR-1a-e bezeichnet, wobei die beiden letzteren keine Kinaseaktivität aufweisen (Alves et al. 2001). Des Weiteren unterscheiden sich die Isoformen in der Anzahl der AS, aus denen sie aufgebaut sind. So ist DDR-1b in der juxtamembranösen Region 37 AS länger als DDR-1a. Die cIsoform ist wiederum aus fünf zusätzlichen AS aufgebaut, die sich in der Kinaseregion befinden. Am Beispiel von Ratten lässt sich zeigen, dass sich während der Entwicklung die Verhältnisse der Isoformen verändern. Der Anteil von DDR-1b nimmt dabei stetig zu, während der von DDR-1a abnimmt (Abdulhussein et al. 2004).

DDR-1

(913 AS)

DDR-2 (855 AS)

Abbildung 2: Schematische Darstellung der Proteine DDR-1 und DDR-2; modifiziert nach Abdulhussein et al. 2004, S. 31464; AS: Aminosäuren, DiscD: Discoidin Domäne, stalk: stalk-Region, TM: transmembranöse Domäne, JM: juxtamembranöse Domäne, Kinase: Domäne mit Kinaseaktivität

In der Evolution der DDR-Proteine gibt es Hinweise darauf, dass die Familie des nervalen Botenstoffes Neurotrophin bei Säugetieren eng mit dem DDR-1 verwandt ist. Neurotrophin ist ebenso wie DDR-1 eine RTK und ist im Aufbau bis zu $58 \%$ homolog mit DDR-1 (Gamulin et al. 1997). 


\subsubsection{Discoidin in anderen Proteinen}

Neben den RTKn gibt es noch andere Proteine, die Discoidin beinhalten. Bei Säugern sind die Neurolipine und die Neurorexine bekannt. Diese sind an der Entwicklung des Nervensystems beteiligt. Neurolipine besitzen eine doppelte DiscD, die zwischen anderen Domänen liegt, die in Zelladhäsionsproteinen häufig exprimiert werden. Auffallend ist, dass eine ca. 80 AS lange Region, die sich beim Neurolipin an das Discoidin anschließt, ebenso in der extrazellulären Region des DDR-2 vorkommt (AS 254-336) (Lai und Lemke 1994).

Des Weiteren findet man DiscDn in verschiedenen Sekretionsproteinen, wie z. B. in den Koagulationsfaktoren V und VIII oder dem menschlichen Retinoschisin, einem Netzhaut-spezifischen Protein, das von Bipolarzellen und Photorezeptoren als homooktamerischer Proteinkomplex sezerniert wird (Wu et al. 2005). Beide Proteinformen, die Koagulationsfaktoren und das Retinoschisin, stehen in einem engen Zusammenhang mit Krankheitsbildern des Menschen, welche durch Punktmutationen im Discoidin auftreten.

Im gesunden Organismuns entstehen während der Koagulation des Blutes Bindungen zwischen den Discoidin-Anteilen der Faktoren V und VIII und Phospholipiden auf den Thrombozyten. Verhindern Mutationen eine regelrechte Expression von Discoidin, kommt es zum Owren-Syndrom (Parahämophilie) bzw. zu Hämophilie A (Kane und Davie 1988, Liu et al. 2000). Eine Mutation der Discoidinkomponente des Retinoschisins führt zu einer Fehlfunktion des Proteins und dadurch zur frühkindlichen Erblindung (Wu et al. 2005).

\subsubsection{Unterschiede zwischen DDR-1 und DDR-2}

DDR-1 und DDR-2 kommen in verschiedenen Geweben wie z. B. Knochen, Knorpel, Haut, Gehirn, Skelett- und Herzmuskel von Menschen und Mäusen vor. Sie unterscheiden sich nicht nur in ihrem jeweiligen Aufbau, sondern v. a. in der Spezifität ihrer Liganden. Dabei dienen sowohl bei DDR-1 als auch bei DDR-2 verschiedene Kollagene als passende Bindungsmoleküle am Epitop des Rezeptors. Die extrazelluläre Domäne von DDR-1 besitzt eine höhere Affinität zu Kollagen Typ I als die des DDR-2-Proteins. Wahrscheinlich steht dieser Unterschied in der Bindungseigenschaft im Zusammenhang mit Variationen in der stalk-Region des jeweiligen Proteins. Diese stimmen nur zu 44 \% überein, während die Discoidin Domänen 58 \% Homologie aufweisen (Abdulhussein et al. 2004). DDR-1 interagiert 
zwar bevorzugt mit Kollagen Typ I, kann aber ebenso von Kollagenen Typ II, III, IV und V aktiviert werden (Vogel 1999). 1997 fanden zwei verschiedene Forschungsgruppen unabhängig voneinander heraus, dass die Liganden von DDR-2 die fibrillären Kollagene der Typen I, II und III sind (Vogel et al. 1997, Shrivastava et al. 1997). Abdulhussein et al. 2004 beschreiben, dass DDR-2 zusätzlich durch fibrilläres Kollagen Typ $\vee$ aktiviert wird. Weitere Analysen mit diesen Kollagenen ergaben, dass DDR-2 die Bindung mit Kollagen Typ II bevorzugt (Leitinger et al. 2004). Genau wie Integrine Kollagene binden, ist DDR-2 in der Lage, einzelne AS-Motive in der Triplehelix des Kollagenmoleküls zu erkennen und mit innen Bindungen einzugehen (Konsitsiotis et al. 2008).

Bei der Bindung von Kollagenen, die zur Bildung eines Kollagennetzwerkes fähig sind, haben DDR-1 und DDR-2 sehr spezifische Liganden. DDR-1 geht überwiegend Bindungen mit Kollagen Typ IV ein (Vogel et al. 1997), wohingegen Kollagen Typ X als Interaktionspartner von DDR-2 dient. Allerdings ist seine DiscD unfähig, Kollagen Typ X fest zu binden (Leitinger und Kwan 2006).

Anders als bei der Interaktion von löslichen Wachstumsfaktoren mit RTKn braucht die Aktivierung von DDR-1 und DDR-2 relativ viel Zeit. Die Tyrosinkinase erreicht ihre höchste Aktivität erst 18 Stunden, nachdem der Rezeptor durch einen Liganden stimuliert wurde. Dann ist die RTK jedoch bis zu vier Tage aktiv, ohne dass es zu einer verminderten Aktivität oder Inhibition des Rezeptors kommt (Vogel 1999).

Interessanterweise war es nicht möglich, DDR-1 und DDR-2 durch eine kurze, synthetisch hergestellte Kollagen-Tripelhelix aus 10 Kollagen-Wiederholungen [(GlyPro-Hyp)x10] zu aktivieren (Vogel 1999). Dies steht im Zusammenhang mit dem Expressionslevel der Matrix-Metalloprotease-1 (MMP-1), einem Enzym, das als Substrat natives fibrilläres Kollagen benötigt. MMP-1 wird hochreguliert, wenn DDR-2 aktiviert wird (Vogel et al. 1997).

DDR-1-knockout-Mäuse zeigen ein verringertes Wachstum gegenüber Mäusen vom Wildtyp. Die meisten weiblichen knockout-Mäuse können keine Nachkommen gebären, weil sich die Blastozyste nicht einnisten kann (Vogel et al. 2001).

Auch DDR-2-knockout-Mäuse erreichen nur ca. 70 \% der Körpergröße im Vergleich zum Wildtyp. Wunden in den epidermalen Schichten ihrer Haut brauchen länger, um komplett zu heilen. Bei DDR-1-knockout-Mäusen tritt diese Wundheilungstörung nicht auf (Labrador et al. 2001). 
DDR scheinen wichtige Funktionen in diversen Typen von Karzinomen einzunehmen. In kindlichen Hirntumoren finden sich bis zu dreifach erhöhte Werte (Weiner et al. 1996), aber auch in Brustkrebs (Barker et al. 1995), Ovarialkarzinomen (Laval et al. 1994) und Karzinomen im Ösophagus (Nemoto et al. 1997) finden sich erhöhte Expressionsraten von DDR-1. In-situ-Hybridisierung (ISH) an Grenzschnitten von


Lungen- und Ovarialtumoren zeigten erhöhte Expressionen von DDR-1 und DDR-2 (Alves et al. 1995). Demnach ist anzunehmen, dass beide Rezeptoren, DDR-1 und DDR2, eine wichtige Bedeutung für die Tumorgenese haben.

Abbildung 3: Dreidimensionales Modell der Discoidin-Domäne von DDR-1; modifiziert nach Abdulhussein et al. 2004, S. 31466; ß-Stränge in blau, Schleifen (Loops) in grau.

Die ß-Stränge, die ein ß-barrel (ß-Fass) ausbilden, sind mit S1 - S8 gekennzeichnet, zusätzliche ßStränge mit $ß 1$ - $ß 4$, Schleifen mit Loop 1 - Loop 4.Besonders zu beachten ist die Furche, die sich zwischen Loop 3 und Loop 1 ausbildet.

Mittlerweile ist es gelungen, ein dreidimensionales Modell der DiscD von DDR-1 zu entwickeln (Abb. 3), die mit dem Kollagen in Kontakt tritt. Dabei fallen vier Schlingen (Loops) auf, die sich in der Tertiärstruktur des Moleküls zeigen. Zwei davon, Loop 1 und Loop 3, scheinen für die akkurate Bindung von Kollagenen essentiell zu sein. Diese beiden Schlingen liegen so zueinander, dass sich zwischen innen eine Furche ausbildet. Sie stellt die Bindungsregion, das sogenannte Epitop, des Proteins dar. Dabei quantifiziert die stalk-Region von DDR-1 die Bindungsfähigkeit um das Zehnfache. Sie scheint das Epitop zu stabilisieren und als Folge zu einer besseren Interaktion zu befähigen (Abdulhussein et al. 2004). 


\subsection{Aufgabenstellung}

Osteoarthritis im Kiefergelenk ist eine wichtige Untergruppe der KraniomandibulärenDysfunktion (siehe Abschnitt 4.1.4 Osteoartrithis im Kiefergelenk - ein weit verbreitetes Krankheitsbild). Die genauen molekularbiologischen Mechanismen, die zu Osteoarthritis im Kiefergelenk führen, sind noch nicht vollständig verstanden. Damit Osteoarthritis im Kiefergelenk weiter erforscht werden kann, braucht es Tiermodelle, welche eine hohe Prävalenz auf das Krankheitsbild vorweisen. Bei der Auswahl der Tierart für ein Tiermodell bietet die Maus die meisten Vorteile, da ihre Haltung relativ unkompliziert ist und das Krankheitsbild mit geringem Aufwand an ihr zu untersuchen ist. Bereits jetzt ist eine Vielzahl verschiedener Mausmodelle in der weltweiten Forschung etabliert, welche jedoch Defizite aufweisen, z. B. bei der Prävalenz der Entwicklung oder Ausprägung des Krankheitsbildes (Silbermann und Livne 1979, Metsäranta et al. 1992, Olsen 1995).

Diese Arbeit stellt mit der DDR-1-knockout-Maus ein neues Mausmodell für Osteoarthritis im Kiefergelenk vor. Hier soll gezeigt werden, dass sie sowohl in der Prävalenz als auch in der Ausprägung des Krankheitsbildes den bisher etablierten Modellen überlegen ist.

Der auf molekulargenetischer Ebene veränderte Stamm der DDR-1-knockout-Maus wurde ausgewählt, da bereits bekannt ist, dass ein vermehrtes Vorkommen von DDR2 zu Osteoarthritis im Knorpel führt (Xu et al. 2007). Schminke et al. (2013) konnten zeigen, dass bei einem verringerten Vorkommen von DDR-1, DDR-2 kompensatorisch vermehrt exprimiert wird. Diese Arbeit soll belegen, dass demnach der Stamm der DDR-1-knockout-Maus überduchschnittlich häufig Osteoarthritis entwickelt.

Der Versuchsaufbau besteht aus DDR-1-knockout-Mäusen und einem genetisch nicht veränderten Stamm einer Sv129-Wildtyp-Maus. Es werden immunhistochemische Methoden angewendet, um die Osteoarthritis des Kiefergelenkknorpels darzustellen und PCR-Analysen durchgeführt, um die Ergebnisse auf Level der Genexpression zu bestätigen. 


\section{Material und Methoden}

Die in diesem Abschnitt beschriebenen Methoden sind allgemein bekannt und richten sich nach einem Standardprotokoll.

\subsection{Lichtmikroskopische Immunhistochemie am Kiefergelenk der Maus von Kollagen Typ 1, Kollagen Typ 2, Nidogen-1, Nidogen-2.}

\subsubsection{Gewebepräparation}

Bei den folgend beschriebenen Versuchen wurden folgende Mäusestämme verwendet:
a) DDR-1-knockout
b) Sv129

Der DDR-1-knockout-Mäusestamm wurde erstmals von Vogel et al. (2001) beschrieben. Die in dieser Arbeit verwendeten Tiere stammen von Professor Dr. med. Oliver Groß, der die Tiere von Professor Dr. med. Frauke Alves bezogen hat. Der Sv129-Mäusestamm, der hier als Wildtyp eingesetzt wird, wurde ursprünglich beim Jackson Laboratory erworben.

Die für die Versuche verwendeten Mäuse wurden gemäß den Anordnungen der Tierschutzkommission der Medizinischen Fakultät der Universität Göttingen im MaxPlanck-Institut für Experimentelle Medizin (Göttingen) in keimarmer Umgebung aufgezogen und getötet. Es wurden keine Fehlbildungen oder Abnormalitäten gefunden.

Insgesamt wurden 20 Mäuse untersucht $(n=20)$, die sich folgendermaßen aufteilen.

DDR-1-knockout-Maus, 9 Wochen: 6 Mäuse

DDR-1-knockout-Maus, 12 Wochen: 6 Mäuse

Wildtyp-(Sv129)-Maus, 9 Wochen: 4 Mäuse

Wildtyp-(Sv129)-Maus, 12 Wochen: 4 Mäuse

Direkt nach dem Tod der Maus begann die Präparation. Diese wurde mit anatomischen Pinzetten, Knochenscheren und mikrochirurgischen Scheren 
durchgeführt. Zuerst wurde der Kopf unter Schonung der Gehörgänge, die den Kiefergelenken direkt anliegen, vom restlichen Körper abgetrennt. Der Schädel der Mäuse wurde komplett enthäutet und anschließend in der Mediosagittalachse halbiert. Sämtliche Weichgewebe, wie bspw. Gehirn, Augen und Muskelanteile wurden abgetragen. Von jeweils einer Schädelhälfte wurde der Condylus abgetrennt und für die Zellkultur aufbereitet (siehe Abschnitt 2.2.1 Zellisolation und Zellkultivierung). Die anderen kompletten Schädelhälften wurden unmittelbar nach der Präparation in gepufferten Formalin nach Lillie ü. N. bei $4{ }^{\circ} \mathrm{C}$ fixiert. Anschließend wurden die halbierten Schädel zur Entkalkung für ca. 4 Wochen in 20 \% EDTA überführt.

Gepuffertes Formalin nach Lillie, $\mathrm{pH} 7,4$ :

$100 \mathrm{ml}$ 37 \% Formalin (Merck; \# 3997)

$333 \mathrm{ml}$ 0,3 M Sörensen-Puffer

$566 \mathrm{ml}$ aqua dest.

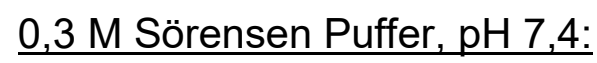

Lösung A

(Kaliumhydrogenphosphonat):

$41,37 \mathrm{~g} \mathrm{KH}_{2} \mathrm{PO}_{4}$

$1 \mathrm{I}$ aqua dest. $\rightarrow$ bei $4^{\circ} \mathrm{C}$ lagern
Lösung B

(Di-Natriumhydrogenphosphonat): $42,58 \mathrm{~g} \mathrm{Na}_{2} \mathrm{H} \mathrm{PO}_{4}$

1 I aqua dest. $\rightarrow$ bei RT lagern

$\rightarrow$ Für fertigen 0,3 M Sörensen Puffer 18,2 ml Lsg. A + 81,8 ml Lsg. B mischen.

\section{$20 \%$ EDTA, $\mathrm{pH} 7,4$ :}

$895 \mathrm{ml}$ aqua dest.

$1055 \mathrm{~N} \mathrm{NaOH}$

200 g EDTA (Sigma-Aldrich, E5134)

$\rightarrow$ In brauner Flasche auf aktiven Magnetrührer für ca. $2 \mathrm{~h}$ bei $\sim 60^{\circ} \mathrm{C}$ bis Lsg. klar.

$\rightarrow$ Den pH-Wert kontrollieren und bei RT lagern.

Es wurden jeweils zwei halbe Schädel mit $50 \mathrm{ml} 20 \%$ EDTA-Lsg. in einen lichtundurchlässigen Behälter gegeben. Die EDTA-Lsg. wurde täglich gewechselt. Nach vollständiger Entkalkung, welche zwischen 10 und 14 Tagen erfolgte, wurden die Schädelhälften in $70 \%$ Ethanol überführt und bei $4{ }^{\circ} \mathrm{C}$ für mindestens drei Tage gelagert. 


\subsubsection{Protokoll zur Herstellung der histologischen Präparate}

Daraufhin wurden die Schädel dehydriert und schließlich in Paraffin eingebettet. Es wurde gemäß einem standardisierten Protokoll verfahren. Dieses beinhaltet die Schritte von der aufsteigenden Alkoholreihe und Xylol für die Dehydrierung der Präparate bis zur Einbettung im Paraffin. Die einzelnen Schädel wurden in spezielle Plastikkäfige gelegt und dann mithilfe eines Einbettungsautomaten (Duplex Processer, Shandon Elliot, Cheshire, England) wie folgt eingebettet.

$\begin{array}{lll}\text { Position } 1 & 70 \% \text { Ethanol } & 3 \mathrm{~h} \\ \text { Position } 2 & 80 \% \text { Ethanol } & 1 \mathrm{~h} \\ \text { Position } 3 & 90 \% \text { Ethanol } & 1 \mathrm{~h} \\ \text { Position } 4 & 96 \% \text { Ethanol } & 1 \mathrm{~h} \\ \text { Position } 5 & \text { abs. Ethanol } & 2 \mathrm{~h} \\ \text { Position } 6 & \text { Isopropylalkohol } & 2 \mathrm{~h} \\ \text { Position } 7 & \text { Isopropylalkohol } & 1,5 \mathrm{~h} \\ \text { Position } 8 & \text { Xylol } & 30 \mathrm{~min} \\ \text { Position } 9 & \text { Xylol } & 45 \mathrm{~min} \\ \text { Position } 10 & \text { Xylol } & 45 \mathrm{~min} \\ \text { Position } 11 & \text { Paraplast Plus }\left(52^{\circ} \mathrm{C}\right) & 30 \mathrm{~min}\left(60^{\circ} \mathrm{C}\right) \\ \text { Position } 12 & \text { Paraplast Plus }\left(56^{\circ} \mathrm{C}\right) & 7 \mathrm{~h}\left(60^{\circ} \mathrm{C}\right)\end{array}$

Im Anschluss wurden die Präparate in spezielle Formen gelegt und mithilfe einer Ausgießstation in Paraffin eingelegt. Das Aushärten des Paraffins geschah ü. N. bei RT. Danach konnten aus den ausgehärteten Paraffinblöcken lichtmikroskopische Schnittpräparate hergestellt werden.

Geschnitten wurden die Blöcke mit einem Jung Biocut 2035 - Mikrotom (Leica, Nussloch, Deutschland). Es wurden Schnitte mit einer Stärke von $7 \mu \mathrm{m}$ angefertigt. Die Schnitte wurden, nachdem sie auf Superfrost Plus Objektträger (Menzel-Gläser, Braunschweig, Deutschland) übertragen wurden, ü. N. in einem Wärmeschrank bei 37 ${ }^{\circ} \mathrm{C}$ gelagert. Jeder 15. Schnitt wurde mithilfe eines Färbeautomaten (Stainix DiaPath, Weinkauf, Medizintechnik, Deutschland) in Hämalaun-Eosin (HE) bzw. Toluidinblau gefärbt. Durch die Hämalaun-Eosin-Färbung wird die Struktur des Präparates 
angefärbt, während die Toluidinblau-Färbung Glykosaminoglykane (GAG) darstellt. GAG sind spezielle Proteoglykane, welche im Knorpel vorkommen. Zunächst erfolgte die Entparaffinisierung der Objektträger, bevor diese dann per Hand im Färbeautomaten plaziert werden konnten. Im Anschluss befanden sich die Präparate für insgesamt $16 \mathrm{~min}$ in einem Xylolbad (8 min Xylolbad 1; $8 \mathrm{~min}$ Xylolbad 2). Danach wurden die folgenden Schritte von dem oben genannten Färbeautomaten durchgeführt.

Hämalaun (nach Meyer):

(Merck, \# 1.09249)

$\rightarrow$ Kann in der gekauften Konzentration genutzt werden.

\section{$\underline{0,1 \% \text { Eosin } Y:}$}

$1 \mathrm{~g}$ Eosin Y (AppliChem, \# A0822,0025)

1 I aqua dest.

$\rightarrow$ Vor der Färbung 2 Tropfen Eisessig dazugeben.

0,04\% Toluidinblau O:

0,04 g Toluidin Blue O (Sigma-Aldrich, \# T3260)

$100 \mathrm{ml}$ 0,1 M Natriumacetat Puffer (Sigma-Aldrich, \# S2404) $\rightarrow 4 \mathrm{ml}$ des Puffers auf $120 \mathrm{ml}$ aqua dest. $\rightarrow$ mit $\mathrm{HCl}$ auf $\mathrm{pH} 4$ einstellen

\section{$\underline{0,1 \% \text { Fast Green FCF: }}$}

0,1 g Fast Green FCF (Sigma-Aldrich, \# F7258)

$100 \mathrm{ml}$ aqua dest. 


\begin{tabular}{|c|c|c|c|}
\hline \multirow{2}{*}{ Hämalaun-Eosin-Färbung } & \multicolumn{2}{c|}{ Toluidinblau-Färbung } \\
\hline abs. Ethanol & $5 \mathrm{~min}$ & abs. Ethanol & $4 \mathrm{~min}$ \\
\hline $80 \%$ Ethanol & $10 \mathrm{~min}$ & $80 \%$ Ethanol & $4 \mathrm{~min}$ \\
\hline aqua dest. & $5 \mathrm{~min}$ & aqua dest. & 2 min \\
\hline $\begin{array}{c}\text { Hämalaun (nach } \\
\text { Meyer) }\end{array}$ & $4 \mathrm{~min}$ & $0,04 \%$ & $10 \mathrm{~min}$ \\
\hline aqua dest. & $1 \mathrm{~min}$ & aqua dest. & 2 min \\
\hline fließend Wasser & $15 \mathrm{~min}$ & fließend Wasser & $1 \mathrm{~min}$ \\
\hline $0,1 \%$ Eosin Y & $7 \mathrm{~min}$ & $0,1 \%$ Fast Green & 2 min \\
\hline aqua dest. & & FCF & $1 \mathrm{~min}$ \\
\hline $80 \%$ Ethanol & $5 \mathrm{~min}$ & aqua dest. & $2 \mathrm{~min}$ \\
\hline abs. Ethanol & $2 \mathrm{~min}$ & $80 \%$ Ethanol & 2 min \\
\hline abs. Ethanol & $2 \mathrm{~min}$ & abs. Ethanol & $5 \mathrm{~min}$ \\
\hline Xylol & $3 \mathrm{~min}$ & Xylol & $3 \mathrm{~min}$ \\
\hline
\end{tabular}

Nachdem die Färbung abgeschlossen war, wurden die Objektträger mittels Deckgläschen und einem speziellen Medium (Eukitt, Sigma-Aldrich, \# 03989) eingedeckt. Anschließend lagerten die Objekträger bei RT, bis das Eindeckmedium ausgehärtet war. Danach konnten die Präparate unter dem Lichtmikroskop (PrimoStar, Zeiss, Göttingen, Deutschland) histopathologisch beurteilt werden.

Die Objekträger wurden in folgender Reihenfolge rehydriert:

$\begin{array}{ll}\text { 1. } 15 \mathrm{~min} & \text { Xylol } \\ \text { 2. } 10 \mathrm{~min} & \text { Xylol } \\ \text { 3. } 5 \mathrm{~min} & \text { abs. Ethanol } \\ \text { 4. } 5 \mathrm{~min} & 96 \% \text { Ethanol } \\ \text { 5. } 5 \mathrm{~min} & 90 \% \text { Ethanol } \\ \text { 6. } 5 \mathrm{~min} & 80 \% \text { Ethanol } \\ \text { 7. } 5 \mathrm{~min} & 70 \% \text { Ethanol } \\ \text { 8. } 5 \mathrm{~min} & 50 \% \text { Ethanol } \\ \text { 9. } 10 \mathrm{~min} & 1 \times \mathrm{PBS}\end{array}$


Im letzten Schritt (10 min 1 x PBS) wurden die Präparate gewaschen und letzte Reste von Ethanol entfernt. Zwischen jedem der folgenden Schritte wurden die Objektträger in einer Standküvette 10 min mit 1 x PBS gewaschen.

Da die endogene Peroxidase gegenüber Licht eine Empfindlichkeit aufweist, wurden die Präparate für $45 \mathrm{~min}$ in eine lichtundurchlässige Küvette mit $70 \mathrm{ml}$ Methanol und $700 \mu$ 30-prozentigem $\mathrm{H}_{2} \mathrm{O}_{2}$ gestellt. Anschließend folgte der erste Schritt des Vorverdaus in einer mit Protaqs I gefüllten Standküvette für 20 min bei $60{ }^{\circ} \mathrm{C}$. Danach wurden die Objektträger in eine feuchte Kammer überführt. Eine feuchte Kammer ist eine Petrischale, in der Filterpapier ausgelegt ist, welches zuvor mit aqua dest. benetzt wurde. Daraufhin wurde die Petrischale mit einer größeren Petrischale als Deckel abgedeckt. Nach dem Waschen im PBS wurden die Objektträger mit Filterpapier abgewischt, ohne dabei die aufgetragenen Schnitte zu beschädigen, und in die Petrischale gelegt. Es folgte der zweite Schritt des Vorverdaus, bei dem $100 \mu \mathrm{l}$ Hyaluronidase $0,2 \%$ in 1 x PBS auf das Präparat pipettiert und für 5 min bei RT inkubiert wurde. Danach folgte dieser Schritt auch jeweils mit Chondroitinase ABC und Protease XXIV. Nach dem letzten Schritt im Vorverdau der Protease XXIV wurde nicht mit 1 x PBS gewaschen, sondern direkt für 10 min mit $100 \mathrm{ml}$ pro Schnitt $1 \%$ BSA in PBS (pH 7,4) geblockt.

\section{Protease XXIV, $\mathrm{pH} 7,6$ :}

25 mg Protease XXIV (Sigma-Aldrich, P8038)

$45 \mathrm{ml}$ aqua dest.

$25 \mathrm{mg} \mathrm{CaCl} 2$

$5 \mathrm{ml} \mathrm{0,05}$ M Tris-HCl, $\mathrm{pH}$ 7,6

\section{0,05 MTris- $\mathrm{HCl}, \mathrm{pH} 7,6$ :}

$6 \mathrm{~g}$ Tris Base

$250 \mathrm{ml}$ aqua dest.

$36 \mathrm{ml} 1 \mathrm{~N} \mathrm{HCl}$

$\rightarrow$ auf 1 I mit aqua dest. auffüllen

\section{Chondroitinase ABC:}

In $100 \mathrm{ml}$ aq. dest. werden gelöst:

0,61 g Tris $\mathrm{NH}_{2} \mathrm{C}\left(\mathrm{CH}_{2} \mathrm{OH}\right) 3$ (50 mM, pH 8.0) 


\section{0,492 g Natriumacetat $\mathrm{C}_{2} \mathrm{H}_{3} \mathrm{NaO}_{2}(60 \mathrm{mM})$ (Merck, \# 1.06264)}

0,02 g BSA (0,02 \%) (Sigma-Aldrich, \# A9647)

1 Unit Chondroitinase (Sigma-Aldrich, \# C2905) wird in $1 \mathrm{ml}$ dieses Ansatzes gelöst

\section{Hyaluronidase:}

6,66 ml einer 0,3 M Sörensen-Pufferlösung (s. Puffer/Lsg. oder Fix LM) werden mit aqua dest. auf $100 \mathrm{ml}$ aufgefüllt (Endkonzentration: 0,02 M Phosphatpufferlösung) $0,45 \mathrm{~g} \mathrm{NaCl}(77 \mathrm{mM})$ $0,01 \mathrm{~g} \mathrm{BSA}(0,01 \%)$ 100 mg Hyaluronidase (1 mg/ml) (Sigma-Aldrich, \# H3506)

Während des Vorverdaus konnten die primären Antikörper angesetzt werden. Die jeweiligen Antikörper Kollagen Typ I (Chemicon, Katalog \#: AB765P Lot \#: LV1471696), Kollagen Typ II (CIICl, Aeschlimann et al. 1995), JF4 für Nidogen-1 und 1080+E2 für Nidogen-2 (Kruegel et al. 2008) wurden 1:100 in 1 \% BSA in PBS (pH $7,4)$ verdünnt. Jeder Schnitt wurde zur Inkubation in der feuchten Kammer mit $100 \mu \mathrm{l}$ des verdünnten Ansatzes benetzt und ü. N. bei RT belassen. Für die NegativKontrollen wurde anstelle des primären Antikörpers jeweils $100 \mu 1 \%$ BSA in PBS $(\mathrm{pH} \mathrm{7,4)} \mathrm{zur} \mathrm{Inkubation} \mathrm{eingesetzt.}$

Als nächstes wurde der jeweilige sekundäre Antikörper aufgetragen. Bei Nidogen-1 erfolgte der Nachweis durch einen sekundären anti-Rat-AK/HRP-gekoppelten Komplex (Daki, \# P0450), der für 1 h zur Inkubation hinzugefügt wurde. Der sekundäre AK wurde wieder 1:100 in 1\% BSA in PBS ( $\mathrm{pH} \mathrm{7,4)} \mathrm{verdünnt} \mathrm{und} \mathrm{davon} \mathrm{nochmals}$ $100 \mu \mathrm{l}$ auf jeden Schnitt pipettiert.

Der Nachweis von Nidogen-2 wurde mit einem 1:50 in $1 \%$ BSA in PBS (pH 7,4) verdünnten Anti-Rabbit (Dako, \# Z0196) Brückenantikörper (100 $\mu \mathrm{l} /$ Schnitt) für $30 \mathrm{~min}$ durchgeführt. Daraufhin folgte der Rabbit-PAP-Komplex (Dako, \# Z0113), bei einer Verdünnung von 1:150 in 1 \% BSA in PBS (pH 7,4). Es wurden wieder $100 \mu \mathrm{l} /$ Schnitt auf die Präparate pipettiert und für $30 \mathrm{~min}$ in der feuchten Kammer inkubiert.

Die nächsten Schritte sind für alle Antikörper wieder identisch. Auf die Schnitte wurden $200 \mu \mathrm{l} /$ Schnitt DAB pipettiert. Dabei lagen die Objektträger diesmal in einer feuchten Kammer aus Petrischalen, die mithilfe von Alufolie lichtundurchlässig umschlossen wurde. 
3,3'-Diaminobenzidin (DAB) (Sigma FASTTM DAB-Tabletten, Sigma-Aldrich, \# D4293)

\section{Tablette DAB}

1 Tablette $\mathrm{H}_{2} \mathrm{O}_{2}$

$5 \mathrm{ml}$ aqua dest.

Das DAB sollte immer frisch angesetzt werden, dunkel gelagert werden und hat eine kanzerogene Wirkung.

Nach 7 min wurden die Schnitte in 1 x PBS gegeben und die Reaktion mit dem DAB auf diese Weise gestoppt. Anschließend wurde mit Hämalaun nach Meyer (Merck, \# 1.09249) gegengefärbt, um das vom $D A B$ nicht angefärbte Gewebe besser beurteilen zu können. Das Hämalaun wurde im Verhältnis 1:4 mit aqua dest. verdünnt und die Schnitte ca. 10 sek darin geschwenkt. Danach wurden die Präparate in eine Küvette gestellt und unter fließendem Wasser ca. 2 min lang gewaschen, bis das Wasser in der Küvette keine sichtbaren Spuren von dem Hämalaun aufwies. Schließlich wurden die Schnitte wieder dehydriert. Hierfür wurden sie durch eine aufsteigende Alkoholreihe geführt.

$\begin{array}{ll}\text { 1. } 5 \mathrm{~min} & 50 \% \text { Ethanol } \\ \text { 2. } 5 \mathrm{~min} & 70 \% \text { Ethanol } \\ \text { 3. } 5 \mathrm{~min} & 80 \% \text { Ethanol } \\ \text { 4. } 5 \mathrm{~min} & 90 \% \text { Ethanol } \\ \text { 5. } 5 \mathrm{~min} & 96 \% \text { Ethanol } \\ \text { 6. } 5 \mathrm{~min} & \text { abs. Ethanol } \\ \text { 7. } 5 \mathrm{~min} & \text { Xylol (1) } \\ \text { 8. } 5 \mathrm{~min} & \text { Xylol (2) }\end{array}$

Schließlich wurden die Schnitte mit Eindeckmedium eingedeckt, bei RT getrocknet und unter dem Lichtmikroskop beurteilt.

Es wurden für jede Reaktion Kontrollen angefertigt. Mit diesen wurde in gleicher Weise verfahren, nur dass hierbei jeweils der primäre Antikörper durch 1 x PBS ersetzt wurde. Folglich zeigten sie keine bzw. sehr schwache, akzidentielle Reaktionen. 


\subsection{Genexpressionsanalysen}

Bevor die q-PCR mit der darin eingesetzten cDNA angewendet werden konnte, bedurfte es einiger vorbereitender Arbeitsschritte. Diese sind in den folgenden Abschnitten dargestellt.

\subsubsection{Zellisolation und Zellkultivierung}

Für die Aufzucht von nativen Chondrozyten in der Zellkultur wurde jeweils $1 \mathrm{~mm}^{3}$ Gewebe aus dem Knorpel des Condylus einer 9 Wochen alten DDR-1-knockout-Maus entnommen. Ebenso geschah dies bei gleichaltrigen Wildtyp-Mäusen. Der dem Condylus aufliegende Gelenkknorpel wurde mit einem Skalpell von dem subchondralen Knochen abgetrennt. Es wurde darauf geachtet, dass kein knöchernes Gewebe in den Proben enthalten war. Die Gewebestücke wurden in eine MonolayerZellkultur überführt und dort bei absoluter Ruhe unter standardisierten Zellkulturbedingungen in $10 \mathrm{ml}$ Kultivierungsmedium für 10 Tage belassen. Das Kultivierungsmedium wurde alle zwei Tage erneuert.

\section{Kultivierungsmedium:}

$500 \mathrm{ml}$ Dulbecco's modified Eagle's medium (DMEM) (Gibco, \# 21885)

$50 \mathrm{ml}$ fetal bovine serum (10\%; FBS) (Invitrogen, \# 41F2061K)

$5 \mathrm{ml}$ Penicillin/Streptomycin (5000 units/50 mg; PAN Biotech, \# P06-07100)

Um den Gelenkknorpel kam es zur Migration von Zellen in die Peripherie des Kultivierungsmediums. Nach 10 Tagen konnte das ursprüngliche Knorpelgewebe entfernt und die migrierten Chondrozyten in Flaschen $\left(75 \mathrm{~cm}^{2}\right.$, Sarstedt, \# 83.1813.002) überführt und in einer Konzentration von $10^{3}$ Zellen/ $/ \mathrm{cm}^{2}$ ausgesät werden. Es wurden $10 \mathrm{ml}$ Kultivierungsmedium hinzugegeben, welches alle zwei Tage ausgetauscht wurde. Nach zwei Passagen wurde eine ausreichende Zellzahl erreicht, um sie in die Alginatkultur zu überführen oder aus den Zellen mRNA zu isolieren.

Zur Zellgewinnung aus der Monolayer-Zellkultur wurde zunächst das Medium abgesaugt. Danach wurden die Zellen mit PBS gewaschen und mechanisch abgelöst. Anschließend wurde das PBS mit den darin enthaltenen Zellen für 10 min bei 1200 rpm abzentrifugiert, der Überstand verworfen und das entstandene Zellpellet für die Isolierung von mRNA verwendet werden. 


\subsubsection{1 mRNA Isolierung aus der Monolayer-Zellkultur}

Sämtliche Arbeiten mit RNA wurden mit Handschuhen durchgeführt, um die Kontamination mit RNasen zu vermeiden. Die gesamte mRNA-Isolation wurde unter standardisierten Bedingungen durchgeführt. Die RNA-Isolierung aus Chondrozyten aus dem Kiefergelenksknorpel der Versuchsmäuse wurde mit einem dafür vorgesehenen RNeasy Mini Kit (Qiagen, \# 74106) entsprechend den Herstellerempfehlungen durchgeführt. Die Arbeitsschritte im Detail wurden wie folgt durchgeführt: Dabei entspricht die nachfolgende Beschreibung auch dem Protokoll, welches für die Zellpellets der 3D-Alginatkultur (s. u.) angewandt wurde.

Aus den Zellpellets, die direkt aus den Zellen der Monolayer-Kultur gewonnen wurden, konnte nun die mRNA isoliert werden. Im ersten Schritt mussten die Zellen zunächst lysiert werden. Dafür wurden die Zellen mit $350 \mu$ RLT-Puffer (Qiagen, \# 79216) und 3,5 $\mu$ l ß-Mercaptoethanol (Sigma-Aldrich, \# 63689) versetzt. Anschließend wurden 350 $\mu \mathrm{l}$ abs. Ethanol addiert und das gesamte Gemisch auf eine RNeasy Mini Säule pipettiert.

Die Bindung der RNA an die Silica-Membran der Mini-Säule erfolgte unter Zentrifugation für 20 sek bei 13600 rpm. Der Durchfluss wurde verworfen. Die an die Silica-Membran gebundene RNA wurde nun gereinigt. Dafür wurden folgende Waschpuffer mit aufsteigendem Elektrolytgehalt in die Säule gegeben. Zunächst wurden $700 \mu \mathrm{l}$ RW1-Puffer auf die Säule pipettiert, zentrifugiert und der Durchfluss verworfen. Danach wurde ebenso mit $500 \mu \mathrm{l}$ RPE-Puffer verfahren.

Als nächstes wurden die Säulen in ein neues Sammelröhrchen gegeben und für 1 min bei 13600 rpm trocken zentrifugiert. Die Säule wurde darauf in einen Eppendorfcup (1,5 ml, Eppendorf, \# 0030125150) überführt. Direkt auf die Membran wurden $100 \mu \mathrm{l}$ RNase-freies Wasser pipettiert und für $10 \mathrm{~min}$ bei RT belassen. Dadurch wurde die RNA rehydratisiert und lag somit in freier Form vor. Dann wurde erneut 1 min bei 13600 rpm zentrifugiert. Der dabei entstandene Durchfluss enthielt die RNA. Die Konzentration der RNA in der gewonnenen wässrigen Lösung wurde mittels eines Biophotometers (Eppendorf, Hamburg, Deutschland) spektroskopisch bestimmt. Hierzu wurden $2 \mu \mathrm{l}$ der RNA-Lsg. verwendet und die Absorption bei $260 \mathrm{~nm}$ und 280 $\mathrm{nm}$ gemessen. Die Messung bei $260 \mathrm{~nm}$ gibt dabei den RNA-Gehalt an, während der Proteingehalt bei $280 \mathrm{~nm}$ gemessen wird. Der Quotient zwischen den beiden Werten ist ein Maß für die Reinheit der Probe. Bei allen Versuchen lag dieser Wert in einem Normbereich zwischen 1,7 und 2,0. 


\subsubsection{Alginatkultur}

Die Alginatkultur bietet den Chondrozyten eine physiologische Umgebung, in der sie differenzieren können. Die Chondrozyten wurden gezählt und zu je 40000 Zellen in 20 ul 2,4 \% Alginat/0,15 M NaCl 1:1 gelöst, so dass die Endkonzentration des Alginats $1,2 \%$ betrug. Die Suspension wurde in eine Hülsenpipette aufgenommen und in 102 $\mathrm{mM} \mathrm{CaCl} 2$-Lsg. für maximal 10 min polymerisiert. Damit die einzelnen Alginatkugeln eine möglichst runde Form erhielten, wurde der Kolben mit der enthaltenen $\mathrm{CaCl}_{2}$-Lsg. leicht geschwenkt, um dadurch die Oberflächenspannung zu verringern, so dass sich die Kugeln besser formen lassen. Die entstandenen Kugeln wurden dann vorsichtig mit einem scharfen Löffel aufgenommen und auf eine 24-Well-Platte gegeben. Jedes Well wurde mit 5 Kugeln bestückt und die Überreste der $\mathrm{CaCl}_{2}$-Lsg. vorsichtig mit einer Pasteurpipette abgesaugt. Anschließend erfolgten zwei Waschungen mit $\mathrm{NaCl}$. Schließlich konnte den Kugeln jeweils 500 l DMEM 10 \% FBS, 1 \% P/S dazugegeben werden. Damit erfolgte die Inkubation für drei Wochen bei $37^{\circ} \mathrm{C}$, wobei das Medium alle zwei Tage erneuert wurde.

$\underline{0,15 \mathrm{M} \mathrm{NaCl}}:$

$0,876 \mathrm{~g} \mathrm{NaCl}$

$100 \mathrm{ml}$ aqua dest.

$102 \mathrm{mM} \mathrm{CaCl}_{2}$ :

$1,132 \mathrm{~g} \mathrm{CaCl}_{2}$

$100 \mathrm{ml}$ aqua dest.

2,4\% Alginat:

$0,12 \mathrm{~g}$ Alginat

$5 \mathrm{ml}$ aqua dest.

\section{Kultivierungsmedium}

500 ml DMEM (Gibco, \# 21885)

$50 \mathrm{ml}$ FBS (Gibco 10270-106)

$5 \mathrm{ml}$ Penicillin/Streptomycin (50000 units / mg; PAN Biotech, \# P06-07100) 


\subsubsection{3 mRNA Isolierung aus der Alginatkultur}

Die RNA-Isolierung aus den Chondrozyten der Alginatkultur geschah wieder mit einem RNeasy Mini Kit (Qiagen, \# 74106) entsprechend den Herstellerempfehlungen.

Zunächst begann die Lyse der Alginatkugeln. Dafür musste das Kultivierungsmedium aus den 24-Well-Platten vorsichtig abgesaugt werden. Danch konnten die Alginatkugeln nach einem Waschgang mit PBS $(\mathrm{pH} 7,4)$ in ein frisches Behältnis überführt und mit $1 \mathrm{ml}$ HEPES-EDTA-Lyse-Puffer aufgelöst werden. Durch den Chelatbildner kommt es zur Depolymerisation und zur Freisetzung der Zellen. Die nun freien Zellen wurden für 10 min bei 1200 rpm abzentrifugiert und der Überstand abgesaugt. Es bleibt ein Zellpellet bestehen, aus dem mRNA isoliert wurde. Dabei wurde das Zellpellet der Alginatkultur mit den selben Arbeitsschritten behandelt wie das der Monolayer-Zellkultur.

\section{HEPES-EDTA-Puffer:}

55 mM EDTA:

\section{2,047 g EDTA}

$100 \mathrm{ml}$ aqua dest.

10 mM HEPES:

\section{$0,2383 \mathrm{~g} \mathrm{HEPES}$}

$100 \mathrm{ml}$ aqua dest.

beides 1:1 mischen

Alle Lösungen müssen steril filtriert werden!

\subsubsection{Umschreiben der mRNA in cDNA}

Um eine Degradation der Substrate zu verhindern, wurde konsequent auf Eis gerbeitet.

Damit mittels PCR der Grad der Genexpression festgestellt werden konnte, musste die jeweils gewonnene mRNA in cDNA umgeschrieben werden. Dies geschah mithilfe des QuantiTect Reverse Transcription Kit (Qiagen, \# 205313). Alle folgenden verwendeten Reagenzien sind diesem Kit entnommen. Enthalten waren die Reverse Transkriptase (RevT), gDNA Wipeout Buffer, der Primer Mix und ein Puffer für die RevT. 
Im ersten Schritt wurde die RNA in einem genomic DNA Wipeout Buffer bei $42{ }^{\circ} \mathrm{C}$ für 2 min inkubiert. Jegliche eventuell vorhandene genomische DNA wurde so durch die im Puffer vorhandenen DNasen eliminiert.

Danach wurde die RNA mit einem Mastermix, der aus Primer Mix, dem RT Buffer und der RevT bestand, für 15 min bei $42{ }^{\circ} \mathrm{C}$ inkubiert. Hierbei erfolgte das Umschrieben der RNA in cDNA. Die RevT ist das Schlüsselenzym in dieser Versuchsanordnung. Sie ist eine RNA-abhängige DNA-Polymerase, die an den RNA-Strang einen komplementären DNA-Strang synthetisiert. Daraufhin wurde die ursprüngliche RNA durch den als RNase aktiven Bestandteil des Enzyms wieder entfernt, so dass die cDNA solitär verblieb.

Zum Schluss wurde die RevT in 2 min bei $95^{\circ} \mathrm{C}$ inaktiviert und die Reaktion gestoppt. Schließlich wurde mit DNase freiem Wasser auf ein Endvolumen von $200 \mu$ l aufgefüllt, um dabei eine cDNA-Konzentration von $1 \mathrm{ng} / \mu \mathrm{l} z u$ erhalten. Dies geschah unter der Annahme, dass die RevT einen Umsatz von RNA zu cDNA von 1:1 hat. Die gewonnene cDNA konnte nun für die q-PCR verwendet werden oder wurde bei $-20^{\circ} \mathrm{C}$ gelagert.

\subsubsection{Primerdesign}

Die in dieser Arbeit verwendeten Primer wurden mit Hilfe der Software Primer3 (http://frodo.wi.mit.edu/) entworfen. Alle Primersequenzen wurden durch die Datenbank des National Center for Biotechnology Information (NCBI) überprüft. Sie wurden in das Basic Local Alignment Search Tool (BLAST) eingespeist (http://blast.ncbi.nlm.nih.gov/Blast.cgi) und überprüft. Bei der Synthese der Primer wurde darauf geachtet, dass die Länge der einzelnen Primer zwischen 18 und 22 Basen liegt. Ebenso sollte der Gehalt von Guanin und Cytosin von ca. 50 \% betragen. Um sicherzustellen, dass die Primer nicht versehentlich Nukleotidsequenzen anderer Gene ähneln, wurden sie mit der Online-Datenbank des NCBI ebenfalls abgeglichen. Die spezifischen Primersequenzen wurden von Operon Biotechnologie $\mathrm{GmbH}$ (Operon Biotechnologie $\mathrm{GmbH}$, Köln, Deutschland) synthetisiert. Die Primer wurden lyophilisiert geliefert und den Herstellerangaben nach mit Nuklease-freiem $\mathrm{H}_{2} \mathrm{O}$ resuspendiert. Nach Verdünnung wurden die Primer als Primer-PCR-Mix aus forward und reverse Primer je in einer Konzentration von $10 \mathrm{pmol} / \mu \mathrm{l}$ in der Gradienten-PCR und der q-PCR eingesetzt. 


\begin{tabular}{cccc}
\hline Zielgen & Reverse $\left(5^{\prime} \rightarrow 3^{\prime}\right)$ & Forward $\left(5^{\prime} \rightarrow 3^{\prime}\right)$ & $\begin{array}{c}\text { Annealing- } \\
\text { Temperatur } \\
\left({ }^{\circ} \mathrm{C}\right)\end{array}$ \\
\hline Nidogen 1 & tgtgcgagaatcctccggt & atcccagaggcattgtgacag & 60 \\
Nidogen 2 & gtggtttggatgacacgtcg & tggattacccaatggattgacct & 61 \\
Kollagen Typ I & tgactggaagagcggagagt & gttcgggctgatgtaccagt & 58 \\
Kollagen Typ II & aggtgctaatggcaatcc & gaggaccatcaagaccag & 62,5 \\
Sox 9 & tcagatgcagtgaggagcac & ccagccacagcagtgagtaa & 60 \\
Runx 2 & cagaccagcagcactccata & cagcgtcaacaccatcattc & 63 \\
Aggrecan & aggactgaaatcagcggaga & agggacatggttgttctgc & 60 \\
HPRT 1 & ggtcctttcaccagcaagct & tgacactggcaaaacaatgca & 61 \\
\hline
\end{tabular}

\subsubsection{Gradienten-PCR}

Jeder Primer besitzt eine spezifische Annealing-Temperatur. Diese entspricht der Temperatur, bei der sich der jeweilige Primer während einer PolymeraseKettenreaktion (PCR) optimal an die cDNA anlagert. Durch die Gradienten-PCR wurden die jeweiligen Annealing-Temperaturen ermittelt. Hierfür wurden 8 verschiedene Annealing-Temperaturen pro Primer getestet. Die Konzentration der cDNA, die ursprünglich aus Chondrozyten gewonnen wurde, betrug $1 \mathrm{ng} / \mu \mathrm{l}$. Für jede Temperatur und jeden Primer wurden je ein Ansatz von $10 \mu$ l eingesetzt. Daraus ergibt sich folgendes Pipettierschema pro Well:

\section{Ansatz Gradienten-PCR:}

$\begin{array}{ll}\text { cDNA } & 1 \mu \mathrm{l} \\ \text { Primer (for + rev) } & 2 \mu \mathrm{l} \\ \text { SYBR-Green Mix } & 5 \mu \mathrm{l} \\ \text { Nuklease-freies Wasser } & 2 \mu \mathrm{l}\end{array}$


Protokoll für die Gradienten-PCR:

\begin{tabular}{lll} 
Initiale Denaturierung & 3 min & $95{ }^{\circ} \mathrm{C}$ \\
\hline Denaturierung & 20 sek & $94^{\circ} \mathrm{C}$ \\
Anlagerung (Annealing) & 20 sek & variabel $\quad 45$ Zyklen \\
Verlängerung & 20 sek & $72{ }^{\circ} \mathrm{C}$ \\
\hline Denaturierung & 20 sek & $95^{\circ} \mathrm{C}$ \\
Schmelzkurve & 20 sek & ansteigend um je $0,1^{\circ} \mathrm{C}$ bis $95^{\circ} \mathrm{C}$ \\
Ende & 20 sek & $95^{\circ} \mathrm{C}$
\end{tabular}

Der SYBR-Green Mix (Invitrogen, \# 11733-046), der hier eingesetzt wurde, enthält neben $\mathrm{MgCl}_{2}$, den Fluoreszenzfarbstoff SYBR-Green und den dNTP-Mix zusätzlich eine thermostabile Taq DNA-Polymerase, die die gewünschte DNA vervielfältigt.

Anhand der fluoreszenzvermittelten Extinktion wurde die spezifische AnnealingTemperatur ermittelt. Daraus ließen sich Rückschlüsse auf die Effektivität der einzelnen Primer ziehen. So wurde die Temperatur mit der höchsten Extinktion, welche einen einzelnen, hohen, schlanken Peak in der Schmelzkurve aufwies, als die für den Primer spezifische Annealing-Temperatur festgelegt. Die Annealing-Temperaturen, der hier verwendeten Primer, sind in der oben abgebildeten Tabelle aufgeführt und alle q-PCR-Versuche wurden mit den jeweils passenden Temperaturen durchgeführt.

\subsubsection{Allgemeines zur Real-Time Quantitative PCR}

Die Real-Time Quantitative PCR (q-PCR) dient der Vervielfältigung bestimmter Nukleotidmatrizen. Sie beruht auf dem Prinzip der herkömmlichen PCR. Durch diese etablierte Methode lassen sich Nukleinsäuresequenzen exponentiell amplifizieren und im sofortigen Anschluss quantifizieren. Dies emöglicht eine Aussage über den Grad der Genexpression zu treffen.

Es reichen schon geringe Mengen an Ausgangsmaterial aus, um eine PCR durchzuführen. Bei der q-PCR wird der übliche Vorgang, der schon eine hitzestabile Taq-Polymerase beinhaltet, mittels Zugabe eines interkalierenden Cyanin-Farbstoffes (SYBR-Green) modifiziert. SYBR-Green hat die Eigenschaft, bei Bindung an doppelsträngige Nukleinsäuren deutlich stärker zu fluoreszieren als bei der Bindung an Einzelstränge. Die PCR besteht aus einem sich mehrmals wiederholenden Zyklus, der wiederum aus drei grundlegenden Schritten besteht. Im ersten Schritt wird die 
thermostabile DNA-Polymerase (HotStarTaq Polymerase) durch Erhitzung auf $95^{\circ} \mathrm{C}$ aktiviert und die DNA bei dieser Temperatur in Einzelstränge denaturiert. Im zweiten Schritt erfolgt die Anlagerung (annealing) der spezifischen Primer an die Einzelstränge. Die Primer sind komplementär zu den Randbereichen der zu amplifizierenden DNA-Sequenz. Jeder Primer lagert am besten an den Einzelstrang an, wenn eine bestimmte Annealing-Temperatur herrscht. Diese ist vom jeweiligen Primer abhängig und liegt zwischen $58{ }^{\circ} \mathrm{C}$ und $63{ }^{\circ} \mathrm{C}$. Der dritte Schritt ist die Elongation, bei der die hitzestabile Taq-Polymerase die Komplementärstränge synthetisiert und es zum Einbau des SYBR-Green-Fluoreszenzfarbstoffes kommt. Der erste Zyklus ist beendet.

Diese Schritte aus Denaturierung, Annealing und Elongation werden bis zu 45-mal durchlaufen, wobei sich bei jedem Zyklus die DNA theoretisch verdoppelt und es somit zu einer exponentiellen Vermehrung kommt. In die neu entstandene DNA ist das SYBR-Green eingelagert, wodurch die Amplifikation sichtbar gemacht werden kann. Während der PCR wird ein Schwellenwert definiert. Wird dieser vom Fluoreszenzsignal überschritten, ergibt sich ein spezifischer ct-Wert (cycle threshold). Die Fluoreszenz ist proportional zur eingesetzten Anzahl der DNA-Moleküle. Anhand des ct-Wertes kann man nun Rückschlüsse auf den DNA-Gehalt des Zielgens ziehen. Je höher die Menge an DNA-Molekülen in der Probe ist, desto früher wird der ct-Wert erreicht bzw. je größer der ct-Wert ist, desto weniger von der untersuchten DNA ist in der Probe.

\subsubsection{Protokoll der q-PCR}

Als Proben dienten die jeweils in der Monolayer-Kultur und in der 3D-Alginatkultur gezüchteten Chondrozyten.

Für die q-PCR wurde für jeden Primer ein Mastermix angesetzt. Das verwendete SYBR Green (Platium SYBR Green qPCR SuperMix) beinhaltete bereits die HotStarTaq Polymerase, die dNTP (10 mM) und den Puffer (15 mM $\mathrm{MgCl}_{2}$ ). Alle Reagenzien wurden nach dem folgenden Schema vorbereitet: Um Pipettierungenauigkeiten auszugleichen, wurde anstatt des theoretisch ausreichenden Neunfachen jeweils das Zehnfache des benötigten Mastermixes erstellt. Der verwendete Primer-Mix beinhaltet den jeweiligen forward und reverse Primer in der Konzentration von je $20 \mathrm{pmol} / \mu \mathrm{l}$. 
Die gewonnene cDNA aus den DDR-1-knockout-Mäusen und der Wildtyp-Mäusen wurde nach dem folgenden Schema vorbereitet.

\begin{tabular}{|l|l|l|}
\cline { 2 - 3 } \multicolumn{1}{c|}{} & pro Well & Mastermix (10x) \\
\hline Primer-Mix & $2 \mu \mathrm{l}$ & $20 \mu \mathrm{l}$ \\
\hline SYBER-Green & $5 \mu \mathrm{l}$ & $50 \mu \mathrm{l}$ \\
\hline Nuklease-freies Wasser & $2 \mu \mathrm{l}$ & $20 \mu \mathrm{l}$ \\
\hline
\end{tabular}

Der Mastermix wurde danach in eine PCR-96-Well-Platte zu jeweils $9 \mu \mathrm{l} /$ Well pipettiert und jedem Well $1 \mu \mathrm{l}$ cDNA (entspricht $10 \mathrm{ng} / \mu \mathrm{l}$ ) addiert. Die Wells wurden mit Optical Flat Caps verschlossen und die Platte für 10 sek anzentrifugiert, um zu gewährleisten, dass sich der gesamte Ansatz unten im Well befindet.

Die q-PCR wurde jeweils dreimal mit dreifachen Ansätzen mit Hilfe eines Mastercycler Realplex ${ }^{2} S$ (Eppendorf, Hamburg, Deutschland) und mit dem folgenden Protokoll durchgeführt.

Initiale Denaturierung 3 min $\quad 95^{\circ} \mathrm{C}$

\begin{tabular}{lll}
\hline Denaturierung & 20 sek & $95{ }^{\circ} \mathrm{C}$ \\
Anlagerung (Annealing) & 20 sek & $58-63{ }^{\circ} \mathrm{C} \quad 45$ Zyklen \\
Verlängerung (Elongation) & 20 sek & $72{ }^{\circ} \mathrm{C}$ \\
\hline Denaturierung & 20 sek & $95{ }^{\circ} \mathrm{C}$ \\
Schmelzkurve & 20 sek & aufsteigend um je $0,1^{\circ} \mathrm{C}$ bis $95^{\circ} \mathrm{C}$ \\
Ende & 20 sek & $95{ }^{\circ} \mathrm{C}$
\end{tabular}

Die Daten der q-PCR wurden dann statistisch ausgewertet (siehe Statistik).

\subsubsection{Sequenzierung der PCR-Produkte und BLAST-Algorithmus}

Die Sequenzierung der PCR-Produkte diente der Validierung. So wurde sichergestellt, dass das vom Primer amplifizierte Produkt dem gewünschten Produkt entsprach. Die PCR-Produkte wurden an die Sequence Laboratories Göttingen GmbH (Göttingen, Deutschland) geschickt. Dort wurde eine Sequenzierung mit Hilfe der Methode nach Sanger, eine enzymatische DNA-Sequenzierung, durchgeführt. Die durch die Sequenzierung entstandenen Nukleotidsequenzen wurden wiederum in der NCBI- 
Datenbank (http://www.ncbi.nlm.nih.gov) miteinander verglichen. Dadurch wurde sichergestellt, dass das PCR-Produkt auch dem Zielgen entsprach. Alle verwendeten Primer zeigten jeweils eindeutig eine am besten geeignete Annealing-Temperatur. Zudem bestätigten die Ergebnisse der Sequenzierung die zu erwartende cDNASequenz der entsprechenden Primerpaare. Schließlich konnten die Primer für die jeweiligen Versuche verwendet werden.

\subsubsection{Statistik}

Die erforderliche Normalisierung der PCR-Daten erfolgte gegen die mRNA von Chondrozyten aus embryonalem Mäusegewebe mit Hilfe des Housekeeping-Gens HPRT-1 (Hypoxanthin-Phosphoribosyl-Transferase 1). Die Ergebnisse wurden anhand eines von Pfaffl (2001) publizierten Algorhythmus berechnet. HousekeepingGene werden in Organismen konstant exprimiert, da sie essentiell für die Zellfunktion sind. Idealerweise unterliegen sie keinen regulatorischen Einflüssen. HPRT 1 wies in unseren Proben identische ct-Werte auf und wurde demnach konstitutiv exprimiert. Deshalb eignete es sich für den Einsatz als Housekeeping-Gen.

Um die Effizienz der PCR zu bestimmen, wurde eine Standardkurve exemplarisch für HPRT-1 durch eine Standardverdünnungsreihe generiert. Als Standard-DNA wurde die cDNA der chondrogenen Progenitorzellen mit einer Konzentration von $1 \mathrm{ng} / \mu \mathrm{l}$ eingesetzt. Der Verdünnungsbereich der cDNA lag zwischen 1:1 und 1:1000 (Verdünnungen jeweils in 1:10 Schritten). Diese wurden in den oben beschriebenen PCR-Ansatz eingesetzt.

Die aus den durchgeführten PCR-Versuchen erhaltenen ct-Werte wurden in jedem Probentriplet untereinander verglichen. Sie wichen $<0,5$ ct-Punkte in der Standardabweichung vom jeweiligen Mittelwert des PCR-Versuchs ab. Anschließend wurden die Mittelwerte der ct-Werte aus den drei Versuchsläufen errechnet und miteinander verglichen. Diese zeigten ebenfalls eine Standardabweichung von $<0,5$ ct-Punkten. So wurde sichergestellt, dass alle durch die q-PCR ermittelten Ergebnisse einer Intertest- und Intratest-Variationsbreite von < 1 \% unterlagen.

Der relative Expressionsunterschied zwischen dem Housekeeping-Gen zur Referenzprobe, normalisiert durch das Referenzgen HPRT-1, wurde hierbei aus der arithmetischen Formel $E^{-\Delta \Delta C T}(E=$ Effizienz der PCR) berechnet (Pfaffl 2001). 


\section{Ergebnisse}

3.1 Lichtmikroskopische Färbungen und Immunhistochemie von Kollagen Typ I, Kollagen Typ II, Nidogen 1 und Nidogen 2 im Kiefergelenksknorpel der DDR1-knockout-Maus

Dies ist die erste Studie, die lichtmikroskopisch die Kollagene vom Typ I und Typ II sowie die Glykoproteine Nidogen 1 und Nidogen 2 im Knorpel des Kiefergelenks der DDR-1-knockout-Maus darstellt. Des Weiteren wurde die Genexpression von Kollagen Typ I, Aggrecan, Sox-9 und Runx-2 in den Chondrozyten der knockout-Maus untersucht. 

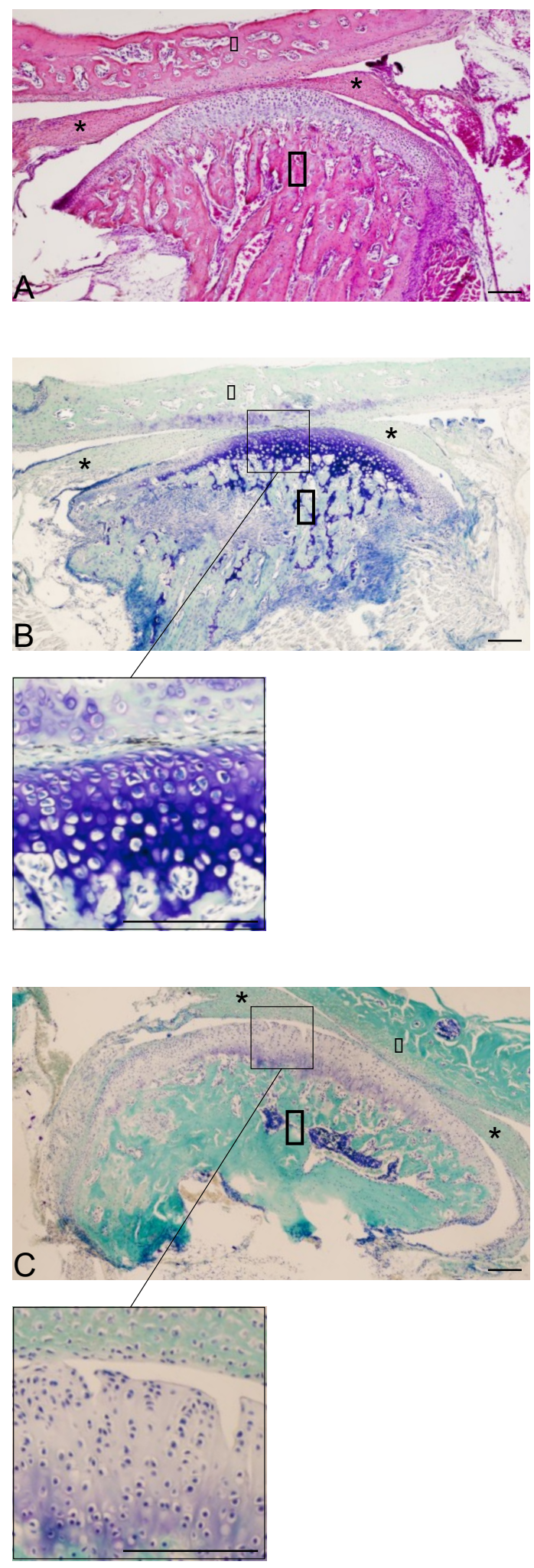

Abbildung 4: A Lichtmikroskopische Übersicht in HE-Färbung am Kiefergelenk einer 9 Wochen alten Wildtyp-Maus. Markiert sind die Schädelbasis (kleines Rechteck), der Discus articularis (Sterne) und der Condylus mit subchondralem Knochengewebe (großes Rechteck), das von Gefäßen durchzogen ist. Maßstabsbalken: $150 \mu \mathrm{m}$. (Diese Abb. entspricht Fig. 3b aus der Publikation.)

B Lichtmikroskopische Toluidinblaufärbung am Kiefergelenk einer 9 Wochen alten Wildtyp-Maus. Markiert sind die Schädelbasis (kleines Rechteck), der Discus articularis (Sterne) und der Condylus mit subchondralem Knochen (großes Rechteck).

Darunter zeigt der vergrößerte Ausschnitt den Gelenkspalt.

Maßstabsbalken: $150 \mu \mathrm{m}$

(Diese Abb. entspricht Fig. 11 aus der Publikation.)

C Lichtmikroskopische Toluidinblaufärbung am Kiefergelenk einer 9 Wochen alten DDR-1-knockoutMaus.

Markiert sind die Schädelbasis (kleines Rechteck), der Discus articularis (Sterne) und der Condylus (großes Rechteck). Darunter der vergrößerte Ausschnitt.

Maßstabsbalken: $150 \mu \mathrm{m}$

(Diese Abb. Entspricht der Fig. $1 j$ aus der Publikation. Der vergrößerte Ausschnitt entspricht der Fig. 1 k aus der Publikation.) 
Eine Übersicht des ATM der Maus bietet Abb. $4 \mathrm{~A}$ in HE-Färbung. Der Discus articularis (Sternchen) liegt zwischen der Schädelbasis (kleines Rechteck) und dem Condylus (großes Rechteck). Dieser besteht wiederum aus dem subchondralen Knochen, mit vielen Gefäßeinsprossungen, und dem knorpeligen Anteil, der teilweise dem Discus articularis anliegt. Letzterer wird zwischen Schädelbasis und Condylus komprimiert, so dass sich Condylus und Schädelbasis annähern, jedoch nie in direkten Kontakt treten.

Die Präparate, die mit Toluidinblau angefärbt wurden, geben Auskunft über den Proteoglykangehalt im Gewebe. Bei der Wildtyp Maus in Abb. 4 B zeigt sich das Vorkommen von Proteoglykanen im Knorpel durch die intensive Blaufärbung. Die Chondrozyten selbst und das sie umgebende Chondron beinhalten keine Proteoglykane, während in der territorialen und interterritorialen Matrix die Hauptmasse der Proteoglykane liegt. Der lichtmikroskopische Nachweis gelingt bis in die superfizialen Zellschichten, wie in dem vergrößerten Ausschnitt gut zu erkennen ist. In den Randbereichen scheint der Knorpel frei von Proteoglykanen zu sein. Diese Aufhellungen zeigen jedoch höchstwahrscheinlich den Übergang in bindegewebige Anteile und beinhalten deshalb keine Proteoglykane. Der Discus articularis zeigt sich ebenso frei von Proteoglykanen. In der artikulierenden Fläche der Schädelbasis ist der Nachweis schwach positiv.

Im Vergleich zum Wildtyp ist bei der gleichaltrigen knockout-Maus trotz ihres mit 9 Wochen noch relativ jungen Alters eine eindeutige Degradierung der Proteoglykane zu erkennen (Abb. $4 \mathrm{C}$ ). In der Tangential- und Transitionalzone konnten keine Proteoglykane nachgewiesen werden, während es in der Radiärzone leicht positive Reaktionen gab. Des Weiteren zeigt die Vergrößerung, dass sich in der artikulierenden Knorpeloberfläche tiefe Einrisse finden, die neben dem Proteoglykanverlust ein Zeichen für Osteoarthritis sind. 

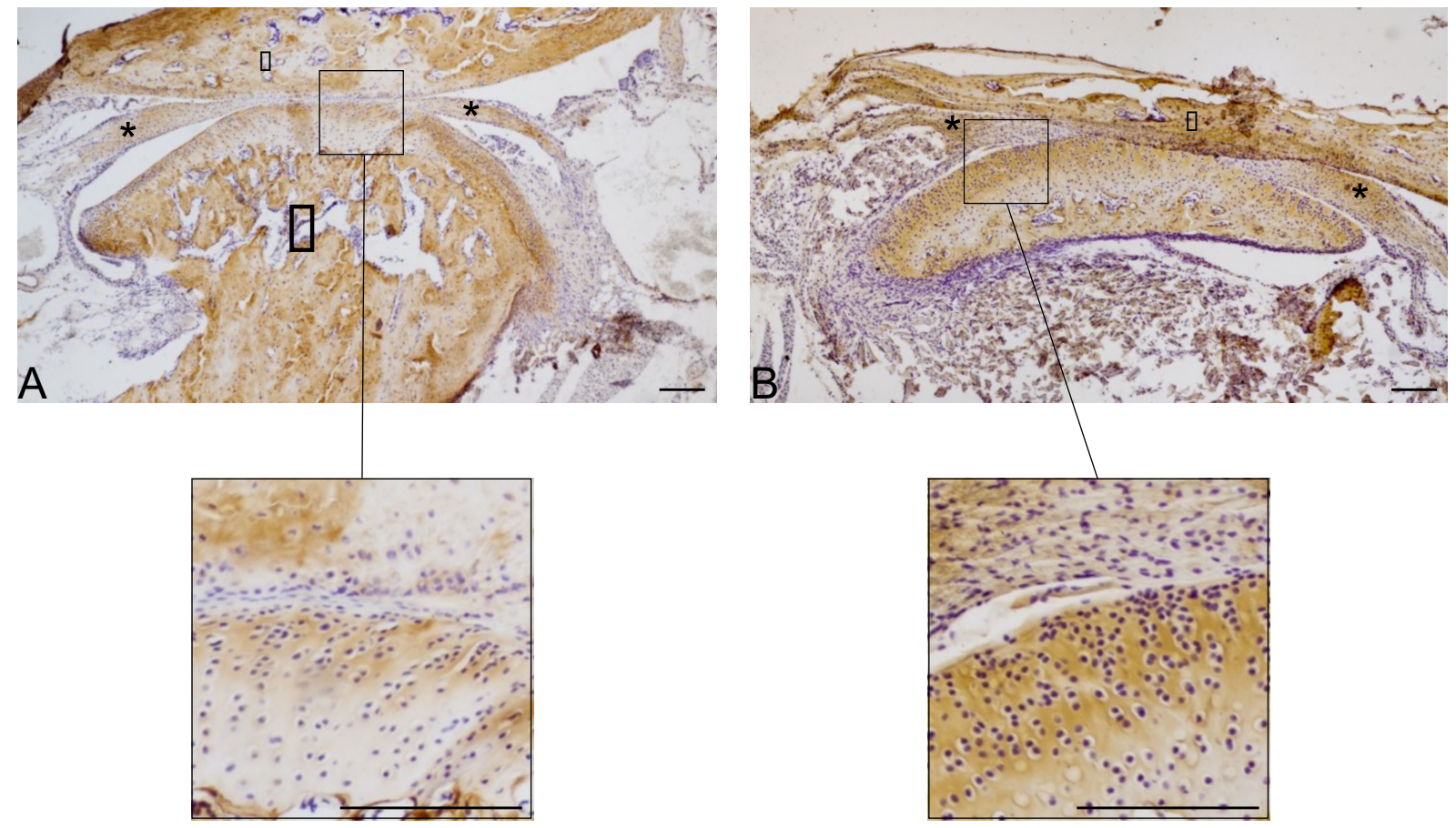

Abbildung 5: Lichtmikroskopische Immunhistochemie: Kollagen Typ I am Kiefergelenk der 9 Wochen alten Wildtyp-Maus A und der DDR-1-knockout-Maus B jeweils in Übersicht und Vergrößerung.

Markiert sind die Schädelbasis (kleines Rechteck), der Discus articularis (Sterne) und der Condylus mit subchondralem Knochengewebe (großes Rechteck), Maßstabsbalken: $150 \mu \mathrm{m}$

Die deutliche Reaktion des gegen Kollagen Typ I gerichteten Antikörpers ist auf Abb. 5 A gut zu erkennen. Im subchondralen Knochen ist der lichtmikroskopische Nachweis stärker als im Knorpelgewebe des Condylus, in dem es nur eine schwächere Reaktion gibt (siehe vergrößerter Ausschnitt von Abb. 5 A).

Bei der DDR-1-knockout-Maus zeigt sich für Kollagen Typ I eine homogene Anfärbung der Tangential- und der Transitionalzone des Knorpels, während nach radiär die Intensität etwas abzunehmen scheint. Der Vergleich der beiden vergrößerten Ausschnitte lässt auf einen höheren Kollagen Typ I-Gehalt im Knorpel der DDR-1knockout-Maus schließen. 

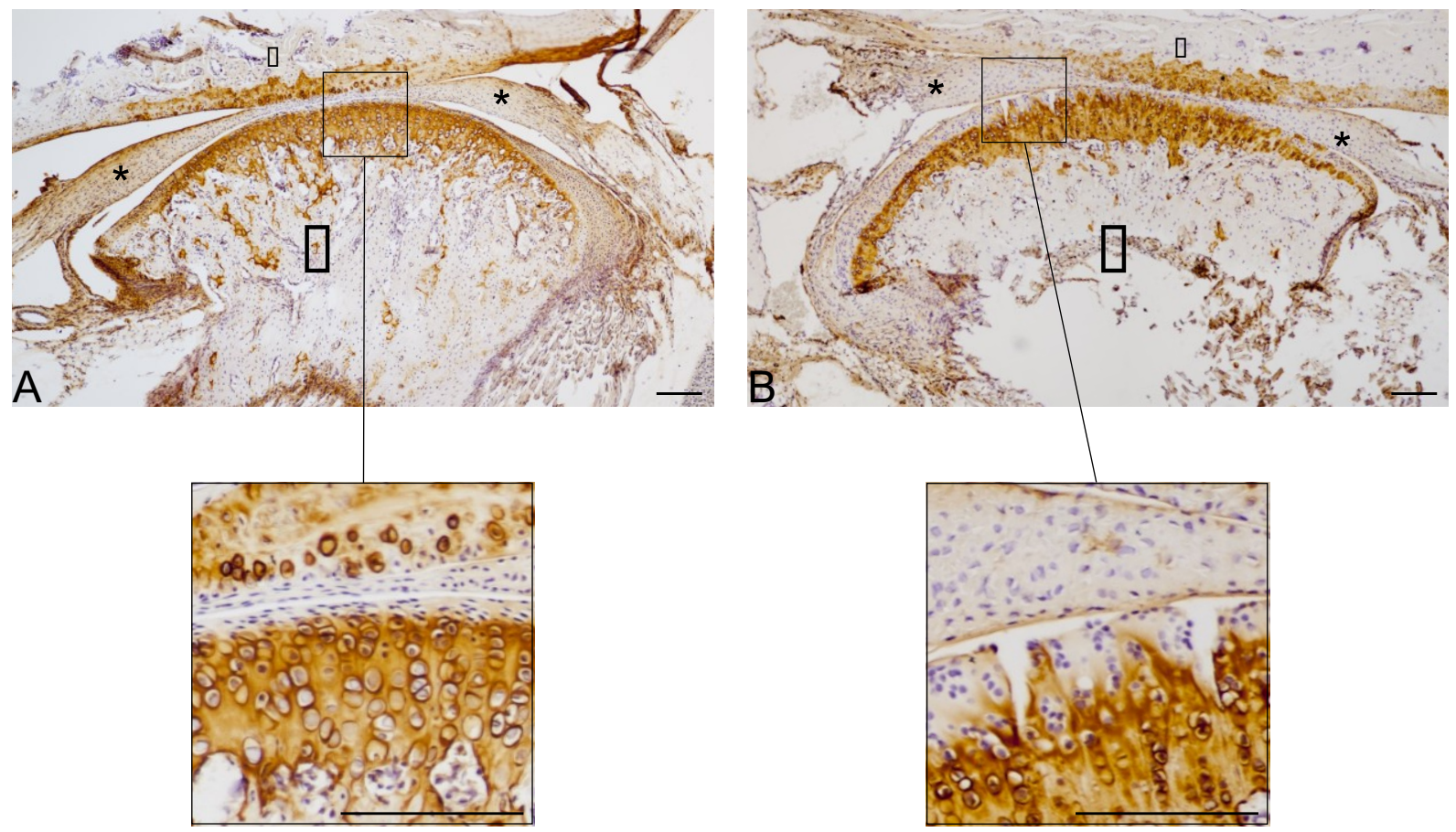

Abbildung 6: Lichtmikroskopische Immunhistochemie: Kollagen Typ II am Kiefergelenk der 9 Wochen alten Wildtyp-Maus A und der DDR-1-knockout-Maus B jeweils in Übersicht und Vergrößerung.

Markiert sind die Schädelbasis (kleines Rechteck), der Discus articularis (Sterne) und der Condylus mit subchondralem Knochengewebe (großes Rechteck), Maßstabsbalken: $150 \mu \mathrm{m}$.

Die Abb. 6 A entspricht der Fig. $2 f$ und der vergrößerte Ausschnitt der Fig. $2 h$ der Publikation. Die Abb. 6 B entspricht die Fig. $2 e$ und der vergrößerte Ausschnitt der Fig. $2 g$ der Publikation.

Für Kollagen Typ II gelingt der immunhistochemische Nachweis bei der knockoutMaus und ebenso bei der Wildtyp-Maus. Sowohl im Knorpel des Condylus als auch in der artikulierenden Gelenkfläche der Schädelbasis zeigen sich intensive Anfärbungen. Bei der Wildtyp-Maus sind die Transational- und Radiärzone homogen angefärbt, mit dem klaren Unterschied zu den superfizialen Zellreihen, die ohne Anfärbung bleiben, wie in der Vergrößerung von Abb. 6 A gut zu erkennen ist.

Anders verhält es sich in Abb. $6 \mathrm{~B}$, wo auf der Übersicht generell ein klarer Rückgang von Kollagen Typ II aus den oberflächlicheren Schichten zu erkennen ist. Allerdings sind auch Ausläufer von Kollagen Typ II zu erkennen, die bis an die Knorpeloberfläche heranreichen, wie der vergrößerte Ausschnitt zeigt. Dies ist besonders in Bereichen der Fall, in denen typische osteoarthritische Veränderungen wie feine oberflächliche Einrisse am Knorpel zu erkennen sind. Das Vorkommen von Kollagen Typ II ist hier demnach nicht mehr strikt auf die Transational- und Radiärzone beschränkt. 

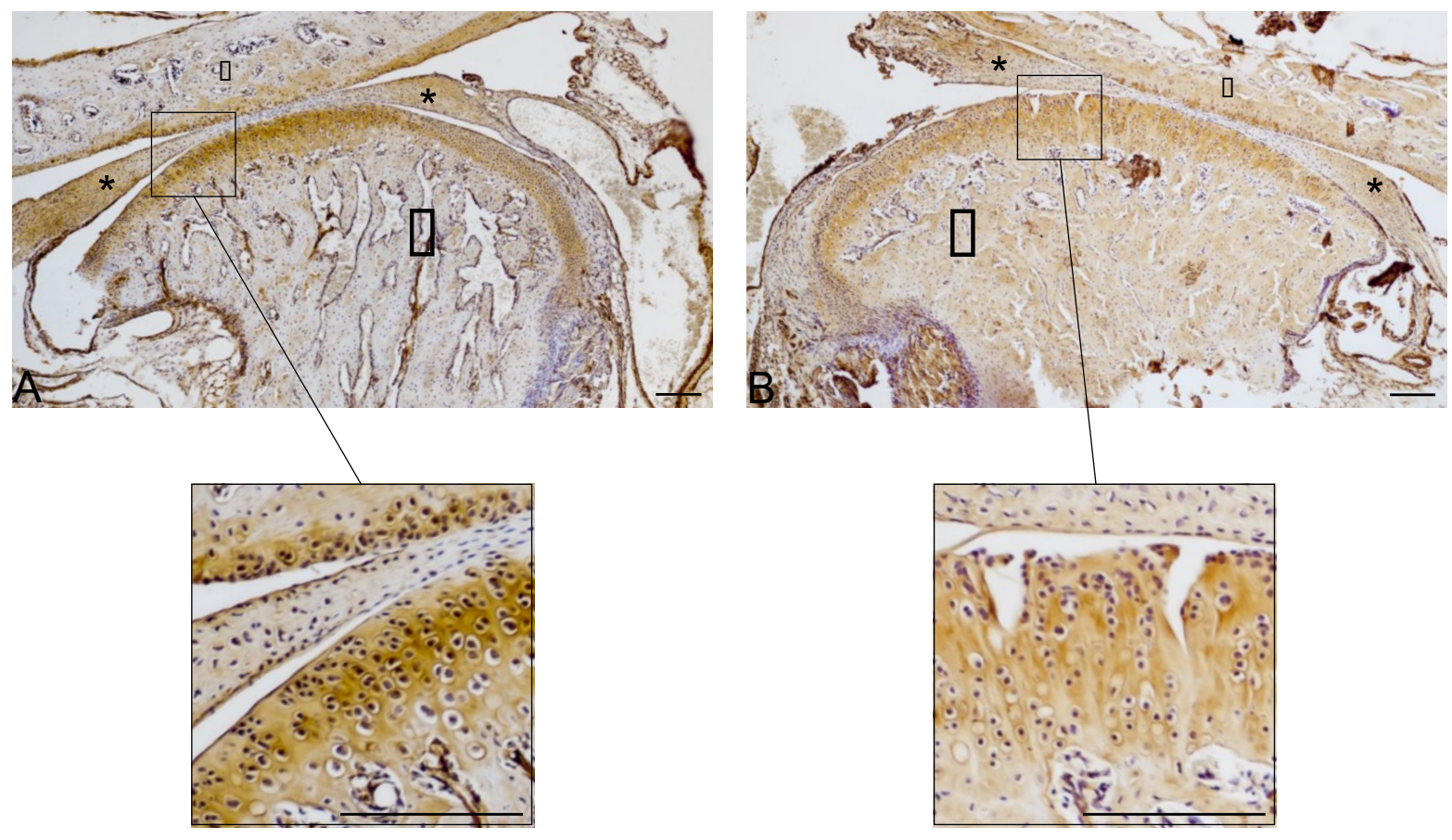

Abbildung 7: Lichtmikroskopische Immunhistochemie: Nidogen 1 am Kiefergelenk der 9 Wochen alten Wildtyp-Maus A und der DDR-1-knockout-Maus B jeweils in Übersicht und Vergrößerung.

Markiert sind die Schädelbasis (kleines Rechteck), der Discus articularis (Sterne) und der Condylus mit subchondralem Knochengewebe (großes Rechteck), Maßstabsbalken: $150 \mu \mathrm{m}$.

Die Abb. 7 B entspricht die Fig. 2i und der vergrößerte Ausschnitt der Fig. 2k der Publikation.

In Abb. 7 A liegt eine Reaktion für Nidogen 1 vor, die sich am stärksten in der Transitionalzone zeigt, wohingegen die Superfizialzone und Radiärzone schwächere Nachweise von Nidogen 1 aufzeigen. In der Vergrößerung der Wildtyp-Maus ist der verstärkte Nachweis von Nidogen 1 in der perizellulären Matrix der Chondrozyten zu erkennen.

Insgesamt ist die Reaktion gegenüber dem Wildtyp eher abgeschwächt. Interterritorial gelingt der stärkste Nachweis von Nidogen 1. Die Reaktion ist auch hier in der Transitionalzone ausgeprägter als radiär. Die Vergrößerung zeigt einen Bereich, wo es im Rahmen der Osteoarthritis zu tiefen Fissuren in der Oberfläche des Gelenkknorpels gekommen ist. Hier ist perizellulär eine Abschwächung im Vergleich zum Wildtyp erkennbar, während sich interterritorial nach wie vor eine solide Reaktion zeigt. 

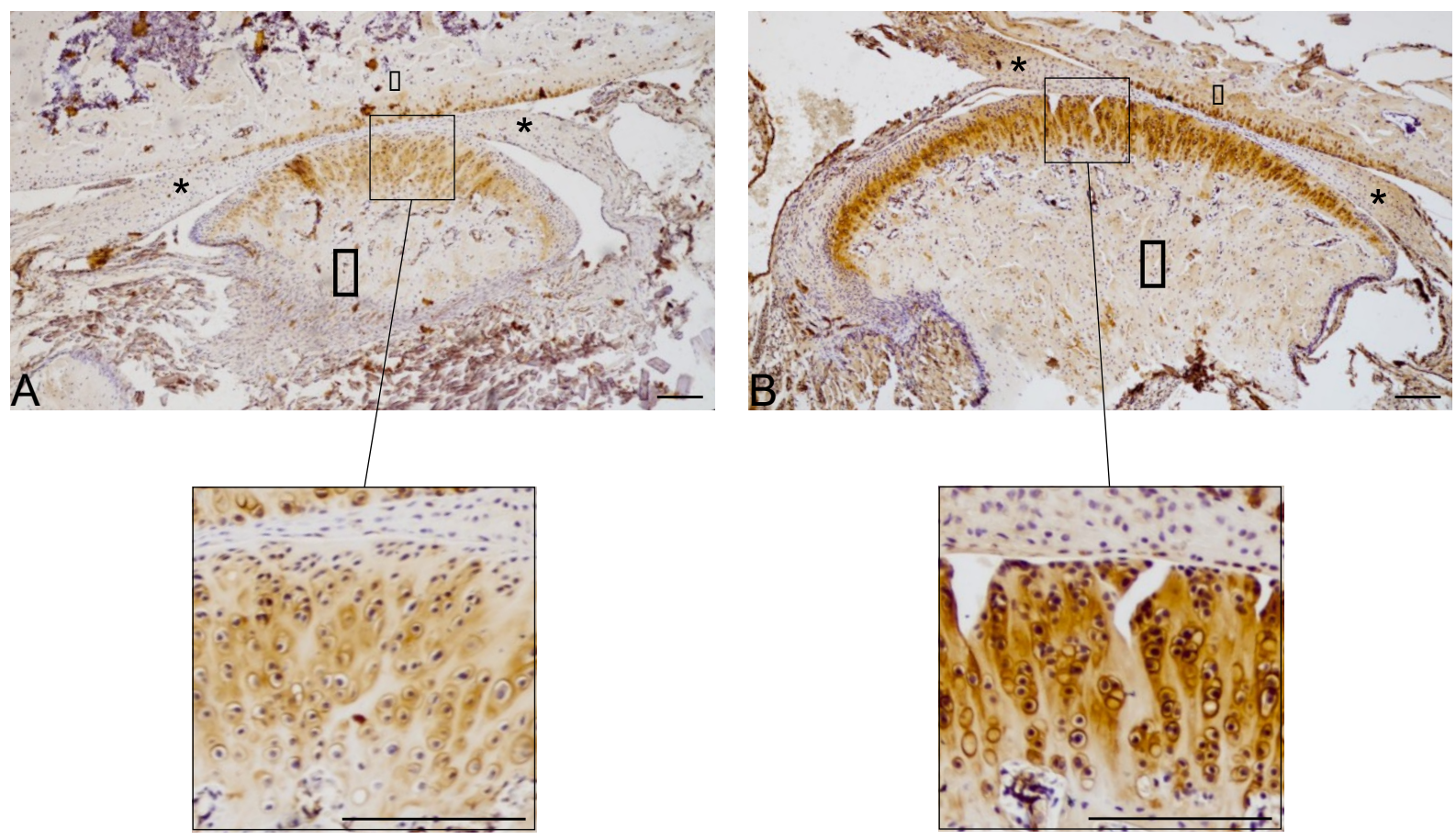

Abbildung 8: Lichtmikroskopische Immunhistochemie: Nidogen 2 am Kiefergelenk der 9 Wochen alten Wildtyp-Maus A und der DDR-1-knockout-Maus B jeweils in Übersicht und Vergrößerung.

Markiert sind die Schädelbasis (kleines Rechteck), der Discus articularis (Sterne) und der Condylus mit subchondralem Knochengewebe (großes Rechteck), Maßstabsbalken: $150 \mu \mathrm{m}$.

Die Abb. 8 A entspricht der Fig. $2 n$ und der vergrößerte Ausschnitt der Fig. $2 p$ der Publikation.

Der Nachweis von Nidogen 2 gelingt bei der DDR-1-knockout-Maus deutlich. Auch bei der Wildtyp-Maus lässt sich Nidogen 2 v. a. perizellulär und in der Transitionalzone nachweisen (Abb. 8 A). Zur Oberfläche hin und in der Radiärzone wird die Reaktion weniger stark. Jedoch sind radiär auch noch vereinzelt perizelluläre Reaktionen zu sehen.

Immunhistochemisch zeigt sich ein vermehrtes Vorkommen im Kiefergelenksknorpel der knockout-Maus (Abb. 8 B). Weiterhin erscheint in der Transitionalzone der Gehalt von Nidogen 2 am höchsten. Hier gelingt der Nachweis auch in der interterritorialen Matrix, wobei perizellulär die Anfärbung nach wie vor am intensivsten ist. Dies kommt in dem vergrößerten Ausschnitt von Abb. 8 B gut zur Darstellung. Hier liegen die Zellen in dicht gepackten Haufen, sog. Clustern, und die Anfärbung ist besonders intensiv. 


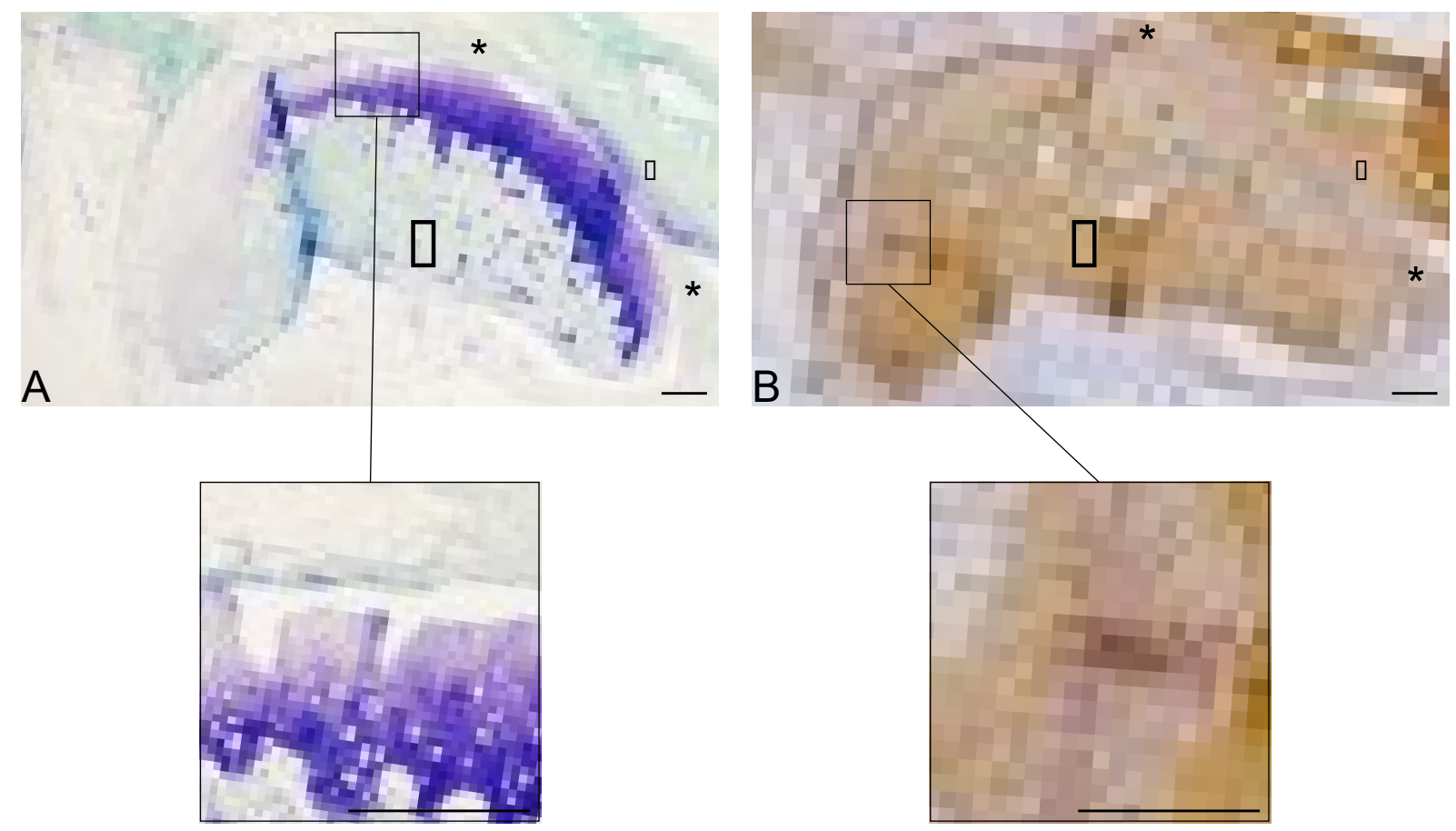

Abbildung 9: Jeweils lichtmikroskopische Darstellung der Kiefergelenke von 12 Wochen alten DDR-1knockout-Mäusen. A Toluidinblaufärbung, B Immunhistochemie mit Kollagen Typ I jeweils mit Vergrößerung.

Markiert sind die Schädelbasis (kleines Rechteck), der Discus articularis (Sterne) und der Condylus mit subchondralem Knochengewebe (großes Rechteck), Maßstabsbalken: $150 \mu \mathrm{m}$.

Die Abb. 9 B entspricht der Fig. 2a in der Publikation.

In Abb. $9 \mathrm{~A}$ ist ein deutlicher Verlust von Proteoglykanen in den superfizialen Knorpelschichten sichtbar, einhergehend mit einer auffallend unregelmäßigen Gelenkfläche, die zum Teil tiefe Fissuren aufweist (siehe Vergrößerung). Zusätzlich ist ein erhöhter perizellulärer Proteoglykangehalt in den tieferen Zellschichten zu erkennen, wo es noch zu keiner kompletten Degradierung der Proteoglykane gekommen ist. Mit zunehmender Tiefe der Zellschicht vergrößert sich der Durchmesser der Chondrozyten.

Abb. 9 B zeigt einen positiven Nachweis von Kollagen Typ I im subchondralen Knochen und im Kiefergelenksknorpel. Im Vergleich zu Präparaten von jüngeren Tieren erscheint die Reaktion verstärkt (vergleiche Abb. $5 \mathrm{~A}$ und B). Eine Größenzunahme der Chondrozyten, die mit Tiefe der Zellschicht zunimmt, ist deutlich erkennbar. Zudem sind kleinere Unregelmäßigkeiten, die ein Korrelat von Osteoarthritis sind, auf der Oberfläche des Condylus zu erkennen. Der vergrößerte Ausschnitt zeigt ein sich vermutlich in einem narbigen Umbau befindendes Areal. 



Abbildung 10: Jeweils lichtmikroskopische Imunhistochemie für Nidogen 1 A und für Nidogen 2 B an Kiefergelenken von 12 Wochen alten DDR-1-knockout-Mäusen jeweils mit Vergrößerung.

Markiert sind die Schädelbasis (kleines Rechteck), der Discus articularis (Sterne) und der Condylus mit subchondralem Knochengewebe (großes Rechteck), Maßstabsbalken: $150 \mu \mathrm{m}$.

Die Abb. 10 B entspricht der Fig. $2 m$ in der Publikation.

Abb. 10 A zeigt einen homogenen, wenn auch schwachen, Nachweis für Nidogen 1. Im vergrößerten Ausschnitt ist die deutlich zerklüftete Oberfläche des Gelenknorpels gezeigt. Hier sind keine stärkeren Reaktionen im Hinblick auf Nidogen 1 ersichtlich. Ein deutlicher perizellulärer Nachweis von Nidogen 2 ist im Präparat zu erkennen, welches in Abb. 10 B gezeigt ist. Auffallend ist eine Zunahme von Nidogen 2 in Bereichen, in denen die Gelenkfläche durch osteoarthritische Vorgänge Unregelmäßigkeiten aufzeigt. Dies ist im vergrößerten Ausschnitt im Detail gezeigt. 


\subsection{Vergleichende Genexpressionsanalyse von Chondrozyten in Monolayer- Kultur und 3D-Alginatkultur}

Die Auswertung der Ct-Werte der Zellkultur im Monolayer zeigt, dass die Expressionsraten der mRNA von Runx-2 (Abb. 11, unterer Graph) und Kollagen Typ I (Abb. 12, unterer Graph) bei den DDR-1-knockout-Mäusen signifikant über den mRNA Level des vergleichbaren Wildtyps liegen. Hingegen weisen die Chondrozyten der DDR-1-knockout-Mäuse eine signifikant niedrigere Expression von mRNA bei Sox-9 (Abb. 11, oberer Graph) und Aggrecan (Abb. 12, oberer Graph) gegenüber der Wildtyp Maus auf. Für die eben beschriebenen Ct-Werte wurden diese nach Pfaffl (2001) normalisiert.

Die knockout-Mäuse zeigen hier Ergebnisse, die typisch für osteoarthritischen Knorpel sind. Sowohl die erhöhte Expressionsrate von Kollagen Typ I und Runx-2 als auch die niedrigere Werte für Aggrecan und Sox-9 sind charakteristisch für die Pathologie von Osteoarthritis.

Die Effekte, die sich durch die Umgebung einer 3D-Alginatkultur in den Chondrozyten zeigen, korrelieren mit den Ergebnissen der 2D-Monolayer-Zellkultur (Abb. 11 und 12). Auch hier liegt die Expressionsrate von Runx-2 (Abb. 13, unterer Graph) und Kollagen Typ I (Abb. 14, unterer Graph) in den DDR-1-knockout-Mäusen höher als in den Wildtyp-Mäusen. Die Ct-Werte von Sox-9 (Abb. 13, oberer Graph) und Aggrecan (Abb. 14, oberer Graph) sind dagegen bei den DDR-1-knockout-Mäusen im Vergleich zum Wildtyp verringert.

Demnach zeigen auch diese Ergebnisse die typischen molekularen Veränderungen, die bei dem osteoarthritischen Krankheitsbild im Gelenkknorpel auftreten. 

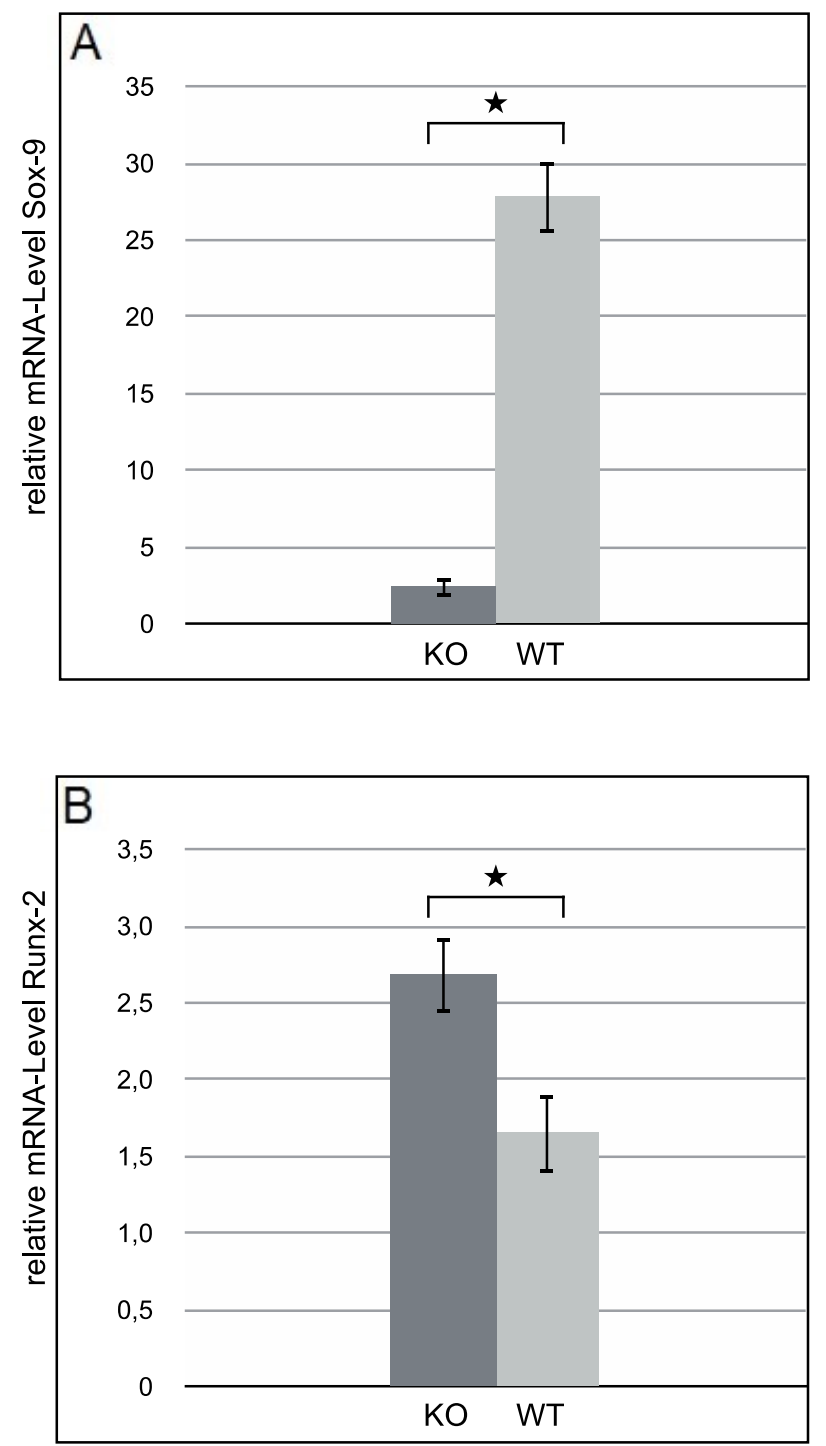

Abbildung 11: Nach Pfaffl normalisierte relative mRNA-Level für Sox-9 und Runx-2 der q-PCR von Zellen aus der Monolayer Kultur von DDR-1knockout-Mäusen (KO) und Wildtyp-Mäusen $(W T)$. Signifikante Ergebnisse sind mit einem Stern gekennzeichnet $(p \leq 0,05)$.

Die Abbildung 11 A entspricht der Fig. 4d aus der Publikation.

Die Abbildung 11 B entspricht der Fig. 4e aus der Publikation. 

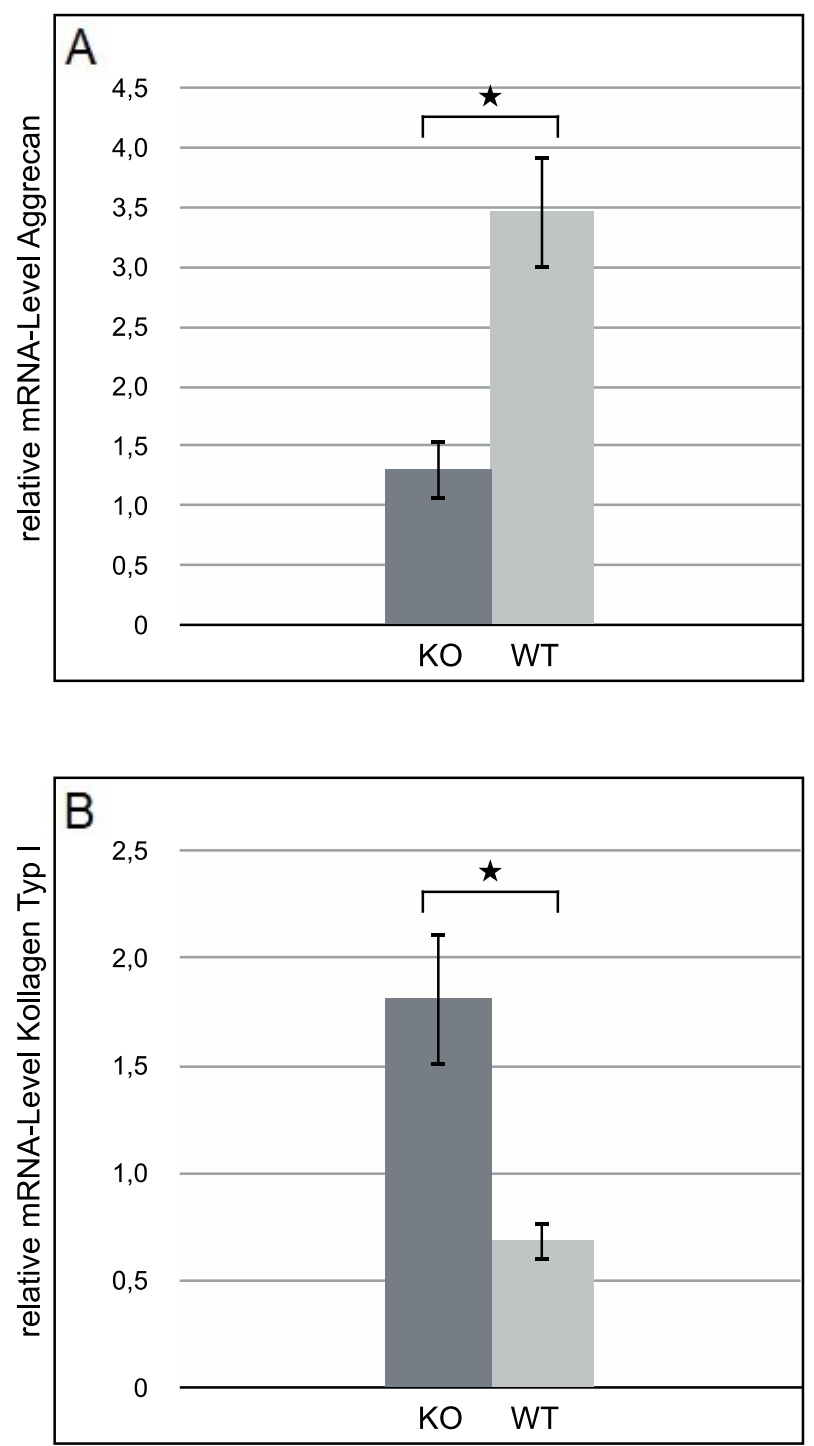

Abbildung 12: Nach Pfaffl normalisierte relative mRNA-Level für Aggrecan und Kollagen Typ I der q-PCR von Zellen aus der Monolayer Kultur von DDR-1-knockoutMäusen (KO) und Wildtyp-Mäusen (WT). Signifikante Ergebnisse sind mit einem Stern gekennzeichnet $(p \leq 0,05)$.

Die Abbildung $12 A$ entspricht der Fig. $4 g$ aus der Publikation und die Abbildung 12B entsprichtder Fig. $4 f$ aus der Publikation. 


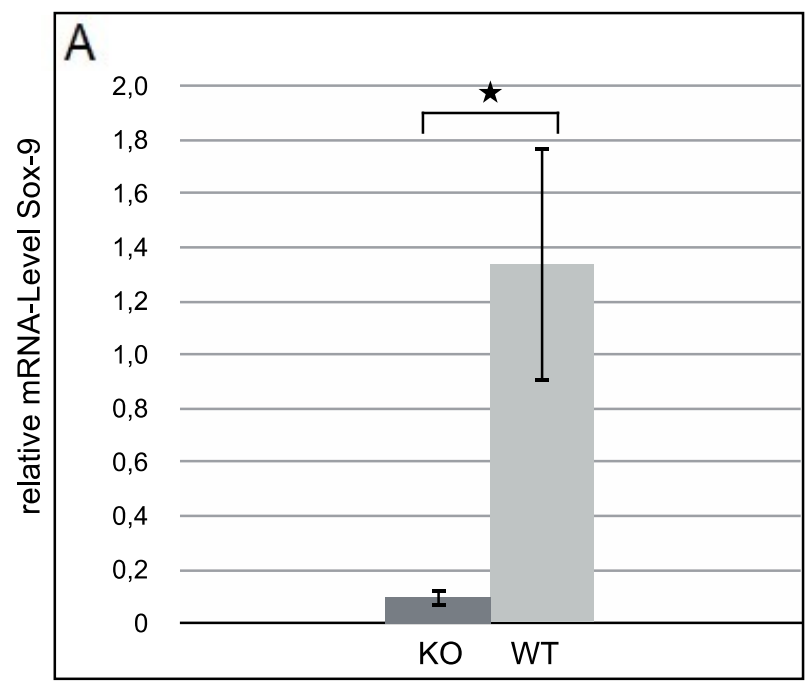

Abbildung 13: Nach Pfaffl normalisierte relative mRNA-Level für Sox-9 und Runx-2 der q-PCR von Zellen aus der 3D-Alginatkultur von DDR-1- knockout-Mäusen (KO) und WildtypMäusen (WT). Signifikante Ergebnisse sind mit einem Stern gekennzeichnet $(p \leq 0,05)$.

Die Abbildung $13 A$ entspricht der Fig. $6 c$ aus der Publikation und die Abbildung 13B entsprichtder Fig. 6a aus der Publikation.

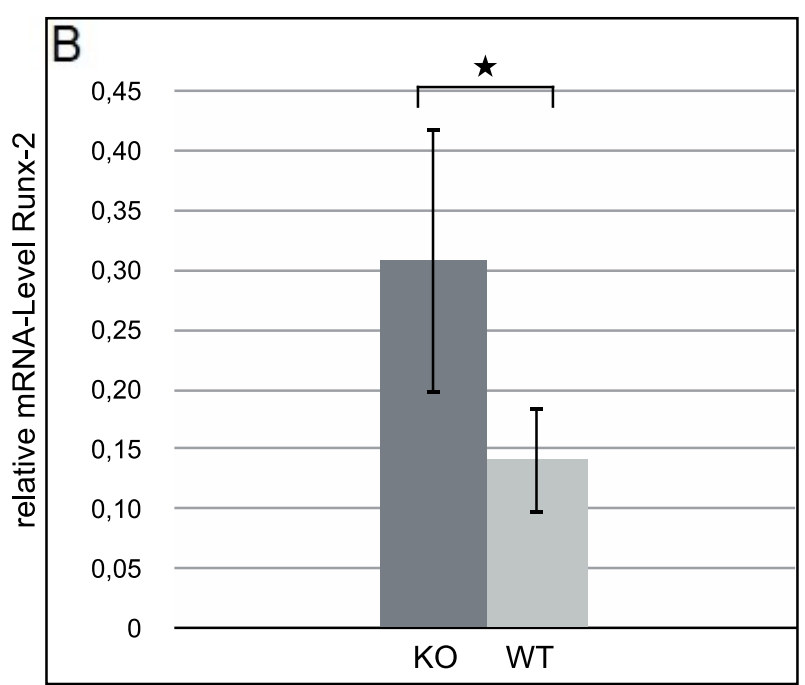




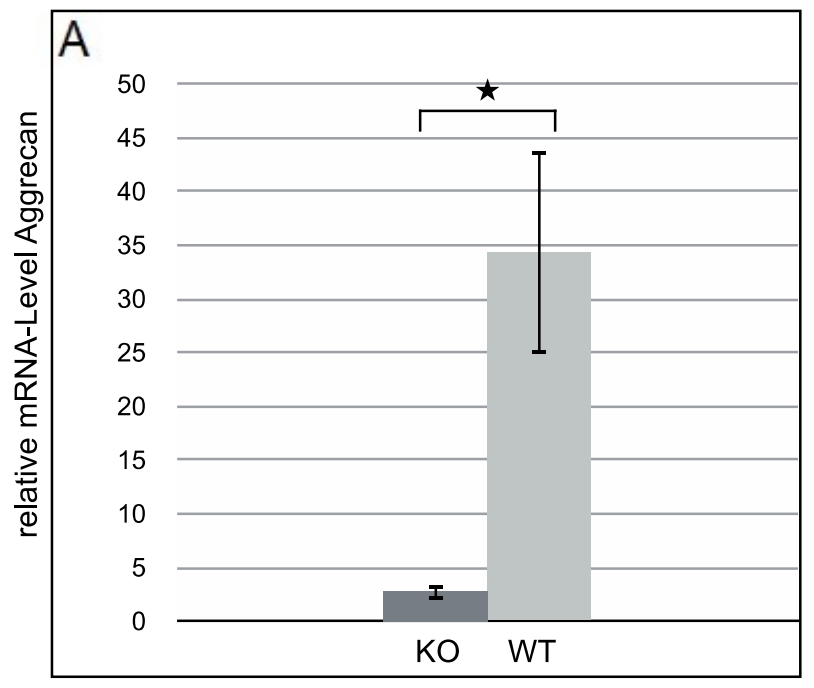

Abbildung 14: Nach Pfaffl normalisierte relative mRNA-Level für Aggrecan und Kollagen Typ I der $q-P C R$ von Zellen aus der 3D-Alginatultur von DDR1-knockout-Mäusen (KO) und Wildtyp-Mäusen (WT). Signifikante Ergebnisse sind mit einem Stern gekennzeichnet $(p \leq 0,05)$.

Die Abbildung 14A entspricht der Fig. $6 d$ aus der Publikation und die Abbildung 11B entspricht der Fig. $6 b$ aus der Publikation.






\section{Diskussion}

\subsection{Diskussion der Ergebnisse der Genexpressionsanalyse und der immunhistochemischen Ergebnisse}

Diese Arbeit stellt ein neues Tiermodell für Osteoarthritis im ATM vor, die DDR-1knockout-Maus. Bei der DDR-1-knockout-Maus kommt es deutlich früher als bei anderen bereits etablierten Mausmodellen zu Osteoarthritis. Ohne das Vorkommen von DDR-1 ergeben sich mehrere wichtige Folgen und Erkenntnisse in Bezug auf die Pathogenese von Osteoarthritis. Dazu gehören die vermehrte Expression von Kollagen Typ I und Runx-2 sowie eine verminderte Expression von Sox-9 und Aggrecan, wie sie in den Ergebnissen der Genexpressionsanalysen und der Immunhistochemie in dieser Arbeit gezeigt werden.

Es gibt ein weites Spektrum an regulierenden Schritten in der Posttranskriptionsphase, die die mRNA-Werte erklären könnten. Demnach ist es vorstellbar, dass etwaige Prozesse bspw. auf der Ebene von MikroRNA, wie bei Sox-9 gezeigt werden konnte, stattfinden (Martinez-Sanchez et al. 2012).

\subsubsection{Veränderung des Chondrozyten und seiner perizellulären Matrix bei Osteoarthritis}

Im gesunden Gelenkknorpel zeigen die Chondrozyten einen einheitlichen und stabilen Phänotyp. Weder differenzieren sie weiter noch proliferieren sie. Betrachtet man im Gegensatz dazu Chondrozyten aus von Osteoarthritis befallenen Gelenken, zeigt sich eine weitere Differenzierung, die zu einem hypertrophen Phänotyp führt. Aus diesem Grund wird angenommen, dass Osteoarthritis im Zusammenhang mit der späten Differenzierung von Chondrozyten steht (von der Mark et al. 1992). Die Mehrheit der Forschungsarbeiten in diesem Gebiet sieht die Hypertrophie der Chondrozyten als ein grundlegendes Merkmal für Osteoarthritis (von der Mark et al. 1992; Fuerst et al. 2009; Little et al. 2009). Ausgelöst wird diese „Aktivierung“ der Chondrozyten durch eine Reihe von entzündlichen und anabolisch wirkenden Zytokinen (Goldring und Otero 2011).

Die Genexpressionsanalysen in der Monolayer- und in der Alginat-Kultur (siehe Abb. 11 - 14) ergaben einen signifikant erhöhten mRNA-Gehalt für Runx-2 bei der 
arthrotischen DDR-1-knockout-Maus gegenüber dem Wildtyp, jedoch signifikant erniedrigte Expressionslevel von Sox-9.

Runx-2 ist ein entscheidender Regulator für die Differenzierung der Chondrozyten und dafür bekannt, als Transkriptionsfaktor direkten Einfluss auf die Hypertrophie von Chondrozyten, deren molekularbiologisches Korrelat Kollagen Typ X darstellt, auszuüben (Zheng et al. 2003, Wang et al. 2004). Ebenso hat Runx-2 einen positiven Einfluss auf die Expression von MMP-13 (Wang et al. 2004, Kamekura et al. 2006).

Die Ergebnisse der Genexpressionsanalysen unterstützen die Ergebnisse der Immunhistochemie. Diese zeigt, dass an den Präparaten der 12 Wochen alten knockout-Mäusen nicht nur ein Verlust von Proteoglykanen in den oberflächlichen Zellschichten (Abb. 9 A) zu sehen ist, sondern auch eine Größenzunahme der Chondrozyten zu erkennen ist (Abb. 9 A und B). Je tiefer sich die Zellschicht befindet, desto größer erscheinen die einzelnen Chondrozyten.

Dies könnte damit zusammenhängen, dass es während des frühen Stadiums der Osteoarthritis nicht nur zu einem Verlust von Proteoglykanen kommt, sondern auch die Chondrone, in denen die Chondrozyten liegen, von pathologischen Veränderungen betroffen sind. Poole et al. (1991) beschreiben das Chondron als anatomische und funktionelle Einheit, die aus Chondrozyt, perizellulärer Matrix mit einer sie umgebenen Kapsel besteht. An die Kapsel grenzt die territoriale Matrix. Dabei ist die Zusammensetzung der perizellulären Matrix von grundlegender Bedeutung für die Chondrozyten und das Aufrechthalten ihrer physiologischen Funktionen. Im osteoarthritischen Knorpel nimmt das Volumen der perizellulären Matrix zu. Dies geht mit Proteoglykanverlust und einer Desorganisation der in der perizellulären Matrix enthaltenen Kollagenfasern einher (Poole et al. 1991).

An dem in der Einleitung vorgestellten cho/+ Mausmodell konnte anhand von immunhistochemischen Färbungen eine Zunahme von DDR-2 bei simultaner Degradierung von Kollagen Typ VI in der perizellulären Matrix, in der es physiologisch zu hohen Anteilen vertreten ist, gezeigt werden. Zusätzlich war ein erhöhtes Vorkommen von HtrA1-Protease (siehe Abschnitt 1.3.3 Die Rolle von MMP-13 in Osteoarthritis) erkennbar (Polur et al. 2010). Im osteoarthritischen Kniegelenk zeigte sich, dass HtrA1-Level in der Synovialflüssigkeit erhöht waren und dass HtrA1 mehrere Komponenten der perizellulären Matrix degradieren kann, darunter auch Aggrecan (Chamberland et al. 2009). 
Eine Verringerung der Expressionsraten für Aggrecan auf Ebene der mRNA zeigte sich in dieser Arbeit, sowohl in der Monolayer-Zellkultur als auch in der Alginatkultur (siehe Abb. 11 - 14). Es ist folglich denkbar, dass in diesem Mausmodell die verminderte Expression von Aggrecan im Zusammenhang mit einer vermehrten Expression von DDR-2 steht.

Die Chondrozyten in den tieferen Zellschichten auf Abb. 9 A und v. a. in Abb. 9 B sind hypertrophiert. Dies könnte durch die Volumenzunahme der jeweiligen perizellulären Matrix erklärbar sein und ist als Zeichen einer osteoarthritischen Veränderung zu werten. In Bereichen, in denn die Proteoglykane noch nicht so stark degradiert sind, wie z. B. in dem vergrößerten Ausschnitt der Abb. $9 \mathrm{~A}$, ist eine deutlich verstärkte Dichte der Proteoglykane in der perizellulären Matrix der Chondrozyten zu sehen. Auch dies ist in osteoarthritischen Prozessen ein bereits bekanntes Phänomen (Xu et al. 2003, Hu et al. 2006, Xu et al. 2009).

Obwohl Chondrozyten im osteoarthritischen Knorpel häufig einen hypertrophen Phänotyp aufweisen, ist es eine lokale Reaktion, die nicht gleichzeitig im gesamten Knorpelgewebe auftreten muss. Brew et al. (2010) zeigen bspw., dass einerseits zwar einige chondrozytäre Gene, wie Sox-9 und Aggrecan, im Verlauf der Osteoarthritis weniger exprimiert wurden. Andererseits wiesen einige Gene, die mit der Hypertrophie der Chondrozyten assoziiert sind, wie Kollagen Typ $X$, keine vermehrten Expressionsraten auf.

Trotzdem ist die perizelluläre Matrix der Chondrozyten zukünftig als ein wichtiger Ansatzpunkt für präventive Maßnahmen in der Verzögerung oder gar Verhinderung von osteoarthritischen Vorgängen zu sehen, da es hier in der Anfangsphase des Krankheitsbildes zu entscheidenen Prozessen kommt, nicht zuletzt zu der Exposition von Kollagen Typ II gegenüber DDR-2 auf den Chondrozyten.

Die Vergrößerung von Abb. 9 B zeigt einen Bereich, der sich wahrscheinlich in einem narbigen bzw. faserknorpligen Umbau befindet. Solche Bezirke könnten darauf hindeuten, dass sich das Gewebe in einem frühen Stadium der Regeneration befindet (Miosge et al. 1998, Tesche und Miosge 2005) oder zumindest den pathologischen Prozess aufzuhalten kann. 


\subsubsection{Auswirkungen durch das Fehlen von DDR-1}

Die einzelnen Mechanismen und Kaskaden, die der Pathogenese von Osteoarthritis des ATM zugrunde liegen, sind weitestgehend noch unbekannt. Das Ziel dieser Arbeit ist es anhand des neuen Tiermodells, der DDR-1-knockout-Maus, einen Teil der molekularen Prozesse, die bei der Entwicklung von Osteoarthritis eine Rolle spielen, weiter zu erforschen und zum Verständnis der Osteoarthritis des Kiefergelenks beizutragen.

Im gesunden Knorpel, so auch im Kiefergelenksknorpel, steht die Oberfläche der Chondrozyten, wenn überhaupt, nur in sehr geringem Kontakt mit Typ-IIKollagenfasern. Letztere liegen im Knorpel physiologisch zu hohen Anteilen in der territorialen und interterritorialen Matrix vor (Hunziker et al. 1997). Die perizelluäre Matrix schirmt den Chondrozyten zusätzlich ab. Kommt es zu einem Fortschreiten von Osteoarthritis, verändert sich das Milieu der EZM und die Zusammensetzung der perizellulären Matrix. Dieser Prozess findet normalerweise sehr langsam, über Monate bzw. Jahre, statt. Die Dichte der Proteoglykane nimmt während des Voranschreitens der Osteoarthritis ab (siehe Abb. 4 B und C, Abb. 9 A) und es kommt zu einer vermehrten Demaskierung von Kollagen Typ II-Fibrillen.

Man kann nun annehmen, dass es einerseits durch den Proteoglykanverlust und andererseits durch die Beeinträchtigung der perizellulären Matrix der Chondrozyten zu einem verstärkten Kontakt zwischen Kollagen Typ II-Fibrillen und den Chondrozyten, die auf ihrer Oberfläche u. a. auch DDR-1 und DDR-2 exprimieren, kommt. Infolge des Verlustes der Proteoglykane und der Degradierung der perizellulären Matrix fehlt folglich die schützende Barriere zwischen Rezeptor (DDR) und Ligand (Kollagen) (Xu et al. 2007). Das Kollagen Typ II bindet an den Rezeptor (vorwiegend DDR-2), welcher dadurch in seinen aktiven Zustand übergeht. Dies ist der Anfang einer biochemischen Kaskade, die den Fortschritt der Osteoarthritis deutlich beschleunigt.

Dabei nehmen HtrA1, DDR-2 und MMP-13 Schlüsselfunktionen ein. Polur et al. (2010) postulieren, dass die HtrA1-vermittelte Degradierung der perizellulären Matrix eines der ersten Ereignisse in der Pathogenese von Osteoarthritis sein könnten. Danach kommt es zur Kollagen Typ II-Interaktion und Stimulation des DDR-2, die zur Folge hat, dass MMP-13 verstärkt exprimiert wird und Kollagen Typ II nun in höherem Maße spaltet. Außerdem steigt in osteoarthritischen Knorpelgewebe von Patienten die Expressionsrate von DDR-2 (Xu et al. 2007). Ferner ist die Expression von DDR-2 
proportional zum osteoarthritischen Schaden am humanen Kniegelenksknorpel (Sunk et al. 2007).

Zwischen den großen Gelenken (z. B. dem Kniegelenk) und dem ATM bei der Maus gibt es sowohl strukturelle als auch entwicklungsbiologische Unterschiede. So hat Kiefergelenksknorpel einen anderen embryologischen Ursprung und wird auch als sekundärer Knorpel bezeichnet (Symons 1965). Zusätzlich besteht auch eine andere molekularbiologische Zusammensetzung. Kommt Kollagen Typ I im Kniegelenksknorpel nur in geringen Konzentrationen vor, wird es im Kiefergelenksknorpel physiologisch vergleichsweise stark exprimiert (Mizoguchi et al. 1992). In dieser Arbeit konnte das Vorhandensein von Kollagen Typ I im ATM in relativ großen Mengen mit immunhistochemischen Methoden bestätigt werden (siehe Abb. 5 A und B, Abb. 9 B). Auf Abb. 5 B ist bei der neun Wochen alten knockout-Maus eine homogene Anfärbung und damit der Nachweis von Kollagen Typ I bis in die Tangentialzone zu erkennen. Dies könnte mit dem physiologischen Vorkommen von Kollagen Typ I im Kiefergelenksknorpel der Maus zu erklären sein. Der Unterschied zum Wildtyp in Abb. 5 A, bei dem Kollagen Typ I in geringerem Maße nachweisbar ist, ist jedoch sehr deutlich. Eine andere Erklärung, weshalb Kollagen Typ I in den oberflächlichen Regionen des Knorpels bei der knockout-Maus in höheren Mengen vorkommt, könnte mit dem Rückgang von Kollagen Typ II in eben diesen Knorpelschichten zusammenhängen. In humanem osteoarthritischen Knorpel konnte eine Zunahme von Kollagen Typ I bei einem Rückgang von Kollagen Typ II beobachtet werden (Gebhard et al. 2003, Miosge et al. 2004). Es ist sehr wahrscheinlich, dass sich die EZM im ATM der Maus ähnlich verhält. Bestätigt wird diese These durch das Präparat der älteren Maus (Abb. 9 B). Hier ist eine stärkere Reaktion für Kollagen Typ I sichtbar, was für osteoarthritische Umbauprozesse spricht, unter denen es zu einer weiteren Zunahme von Kollagen Typ I kommt.

Auch die Ergebnisse der Zellkulturen zeigen eine signifikant höhere Expression von Kollagen Typ I in der knockout-Maus (Abb. 12 und 14). Diese Ergebnisse unterstützen die jenigen der Immunhistochemie zusätzlich.

Dass DDR-2 ein wichtiger pathophysiologischer Bestandteil in der Osteoarthritis ist und zwischen ihm und MMP-13 ein Zusammenhang besteht, ist schon länger bekannt und wurde an verschiedenen Mausmodellen beschrieben (Xu et al. 2005, Xu et al. 2007, Otero et al. 2012). 
Höhere Expressionslevel von DDR-2 wirken über MMP-13 akzelerierend auf den Progress von Osteoarthritis, während Xu et al. (2010) anhand von Mäusen, die in Bezug auf DDR-2 heterozygot waren, zeigen, dass erniedrigte DDR-2 Expressionsraten osteoarthritische Vorgänge im Kniegelenk aufhalten. Im ATM ist ein verzögerter Fortschritt von Osteoarthritis bei einer verringerten Expression von DDR$2 \mathrm{zu}$ beobachten (Salazar et al. 2014). Dies ist der Fall sowohl bei genetisch modifizierten Mäusen als auch bei Mausmodellen, die eine sekundäre Osteoarthritis nach Entfernung des medialen Meniskus im Kniegelenk erlitten haben. Ähnliche Ergebnisse zeigten sich beim Fehlen von MMP-13, welche die Rolle von MMP-13 in Osteoarthritis um ein weiteres Mal belegen (Xu et al. 2010).

Bei der DDR-1-knockout-Maus kommt es zu einer Erhöhung von MMP-13. Die Genexpressionsanalysen in Abb. 11 und 13 zeigen erhöhte Werte bei dem knockoutMausmodell für den Transkriptionsfaktor Runx-2, der u. a. die Expression von MMP13 verstärkt (Wang et al. 2004, Kamekura et al. 2006).

Da diese Arbeit zeigt, dass die DDR-1-knockout-Mäuse eine hohe Inzidenz in Bezug auf Osteoarthritis im ATM haben, könnte DDR-1 als ein protektiver Faktor wirken. Es lässt sich annehmen, dass sobald die Rezeptordichte von DDR-2 auf den Chondrozyten steigt, nicht nur MMP-13 hochreguliert wird, sondern auch weniger DDR-1 exprimiert wird. DDR-1 und DDR-2 sind sich im molekularen Aufbau und in der Wahl ihrer Liganden sehr ähnlich. Demnach wäre es vorstellbar, dass es zu einem Kompensationsmechanismus kommt, sollte ein Rezeptor nicht exprimiert werden. In der Tat konnten Schminke et al. (2014) zeigen, dass bei Fehlen von DDR-1 die Chondrozyten in der Zellkultur DDR-2 verstärkt exprimieren. Der Umkehrschluss wäre folglich ebenso denkbar. Dies könnte bedeuten, dass eine isoliert erhöhte Expressionsrate von DDR-1 kein direkt protektiver Faktor ist, aber vielmehr, dass das Vorhandensein von DDR-1 indirekt den Gehalt an DDR-2 beschränkt und so auch die damit verbundenen Pathologien.

Es sind weitere Unterschiede zwischen dem Gelenkknorpel der großen Gelenke und dem des Kiefergelenks beschrieben. Wadhwa et al. (2005) zeigen, dass in der Superfizialzone des condylären Gelenkknorpels, anders als in anderen Gelenken, keine Kollagen Typ II-Fibrillen zu finden sind. Dies bestätigt sich bei Betrachtung des Wildtyps in Abb. 6 A dieser Arbeit. Im Vergleich dazu zeigt sich in der DDR-1-knockoutMaus zusätzlich ein deutlicher Rückgang von Kollagen Typ II (Abb. 6 B). Dies steht mit 
hoher Wahrscheinlichkeit mit dem erhöhten Expressionslevel von MMP-13 und dem damit einhergehenden Verlust von Kollagen Typ II im Zusammenhang.

Der vergrößerte Ausschnitt der Abb. 6 B zeigt, dass in Bereichen, in denen osteoarthritische Läsionen vorliegen, der Nachweis von Kollagen Typ II auch in der Superfizialzone positiv ist. Normalerweise ist die Expression von Kollagen Typ II auf die unteren Knorpelschichten begrenzt. Die Aufhebung dieser Restriktion ist als Biomarker für osteoarthritische Degeneration im condylären Knorpel beschrieben (Wadhwa et al. 2005). Der Grund für dieses Vorkommen in den superfizialen Knorpelschichten könnte in dem Verlust der gesamten oberen Knorpelkappe, so dass die Kollagen Typ II enthaltende Transitionalzone als oberflächlichste Schicht erscheint. Jedoch ist dieser Fall recht unwahrscheinlich, da die Versuchstiere so jung sind, dass es nicht zu derart starken Erosionen gekommen sein sollte. Auch im Vergleich mit den Wildtyp-Mäusen sind solch starke Schäden histologisch nicht zu erkennen. Sehr viel wahrscheinlicher ist, dass es während der Osteoarthritis zur Appoptose von Zellen kommt, die kein Kollagen Typ II synthetisieren und gleichzeitig zu einer verstärkten Proliferation von Chondroblasten zu beobachten ist, die Kollagen Typ II exprimieren. $\mathrm{Ob}$ das Ungleichgewicht aber auf diese Weise entsteht, bedarf weiterer Untersuchungen.

\subsubsection{Nidogene im Kiefergelenksknorpel der Maus}

Lichtmikroskopisch gelang der Nachweis von Nidogen 1 und Nidogen 2 im Kiefergelenksknorpel der DDR-1-knockout-Maus sowie beim Wildtyp (Abb. 7, Abb. 8). Nidogene zeigen ein unterschiedliches regionales Vorkommen im osteoarthritischen Knorpel, ebenso wie im gesunden Knorpel. Dies deutet darauf hin, dass sie, je nach Status des sie umgebenen Gewebes, mit unterschiedlichen Bindungspartnern interagieren.

Kruegel et al. (2008) vermuten, dass Nidogen 1 Bindungen mit Kollagen Typ II und Aggrecan eingeht und demnach ein Link-Protein darstellen könnte, welches die Stabilität des Knorpels unterstützt. Folglich würde Nidogen 1 in Osteoarthritis andere Bindungen eingehen, da die gesamte physiologische Struktur des Knorpels durch den Krankheitsvorgang verändert wurde. So weisen in-vitro-Versuche auf die Möglichkeit hin, dass Kollagen Typ I und Fibronectin als mögliche Bindungsmoleküle dienen könnten (Kohfeldt et al. 1998, Dziadek et al. 1985). Immunhistochemisch zeigte sich im Kiefergelenksknorpel der DDR-1-knockout-Maus eine veränderte Verteilung von 
Nidogen 1. Bei den Wildtyp-Mäusen zeigte die Anfärbung für Nidogen 1 ein recht homogenes Bild, mit einer besonders prominenten Transitionalzone (Abb. 7 A) und einem deutlichen Nachweis in der perizellulären Matrix (Abb. 7 A, vergrößerter Ausschnitt).

Bei der knockout-Maus gelang der Nachweis immer noch am deutlichsten in der Transitionalzone (Abb. 7 B), wohingegen bei Betrachtung der territorialen Verteilung ein verminderter perizellulärer Nachweis erkennbar war (Abb. 7 B, vergrößerter Ausschnitt). Interterritorial hingegen zeigte sich eine recht homogene Färbung, so dass es den Anschein hat, dass Nidogen 1 die perizelluläre Kapsel verlässt, um in der interterritorialen Matrix die Funktion des Knorpels aufrechtzuerhalten.

Diese Umverteilung von der perizellulären Matrix hin in die interterritoriale Matrix könnte eine Reaktion auf die osteoarthritische Vorgänge im Knorpel sein und der Versuch die Knorpelmatrix zu stabilisieren. Allerdings ließ sich lichtmikroskopisch in Arrealen, die direkte osteoarthritische Veränderungen aufweisen, wie sie in dem vergrößerten Ausschnitt der Abb. 7 B dargestellt sind, kein verstärktes Vorkommen von Nidogen 1 nachweisen. Dies gelang Kruegel et al. (2008) an humanem osteoarthritischen Kniegelenksknorpel. Dass dies im Kiefergelenksknorpel der Maus nicht der Fall ist, könnte mit den bereits erwähnten Unterschieden in der molekularen Zusammensetzung zwischen dem Kiefergelenksknorpel und dem Knorpel der großen Gelenke zusammenhängen. Im gesunden ATM kommt Kollagen Typ I bereits in verhältnismäßig großen Mengen vor und wird nicht erst bei Osteoarthritis exprimiert, wie es im Kniegelenk der Fall zu sein scheint. Demnach liegt es nahe, dass Nidogen 1 im ATM bereits im gesunden Stadium vermehrt Bindungen mit Kollagen Typ I eingeht. Dies geschieht wahrscheinlich in der interterritorialen Matrix, da sich im Kniegelenk eine verstärkte Reaktion in der interterritorialen Zone erst bei nachweisbarer Osteoarthritis zeigt (Kruegel et al. 2008) und Kollagen Typ I im Knorpel des Kniegelenks mit zunehmendem osteoarthritischen Krankheitsprogress in höheren Konzentrationen vorliegt (Sandell und Aigner 2001).

Nidogen 2 konnte immunhistochemisch sowohl im gesunden Knorpel der WildtypMaus als auch im osteoarthritischen Knorpel überwiegend perizellulär, nachgewiesen werden. Abb. 8 A zeigt einen insgesamt schwachen Nachweis von Nidogen 2 im Kiefergelenksknorpel. In der perizellulären Matrix der Zellen, die sich in der Transitional- und der Radiärzone befinden, gelang der Nachweis am deutlichsten, während die oberflächliche Tangentialzone wenig bis keine Anfärbungen zeigt. Bei 
Betrachtung der territorialen Verteilung war neben der perizellulären auch eine sehr leichte territoriale Reaktion zu erkennen. Interterritorial hingegen blieb der Nachweis von Nidogen 2 negativ (Abb. 8 A, vergrößerter Ausschnitt).

Bei der DDR-1-knockout-Maus zeigte sich ein anderes Bild. Insgesamt fiel der immunhistochemische Nachweis von Nidogen 2 stärker aus. Die intensive Anfärbung des Glykoproteins blieb teilweise bis in die Tangentialzone bestehen, obwohl sie in der Transitionalzone am stärksten ausgeprägt war (Abb. 8 B). In dem vergrößerten Ausschnitt von Abb. 8 B ist der Bereich der perizellulären Matrix betont. Dies deutet lichtmikroskopisch auf ein hohes Vorkommen von Nidogen 2 hin. In der Transitionalzone gelang der immunhistochemische Nachweis auch in der interterritorialen Matrix, während sich dort in der Radiärzone weniger bis kein Nidogen 2 aufzeigen lässt. In der direkten Umgebung von Zellhaufen, sog. Clustern, entstand eine intensive Anfärbung. Dies könnte deshalb der Fall sein, da in dem Bereich, wo sich Cluster formieren, die Zellen dicht aneinander liegen und damit auch deren perizelluläre Matrices in engem Bezug zueinanderstehen.

Der deutlichere lichtmikroskopische Nachweis bei der DDR-1-knockout-Maus, könnte auch mit der oben beschriebenen Umverteilung von Nidogen 1 zusammenhängen. Der perizelluläre Gehalt von Nidogen 1 nahm bei Osteoarthritis ab (Abb. 7 B, vergrößerter Ausschnitt) und zur Kompensation stieg der Gehalt von Nidogen 2. Ähnliche Kompensationsvorgänge konnten schon in Skelett- und Herzmuskulatur von Nidogen1-knockout-Mäusen gezeigt werden (Miosge et al. 2002).

Betreffend Nidogen 2 decken sich die Ergebnisse dieser Arbeit teilweise mit denen, die Kruegel et al. (2008) in ihren Versuchen mit humanem Knorpelgewebe gemacht haben. Dabei war Nidogen 2 jedoch strikt perizellulär lokalisiert, wohingegen es im ATM der Maus auch zu einem Nachweis in der territorialen Matrix kam. Diese Divergenz ist wiederum mit dem weiter oben beschriebenen unterschiedlichen Aufbau von Kiefergelenksknorpel und Kniegelenksknorpel sowie von humanem Knorpelgewebe und Gewebe der Maus erklärbar.

\subsubsection{Osteoarthritis im Kiefergelenk - ein weit verbreitetes Krankheitsbild}

Das menschliche Kiefergelenk kann durch eine Vielzahl von pathologischen Vorgängen betroffen sein. Dazu gehören Entzündungen, Traumata, Infektionen, kongenitale Dysfunktionen und Neoplasien. Die häufigste Form ist jedoch die Kraniomandibuläre-Dysfunktion (CMD). CMD ist ein Sammelbegriff für eine 
heterogene Gruppe von Krankheitsbildern, die durch Pathologien im Bereich des ATM oder der fazialen muskulosklelettalen Strukturen hervorgerufen werden (McNeill 1997).

Die CMD ist weit verbreitet. Eine Metaanalyse aus dem Jahr 2011 ergab, dass bis zu $45 \%$ der Patienten an Beschwerden leiden, die eine CMD definieren (Mafredini et al. 2011). Dazu gehören häufige kraniofaziale Schmerzen, Kopfschmerzen, Tinnitus, eine eingeschränkte oder erhöhte Beweglichkeit im ATM, Deviationen bei der Mundöffnung, oftmals in Kombination mit einem Knacken im Kiefergelenk, das durch eine Dislokation des Discus articularis entstehen kann. Anzeichen für Osteoarthritis im ATM zeigen fast $10 \%$ der Patienten (Mafredini et al. 2011). Da Osteoarthritis im ATM normalerweise erst im späten Krankheitsstadium diagnostiziert wird, könnte die wahre Inzidenz jedoch weitaus höher liegen (Wadhwa et al. 2005). Dieser relativ hohe Anteil an Patienten mit Osteoarthritis im ATM zeigt, dass eine genaue Erforschung der pathobiologischen Prozesse des Krankheitsbildes und seiner Therapie absolut indiziert ist, um das Leid der Patienten und die dadurch entstehenden Kosten für die Gesellschaft zu begrenzen. Hinzu kommt, dass viele der derzeitigen therapeutischen Ansätze, wie bspw. anästhetische Injektionen in das Gelenk, wenn überhaupt nur kurze Phasen von Schmerzfreiheit liefern. Wie die meisten gegenwärtig angewendeten Verfahren zielen sie nur auf eine Linderung der Symptome ab, lassen jedoch jeglichen kausalen Therapieansatz an den dysregulierten molekularen Prozessen vermissen. Dagegen wird die Zerstörung des Gelenkes durch die schmerzlindernde Therapie in keiner Weiser aufgehalten. Bis zum heutigen Zeitpunkt ist keine Therapie verfügbar, die die Gelenkstruktur erhält oder sogar regenerative Aspekte aufweist. Dies ist nicht nur im ATM der Fall, sondern betrifft auch alle anderen Gelenke des Körpers, die von Osteoarthritis betroffen sein können.

Zunächst wäre die Etablierung von bestimmten Biomarkern ein wichtiger Schritt, die Krankheit in einem frühen Stadium zu erkennen und mit einer rechtzeitigen Behandlung zu beginnen. Bisher ist der Nachweis von Biomarkern, wie inn bspw. der Restriktionsverlust der Expression von Kollagen Typ II darstellen könnte, nur anhand von histopathologisch aufgearbeiteten Präparaten möglich (siehe Abb. 6 B) und auch noch nicht allgemein etabliert.

MMP-13 scheint das Enzym zu sein, das während der Pathogenese von Osteoarthritis eine Schlüsselfunktion einnimmt und auf welches viele Forschungsgruppen in letzter Zeit ihren Fokus gelegt haben. Eine Restriktion der MMP-13 Expression oder die 
Abschwächung seiner Wirkung wäre ein möglicher Therapieansatz, welcher bereits aussichtsreich erforscht wird (TenBroek 2016). Es gibt diverse Stimuli, die die Expression von MMP-13 im Gewebe erhöhen und die Chondrozyten in einen aktiven Zustand überführen. Einen therapeutischen Ansatz in vivo zu finden, gestaltet sich sicherlich schwierig, da die einzelnen Prozesse zu unterschiedlichen Zeitpunkten an unterschiedlichen Orten stattfinden, die sich sowohl im Knorpel selbst als auch an anderen Orten im Organismus befinden (Nagase et al. 2006). Dies sollte bei zukünftigen Therapieansätzen bedacht werden. Zumal der Versuch durch Krzeski et al. (2007) die Progression von Osteoarthritis mit unspezifischen MMP-Inhibitoren zu stoppen, aufgrund von starken unerwünschten Nebenwirkungen zu keinem zufriendenstellenden Ergebnis führte.

Ein weiterer vielversprechender Ansatz wäre, nicht direkt bei MMP-13 anzusetzen, sondern Faktoren zu beeinflussen, die MMP-13 regulieren. Zu nennen ist dabei neben dem schon erwähnten Runx-2 auch der Transkriptionsfaktor NF-kB, der einen vielversprechenden Ansatzpunkt für eine mögliche Therapie bietet (Marcu et al. 2010). Insgesamt ist die DDR-1-knockout-Maus ein neues Tiermodell, das früher als bereits bekannte Mausmodelle einen osteoarthritischen Phänotyp im ATM zeigt. Deshalb ist sie ein besonders günstiges Modell für in-vivo-Versuche, die möglicherweise den Wissensstand bezüglich neuer Therapiemöglichkeiten bei der CMD und speziell bei Osteoarthritis im ATM voranbringen werden. 


\section{Zusammenfassung}

Osteoarthritis im Kiefergelenk ist eine noch nicht vollständig verstandene Krankheit, obwohl viele Patienten von ihr betroffen sind. Für die Erforschung der molekularbiologischen und pathophysiologischen Grundlagen, die zu der Entstehung von Osteoarthtitis führen, sind Tiermodelle von großer Bedeutung.

Die DDR-1-knockout-Maus wurde in dieser Arbeit als neues Tiermodell für die Erforschung von Osteoarthritis im Kiefergelenk vorgestellt. Durch das Fehlen des DDR-1 vermutete man, dass es zu einer Hochregulierung von DDR-2 und damit zu einer Erhöhung von MMP-13 kommt. Dies ist eine bekannte pathophysiologische Veränderung, welche zu Osteoarthritis führt.

In dieser Arbeit wurden Tiere unterschiedlichen Alters lichtmikroskopisch und immunhistochemisch auf osteoarthritische Veränderungen im Kiefergelenksknorpel untersucht. Es wurden immunhistochemische Nachweise von Kollagen Typ I, Kollagen Typ II, Nidogen 1 und Nidogen 2 durchgeführt. Hierbei zeigte sich, dass die DDR-1knockout-Maus eine ausgeprägte Osteoarthritis im Kiefergelenk entwickelt. Fissuren und Proteoglykanverlust waren bereits ab einem Alter von 9 Wochen nachweisbar. Damit einhergehend konnten weitere, für Osteoarthritis typische Veränderungen nachgewiesen werden. Es kam z. B. zu einem veränderten Verteilungsmuster bei den Nidogenen, zu einer Größenzunahme der Chondrozyten und zu einer Verschiebung des Verhältnisses zwischen Kollagen Typ I und Kollagen Typ II zugunsten von Kollagen Typ I.

Zudem wurden Genexpressionsanalysen von Zellen des Kiefergelenksknorpels angefertigt. Es zeigten sich eine für Osteoarthritis typische Erhöhung der Expressionsraten für Runx-2 und Kollagen Typ I. Demgegenüber waren die Werte von Aggrecan und Sox-9 verringert. Diese Ergebnisse wurden sowohl in der MonolayerKultur als auch in der 3D-Alginatkultur nachgewiesen.

Im Vergleich mit bereits etablierten Mausmodellen, die für die Erforschung von Osteoarthritis im Kiefergelenk eingesetzt werden, zeigt das Modell der DDR-1knockout-Maus die entscheidenden Vorteile, dass die Tiere bereits in einem frühen Lebensalter und einer hohen Inszidenz erkranken. Deshalb eignet sich das Modell der DDR-1-knockout-Maus für die weitere Osteoarthritisforschung, speziell im Kiefergelenk. 


\section{Literaturverzeichnis}

Abdulhussein R, McFadden C, Fuentes-Prior P, Vogel WF (2004): Exploring the collagen-binding site of the DDR1 tyrosine kinase receptor. J Biol Chem $\underline{279}$, 3146270

Aeschlimann D, Kaupp O, Paulsson M (1995): Transglutaminase-catalyzed matrix cross-linking in differentiating cartilage: identification of osteonectin as a major glutaminyl substrate. J Cell Biol $\underline{129}$, 881-92

Adams BD, Samani JE, Holley KA (1996): Triangular fibrocartilage injury: a laboratory model. J Hand Surg Am 21, 189-93

Aigner T, Gerwin N (2007): Growth plate cartilage as developmental model in osteoarthritis research--potentials and limitations. Curr Drug Targets $\underline{8}, 377-85$

Alves F, Vogel W, Mossie K, Millauer B, Hofler H, Ullrich A (1995): Distinct structural characteristics of discoidin I subfamily receptor tyrosine kinases and complementary expression in human cancer. Oncogene $\underline{10}, 609-18$

Alves F, Saupe S, Ledwon M, Schaub F, Hiddemann W, Vogel W (2001): Identification of two novel, kinase-deficient variants of discoidin domain receptor 1: differential expression in human colon cancer cell lines. FASEB J $\underline{15}, 1321-3$

Aydelotte MB, Greenhill RR, Kuettner KE (1988): Difference between subpopulations of cultured bovine articular chondrocytes. II. Proteoglycan metabolism. Connect Tissue Res $\underline{18}$, 223-34

Balbin M, Fueyo A, Knauper V, Lopez JM, Alvarez J, Sanchez LM, Quesada V, Bordallo J, Murphy G, Lopez-Otin C (2001): Identification and enzymatic characterization of two diverging murine counterparts of human interstitial collagenase (MMP-1) expressed at sites of embryo implantation. J Biol Chem $\underline{276}$, 10253-62

Barker KT, Martindale JE, Mitchell PJ, Kamalati T, Page MJ, Phippard DJ, Dale TC, Gusterson BA, Crompton MR (1995): Expression patterns of the novel receptor-like tyrosine kinase, DDR, in human breast tumours. Oncogene 10, 569-75

Bau B, Gebhard PM, Haag J, Knorr T, Bartnik E, Aigner T (2002): Relative messenger RNA expression profiling of collagenases and aggrecanases in human articular chondrocytes in vivo and in vitro. Arthritis Rheum $\underline{46}, 2648-57$

Bi W, Deng JM, Zhang Z, Behringer RR, de Crombrugghe B (1999): Sox9 is required for cartilage formation. Nat Genet $\underline{22}, 85-9$

Bolton MC, Dudhia J, Bayliss MT (1999): Age-related changes in the synthesis of link protein and aggrecan in human articular cartilage: implications for aggregate stability. Biochem J $\underline{377(\mathrm{Pt} \mathrm{1})}, 77-82$ 
Borochowitz ZU, Scheffer D, Adir V, Dagoneau N, Munnich A, Cormier-Daiere V (2004): Spondylo-epi-metaphyseal dysplasia (SEMD) matrilin 3 type: homozygote matrilin 3 mutation in a novel form of SEMD. J Med Genet $\underline{5}, 366-72$

Brandt KD, Radin EL, Dieppe PA, van de Putte L (2006): Yet more evidence that osteoarthritis is not a cartilage disease. Ann Rheum Dis $\underline{65}, 1261-4$

Brew CJ, Clegg PD, Boot-Handford RP, Andrew JG, Hardingham T (2010): Gene expression in human chondrocytes in late osteoarthritis is changed in both fibrillated and intact cartilage without evidence of generalised chondrocyte hypertrophy. Ann Rheum Dis $\underline{69}, 234-40$

Bruckner JD, Lichtman D. M., Alexander A. H. (1992): Complex dislocations of the distal radioulnar joint. Recognition and management. Clin Orthop Relat Res $\underline{275}, 90-$ 103

Bukulmez H, Matthews AL, Sullivan CM, Chen C, Kraay MJ, Elston RC, Moskowitz RW, Goldberg VM, Warman ML (2006): Hip joint replacement surgery for idiopathic osteoarthritis aggregates in families. Arthritis Res Ther $\underline{8}, \mathrm{R} 25$

Cantley LC, Auger KR, Carpenter C, Duckworth B, Graziani A, Kapeller R, Soltoff S (1991): Oncogenes and signal transduction. Cell $\underline{64}, 281-302$

Carlin B, Jaffe R, Bender B, Chung AE (1981): Entactin, a novel basal laminaassociated sulfated glycoprotein. J Biol Chem 256, 5209-14

Chamberland A, Wang E, Jones AR, Collins-Racie LA, LaVallie ER, Huang Y, Liu L, Morris EA, Flannery CR, Yang Z (2009): Identification of a novel HtrA1-susceptible cleavage site in human aggrecan: evidence for the involvement of HtrA1 in aggrecan proteolysis in vivo. J Biol Chem 284, 27352-9

Chen CG, Thuillier D, Chin EN, Alliston T (2012): Chondrocyte-intrinsic Smad3 represses Runx2-inducible matrix metalloproteinase 13 expression to maintain articular cartilage and prevent osteoarthritis. Arthritis Rheum $\underline{64}, 3278-89$

Cheng A, Genever PG (2010): SOX9 determines RUNX2 transactivity by directing intracellular degradation. J Bone Miner Res $\underline{25}, 2680-9$

Clark JM (1991): Variation of collagen fiber alignment in a joint surface: a scanning electron microscope study of the tibial plateau in dog, rabbit, and man. J Orthop Res $\underline{9}, 246-57$

Cohen WA, Servais JM, Polur I, Li Y, Xu L (2014): Articular cartilage degeneration in the contralateral non-surgical temporomandibular joint in mice with a unilateral partial discectomy. J Oral Pathol Med $\underline{43}, 162-5$.

Ding L, Heying E, Nicholson N, Stroud NJ, Homandberg GA, Buckwalter JA, Guo D, Martin JA (2010): Mechanical impact induces cartilage degradation via mitogen activated protein kinases. Osteoarthritis Cartilage $\underline{18}$, 1509-17 
Duance VC, Shimokomaki M, Bailey AJ (1982): Immunofluorescence localization of type-M collagen in articular cartilage. Biosci Rep 2, 223-7

Dziadek M, Paulsson M, Timpl R (1985): Identification and interaction repertoire of large forms of the basement membrane protein nidogen. EMBO J $\underline{4}, 2513-8$

Eavey RD, Schmid TM, Linsenmayer TF (1987): Development of the chick columella: immunohistochemical studies with anti-collagen monoclonal antibodies. Int J Pediatr Otorhinolaryngol $\underline{13}, 99-105$

Embree MC, Iwaoka GM, Kong D, Martin BN, Patel RK, Lee AH, Nathan JM, Eisig SB, Safarov A, Koslovsky DA, Koch A, Romanov A, Mao JJ (2015): Soft tissue ossification and condylar cartilage degeneration following TMJ disc perforation in a rabbit pilot study. Osteoarthritis Cartilage 23, 629-39

Eyre DR, Muir H (1975): The distribution of different molecular species of collagen in fibrous, elastic and hyaline cartilages of the pig. Biochem J $\underline{151}, 595-602$

Felson DT (2006): Clinical practice. Osteoarthritis of the knee. N Engl J Med $\underline{354}$, 841-8

Foster JW, Dominguez-Steglich MA, Guioli S, Kwok C, Weller PA, Stevanovic M, Weissenbach J, Mansour S, Young ID, Goodfellow PN et al. (1994): Campomelic dysplasia and autosomal sex reversal caused by mutations in an SRY-related gene. Nature $\underline{372}, 525-30$

Fuerst M, Bertrand J, Lammers L, Dreier R, Echtermeyer F, Nitschke Y, Rutsch F, Schäfer FK, Niggemeyer O, Steinhagen J, Lohmann CH, Pap T, Rüther W (2009): Calcification of articular cartilage in human osteoarthritis. Arthritis Rheum $\underline{60}, 2694-$ 703.

Gamulin V, Skorokhod A, Kavsan V, Muller IM, Muller WE (1997): Experimental indication in favor of the introns-late theory: the receptor tyrosine kinase gene from the sponge Geodia cydonium. J Mol Evol $\underline{44}, 242-52$

Gannon AR, Nagel T, Kelly DJ (2012): The role of the superficial region in determining the dynamic properties of articular cartilage. Osteoarthritis Cartilage $\underline{20}$, 1417-25

Gebhard PM, Gehrsitz A, Bau B, Soder S, Eger W, Aigner T (2003): Quantification of expression levels of cellular differentiation markers does not support a general shift in the cellular phenotype of osteoarthritic chondrocytes. J Orthop Res 21, 96-101

Gebhard S, Poschl E, Riemer S, Bauer E, Hattori T, Eberspaecher H, Zhang Z, Lefebvre V, de Crombrugghe B, von der Mark K (2004): A highly conserved enhancer in mammalian type $X$ collagen genes drives high levels of tissue-specific expression in hypertrophic cartilage in vitro and in vivo. Matrix Biol 23, 309-22

Glasson SS (2007): In vivo osteoarthritis target validation utilizing geneticallymodified mice. Curr Drug Targets $\underline{8}$, 367-76 
Goldring MB (2006): Update on the biology of the chondrocyte and new approaches to treating cartilage diseases. Best Pract Res Clin Rheumatol 20, 1003-25

Goldring MB, Otero M (2011): Inflammation in osteoarthritis. Curr Opin Rheumatol $\underline{23}, 471-8$

Goldring MB, Tsuchimochi K, ljiri K (2006): The control of chondrogenesis. J Cell Biochem 97, 33-44

Goldring MB, Otero M, Plumb DA, Dragomir C, Favero M, El Hachem K, Hashimoto K, Roach HI, Olivotto E, Borzi RM, Marcu KB (2011): Roles of inflammatory and anabolic cytokines in cartilage metabolism: signals and multiple effectors converge upon MMP-13 regulation in osteoarthritis. Eur Cell Mater 21, 202-20

Guilak F, Fermor B, Keefe FJ, Kraus VB, Olson SA, Pisetsky DS, Setton LA, Weinberg JB (2004): The role of biomechanics and inflammation in cartilage injury and repair. Clin Orthop Relat Res $\underline{423}, 17-26$

Hall BK, Miyake T (2000): All for one and one for all: condensations and the initiation of skeletal development. Bioessays $\underline{22}, 138-47$

Hamerman D (1989): The biology of osteoarthritis. N Engl J Med $\underline{320}, 1322-30$

Hecht JT, Nelson LD, Crowder E, Wang Y, Elder FF, Harrison, WR, Francomano CA, Prange CK, Lennon GG, Deere M et al. (1995): Mutations in exon 17B of cartilage oligomeric matrix protein (COMP) cause pseudoachondroplasia. Nat Genet $\underline{10}, 325-9$

Henry SP, Liang S, Akdemir KC, de Crombrugghe B (2012): The postnatal role of Sox9 in cartilage. J Bone Miner Res $\underline{27}, 2511-25$

Hu K, Xu L, Cao L, Flahiff CM, Brussiau J, Ho K, Setton LA, Youn I, Guilak F, Olsen BR, Li Y (2006): Pathogenesis of osteoarthritis-like changes in the joints of mice deficient in type IX collagen. Arthritis Rheum 54, 2891-900

Hunziker EB, Michel M, Studer D (1997): Ultrastructure of adult human articular cartilage matrix after cryotechnical processing. Microsc Res Tech 37, 271-84

Islam S, Kermode T, Sultana D, Moskowitz RW, Mukhtar H, Malemud CJ, Goldberg VM, Haqqi TM (2001): Expression profile of protein tyrosine kinase genes in human osteoarthritis chondrocytes. Osteoarthritis Cartilage $\underline{9}, 684-93$

Kamekura S, Kawasaki Y, Hoshi K, Shimoaka T, Chikuda H, Maruyama Z, Komori T, Sato S, Takeda S, Karsenty G, Nakamura K, Chung UI, Kawaguchi H (2006):

Contribution of runt-related transcription factor 2 to the pathogenesis of osteoarthritis in mice after induction of knee joint instability. Arthritis Rheum $\underline{54}$, 2462-70

Kane WH, Davie EW (1988): Blood coagulation factors V and VIII: structural and functional similarities and their relationship to hemorrhagic and thrombotic disorders. Blood 71, 539-55 
Kirkham SG, Samarainghe RK (2009): Review article: glucosamine. J Orthop Surg (Hong Kong) $\underline{17}, 72-6$

Knudson CB, Knudson W (2004): Hyaluronan and CD44: modulators of chondrocyte metabolism. Clin Orthop Relat Res 427 Suppl, S152-62

Koelling S, Kruegel J, Irmer M, Path JR, Sadowski B, Miro X, Miosge N (2009): Migratory chondrogenic progenitor cells from repair tissue during the later stages of human osteoarthritis. Cell Stem Cell $\underline{4}, 324-35$

Kohfeldt E, Saski T, Gohring W, Timpl R (1998): Nidogen-2: a new basement membrane protein with diverse binding properties. J Mol Biol 282, 99-109

Konitsiotis AD, Raynal N, Bihan D, Hohenester E, Farndale RW, Leitinger B (2008): Characterization of high affinity binding motifs for the discoidin domain receptor DDR2 in collagen. J Biol Chem $\underline{283}, 6861-8$

Kotlarz H, Gunnarsson CL, Fang H, Rizzo JA (2009): Insurer and out-of-pocket costs of osteoarthritis in the US: evidence from national survey data. Arthritis Rheum $\underline{60}$, 3546-53.

Kruegel J, Sadowski B, Miosge N (2008): Nidogen-1 and nidogen-2 in healthy human cartilage and in late-stage osteoarthritis cartilage. Arthritis Rheum $\underline{58}, 1422-$ 32

Krzeski P, Buckland-Wright C, Balint G, Cline GA, Stoner K, Lyon R, Beary J, Aronstein WS, Spector TD (2007): Development of musculoskeletal toxicity without clear benefit after administration of PG-116800, a matrix metalloproteinase inhibitor, to patients with knee osteoarthritis: a randomized, 12-month, double-blind, placebocontrolled study. Arthritis Res Ther $\underline{9}$, R109

Kuettner KE, Pauli BU, Gall G, Memoli VA, Schenk RK (1982): Synthesis of cartilage matrix by mammalian chondrocytes in vitro. I. Isolation, culture characteristics, and morphology. J Cell Biol $\underline{93}$, 743-50

Kuettner KE (1992): Biochemistry of articular cartilage in health and disease. Clin Biochem 25, 155-63

Kurz B, Lemke AK, Fay J, Pufe T, Grodzinsky AJ, Schunke M (2005):

Pathomechanisms of cartilage destruction by mechanical injury. Ann Anat 187, 47385

Kvist AJ, Nystrom A, Hultenby K, Sasaki T, Talts JF, Aspberg A (2008): The major basement membrane components localize to the chondrocyte pericellular matrix--a cartilage basement membrane equivalent? Matrix Biol 27, 22-33

Labrador JP, Azcoitia V, Tuckermann J, Lin C, Olaso E, Manes S, Bruckner K, Goergen JL, Lemke G, Yancopoulos G, Angel P, Martinez C, Klein R (2001): The collagen receptor DDR2 regulates proliferation and its elimination leads to dwarfism. EMBO Rep 2, 446-52 
Lai C, Lemke G (1994): Structure and expression of the Tyro 10 receptor tyrosine kinase. Oncogene $\underline{9}, 877-83$

Laval S, Butler R, Shelling AN, Hanby AM, Poulsom R, Ganesan TS (1994): Isolation and characterization of an epithelial-specific receptor tyrosine kinase from an ovarian cancer cell line. Cell Growth Differ $\underline{5}, 1173-83$

Lee HY, Han L, Roughley PJ, Grodzinsky AJ, Ortiz C (2013): Age-related nanostructural and nanomechanical changes of individual human cartilage aggrecan monomers and their glycosaminoglycan side chains. J Struct Biol 181, 264-73

Leitinger B, Kwan AP (2006): The discoidin domain receptor DDR2 is a receptor for type $X$ collagen. Matrix Biol 25, 355-64

Leitinger B, Steplewski A, Fertala A (2004): The D2 period of collagen II contains a specific binding site for the human discoidin domain receptor, DDR2. J Mol Biol 344, 993-1003

Li Y, Lacerda DA, Warman ML, Beier DR, Yoshioka H, Ninomiya Y, Oxford JT, Morris NP, Andrikopoulos K, Ramirez F, Wardell BB, Lifferth GD, Teuscher C, Woodward R, Taylor BA, Seegmiller RE, Olsen BR (1995): A fibrillar collagen gene, Col11a1, is essential for skeletal morphogenesis. Cell $\underline{80}, 423-30$

Little CB, Smith MM (2008): Animal Models of Osteoarthritis. Current Rheumatology Reviews $\underline{4}$

Little CB, Barai A, Burkhardt D, Smith SM, Fosang AJ, Werb Z, Shah M, Thompson EW (2009): Matrix metalloproteinase 13-deficient mice are resistant to osteoarthritic cartilage erosion but not chondrocyte hypertrophy or osteophyte development. Arthritis Rheum $\underline{60}$, 3723-33

Liu ML, Shen BW, Nakaya S, Pratt KP, Fujikawa K, Davie EW, Stoddard BL, Thompson AR (2000): Hemophilic factor VIII C1- and C2-domain missense mutations and their modeling to the 1.5-angstrom human C2-domain crystal structure. Blood $\underline{96}$, 979-87

Livne E (1994): Matrix synthesis in mandibular condylar cartilage of aging mice. Osteoarthritis Cartilage $\underline{2}, 187-97$

Livne E, Silbermann M (1986): Further characterization of spontaneous arthritic changes in murine squamo-mandibular joint: histopathological aspects. Histol Histopathol 1, 161-70

Loughlin J (2005): Crystals in hand. Arthritis Res Ther $\underline{7}, 187-8$

Manfredini D, Guarda-Nardini L, Winocur E, Piccotti F, Ahlberg J, Lobbezoo F (2011): Research diagnostic criteria for temporomandibular disorders: a systematic review of axis I epidemiologic findings. Oral Surg Oral Med Oral Pathol Oral Radiol Endod 112, 453-62 
Marcu KB, Otero M, Olivotto E, Borzi RM, Goldring MB (2010): NF-kappaB signaling: multiple angles to target OA. Curr Drug Targets $\underline{11}$, 599-613

Maroudas A, Bayliss MT, Venn MF (1980): Further studies on the composition of human femoral head cartilage. Ann Rheum Dis $\underline{39}, 514-23$

Martin JA, Brown T, Heiner A, Buckwalter JA (2004): Post-traumatic osteoarthritis: the role of accelerated chondrocyte senescence. Biorheology $\underline{41}, 479-91$

Martinez-Sanchez A, Dudek KA, Murphy CL (2012): Regulation of human chondrocyte function through direct inhibition of cartilage master regulator SOX9 by microRNA-145 (miRNA-145). J Biol Chem 287, 916-24

McDermott BT, Ellis S, Bou-Gharios G, Clegg PD, Tew SR (2016): RNA binding proteins regulate anabolic and catabolic gene expression in chondrocytes. Osteoarthritis Cartilage 24, 1263-73

McNeill C (1997): Management of temporomandibular disorders: concepts and controversies. J Prosthet Dent $\underline{77}$, 510-22

Metsäranta M, Garofalo S, Decker G, Rintala M, de Crombrugghe B, Vuorio E (1992): Chondrodysplasia in transgenic mice harboring a 15-amino acid deletion in the triple helical domain of pro alpha 1(II) collagen chain. J Cell Biol 118, 203-12

Miosge N, Waletzko K, Bode C, Quondamatteo F, Schultz W, Herken R (1998): Light and electron microscopic in-situ hybridization of collagen type I and type II mRNA in the fibrocartilaginous tissue of late-stage osteoarthritis. Osteoarthritis Cartilage $\underline{6}$, 278-85

Miosge N, Sasaki T, Timpl R (2002): Evidence of nidogen-2 compensation for nidogen-1 deficiency in transgenic mice. Matrix Biol 21, 611-21

Miosge N, Hartmann M, Maelicke C, Herken R (2004): Expression of collagen type I and type II in consecutive stages of human osteoarthritis. Histochem Cell Biol $\underline{122}$, 229-36

Mitchell PG, Magna HA, Reeves LM, Lopresti-Morrow LL, Yocum SA, Rosner PJ, Geoghegan KF, Hambor JE (1996): Cloning, expression, and type II collagenolytic activity of matrix metalloproteinase-13 from human osteoarthritic cartilage. J Clin Invest $\underline{97}, 761-8$

Mizoguchi I, Nakamura M, Takahashi I, Kagayama M, Mitani H (1992): A comparison of the immunohistochemical localization of type I and type II collagens in craniofacial cartilages of the rat. Acta Anat (Basel) $144,59-64$

Mobasheri A (1998) Correlation between [Na+], [glycosaminoglycan] and $\mathrm{Na}+/ \mathrm{K}+$ pump density in the extracellular matrix of bovine articular cartilage. Physiol Res $\underline{47}$, 47-52 
Mollenhauer J, Aurich ME, Zhong Z, Muehleman C, Cole AA, Hasnah M, Oltulu O, Kuettner KE, Margulis A, Chapman LD (2002): Diffraction-enhanced X-ray imaging of articular cartilage. Osteoarthritis Cartilage $\underline{10}, 163-71$

Mow VC, Holmes MH, Lai WM (1984): Fluid transport and mechanical properties of articular cartilage: a review. J Biomech 17, 377-94

Nagase H, Visse R, Murphy G (2006): Structure and function of matrix metalloproteinases and TIMPs. Cardiovasc Res $\underline{69}$, 562-73

Nemoto T, Ohashi K, Akashi T, Johnson JD, Hirokawa K (1997): Overexpression of protein tyrosine kinases in human esophageal cancer. Pathobiology $\underline{65}, 195-203$

Olsen BR (1995): Mutations in collagen genes resulting in metaphyseal and epiphyseal dysplasias. Bone $\underline{17}$, 45S-49S

Otero M, Plumb DA, Tsuchimochi K, Dragomir CL, Hashimoto K, Peng H, Olivotto E, Bevilacqua M, Tan L, Yang Z, Zhan Y, Oettgen P, Li Y, Marcu KB, Goldring MB (2012): E74-like factor 3 (ELF3) impacts on matrix metalloproteinase 13 (MMP13) transcriptional control in articular chondrocytes under proinflammatory stress. J Biol Chem 287, 3559-3572

Paukkonen K, Helminen HJ (1987): Decrease of proteoglycan granule number but increase of their size in articular cartilage of young rabbits after physical exercise and immobilization by splinting. Anat Rec $\underline{219}$, 45-52

Pfaffl MW (2001): A new mathematical model for relative quantification in realtime RT-PCR. Nucleic Acids Res $\underline{29}$, e45

Pritzker KP (1994): Animal models for osteoarthritis: processes, problems and prospects. Ann Rheum Dis $\underline{53}, 406-20$

Polur I, Lee PL, Servais JM, Xu L, Li Y (2010): Role of HTRA1, a serine protease, in the progression of articular cartilage degeneration. Histol Histopathol $\underline{25}, 599-608$

Poole CA, Flint MH, Beaumont BW (1984): Morphological and functional interrelationships of articular cartilage matrices. J Anat $\underline{138}, 113-38$

Poole CA, Matsuoka A, Schofield JR (1991): Chondrons from articular cartilage. III. Morphologic changes in the cellular microenvironment of chondrons isolated from osteoarthritic cartilage. Arthritis Rheum 34, 22-35

Poole CA, Ayad S, Gilbert RT (1992): Chondrons from articular cartilage. V. Immunohistochemical evaluation of type VI collagen organisation in isolated chondrons by light, confocal and electron microscopy. J Cell Sci $\underline{103}, 1101-10$

Pozgan U, Caglic D, Rozman B, Nagase H, Turk V, Turk B (2010): Expression and activity profiling of selected cysteine cathepsins and matrix metalloproteinases in synovial fluids from patients with rheumatoid arthritis and osteoarthritis. Biol Chem $\underline{391}, 571-9$ 
Pulai JI, Chen H, Im HJ, Kumar S, Hanning C, Hedge PS, Loeser RF (2005): NFkappa B mediates the stimulation of cytokine and chemokine expression by human articular chondrocytes in response to fibronectin fragments. J Immunol 174, 5781-8

Raducanu A, Aszódi A (2008): Knock-Out Mice in Osteoarthritis Research. Curr Rheumatol Rev $\underline{4}, 183-92$

Reboul P, Pelletier JP, Tardif G, Cloutier JM, Martel-Pelletier J (1996): The new collagenase, collagenase-3, is expressed and synthesized by human chondrocytes but not by synoviocytes. A role in osteoarthritis. J Clin Invest $\underline{97}, 2011-9$

Rintala M, Metsäranta M, Säänänen AM, Vuorio E, Ronning O (1997): Abnormal craniofacial growth and early mandibular osteoarthritis in mice harbouring a mutant type II collagen transgene. J Anat 190 (Pt 2), 201-8

Rodriguez-Fontenla C, Calaza M, Evangelou E, Valdes AM et al. (2014):

Assessment of osteoarthritis candidate genes in a meta-analysis of nine genomewide association studies. Arthritis Rheumatol $\underline{66}, 940-9$

Rosen SD, Kafka JA, Simpson DL, Barondes SH (1973): Developmentally regulated, carbohydrate-binding protein in Dictyostelium discoideum. Proc Natl Acad Sci U S A $\underline{70}, 2554-7$

Rudert M, Wirth CJ (1998): Knorpelregeneration und Knorpelersatz. Orthopäde 27, 309-21

Salazar A, Polur I, Servais JM, Li Y, Xu L (2014): Delayed progression of condylar cartilage degeneration, by reduction of the discoidin domain receptor 2 , in the temporomandibular joints of osteoarthritic mouse models. J Oral Pathol Med $\underline{43}, 317-$ 21

Salter DM, Wright MO, Millward-Sadler SJ (2004): NMDA receptor expression and roles in human articular chondrocyte mechanotransduction. Biorheology $\underline{41}, 273-81$

Sandell LJ, Aigner T (2001): Articular cartilage and changes in arthritis. An introduction: cell biology of osteoarthritis. Arthritis Res $\underline{3}, 107-13$

Schmidt K-H: Kiefergelenk (Articulatio temporomandibularis). In: Drenckhahn D (Hrsg.): Benninghoff Anatomie. Band 1: Zellen- und Gewebelehre,

Entwicklungslehre, Skelett- und Muskelsystem, Atemsystem, Verdauungssystem, Harn- und Genitalsystem. 17., durchgesehene Auflage; Elsevier, Urban \& Fischer München Jena 2008, 513-515

Schminke B, Muhammad H, Bode C, Sadowski B, Gerter R, Gersdorff N, Burgers R, Monsonego-Ornan E, Rosen V, Miosge N (2014): A discoidin domain receptor 1 knock-out mouse as a novel model for osteoarthritis of the temporomandibular joint. Cell Mol Life Sci $\underline{71}, 1081-96$

Seegmiller R, Fraser FC, Sheldon H (1971): A new chondrodystrophic mutant in mice. Electron microscopy of normal and abnormal chondrogenesis. J Cell Biol $\underline{48}$, 580-93 
Shlopov BV, Lie WR, Mainardi CL, Cole AA, Chubinskaya S, Hasty KA (1997): Osteoarthritic lesions: involvement of three different collagenases. Arthritis Rheum $\underline{40}, 2065-74$

Shrivastava A, Radziejewski C, Campbell E, Kovac L, McGlynn M, Ryan TE, Davis S, Goldfarb MP, Glass DJ, Lemke G, Yancopoulos GD (1997): An orphan receptor tyrosine kinase family whose members serve as nonintegrin collagen receptors. Mol Cell $1,25-34$

Silbermann M, Livne E (1979): Age-related degenerative changes in the mouse mandibular joint. J Anat $\underline{129}, 507-20$

Smits P, Dy P, Mitra S, Lefebvre V (2004): Sox5 and Sox6 are needed to develop and maintain source, columnar, and hypertrophic chondrocytes in the cartilage growth plate. J Cell Biol 164, 747-58

Snead MP, Yates JR (1999): Clinical and molecular genetics of Stickler syndrome. J Med Genet 36, 353-9

Sugiki T, Uyama T, Toyoda M, Morioka H, Kume S, Miyado K, Matsumoto K, Saito H, Tsumaki N, Takahashi Y, Toyama Y, Umezawa A (2007): Hyaline cartilage formation and enchondral ossification modeled with KUM5 and OP9 chondroblasts. J Cell Biochem 100, 1240-54

Suk EK, Malkin I, Dahm S, Kalichman L, Ruf N, Kobyliansky E, Toliat M, Rutsch F, Nurnberg P, Livshits G (2005): Association of ENPP1 gene polymorphisms with hand osteoarthritis in a Chuvasha population. Arthritis Res Ther $\underline{7}$, R1082-90.

Sunk IG, Bobacz K, Hofstaetter JG, Amoyo L, Soleiman A, Smolen J, Xu L, Li Y (2007): Increased expression of discoidin domain receptor 2 is linked to the degree of cartilage damage in human knee joints: a potential role in osteoarthritis pathogenesis. Arthritis Rheum $\underline{56}, 3685-92$

Symons NB (1965): A histochemical study of the secondary cartilage of the mandibular condyle in the rat. Arch Oral Biol $\underline{10}, 579-84$

TenBroek EM (2016): Randomized controlled studies on the efficacy of antiarthritic agents in inhibiting cartilage degeneration and pain associated with progression of osteoarthritis in the rat. Arthritis Res Ther $\underline{18}, 24$

Tesche F, Miosge N (2005): New aspects of the pathogenesis of osteoarthritis: the role of fibroblast-like chondrocytes in late stages of the disease. Histol Histopathol $\underline{20}, 329-37$

Timpl R (1996): Macromolecular organization of basement membranes. Curr Opin Cell Biol $\underline{8}, 618-24$

Van der Geer P, Wiley S, Gish GD, Lai VK, Stephens R, White MF, Kaplan D, Pawson T (1996): Identification of residues that control specific binding of the Shc 
phosphotyrosine-binding domain to phosphotyrosine sites. Proc Natl Acad Sci U S A $\underline{93}, 963-8$

Verzijl N, DeGroot J, Thorpe SR, Bank RA, Shaw JN, Lyons TJ, Bijlsma JW, Lafeber FP, Baynes JW, TeKoppele JM (2000): Effect of collagen turnover on the accumulation of advanced glycation end products. J Biol Chem $\underline{275}, 39027-31$

Vogel W (1999): Discoidin domain receptors: structural relations and functional implications. FASEB J 13 Suppl, S77-82

Vogel W, Gish GD, Alves F, Pawson T (1997): The discoidin domain receptor tyrosine kinases are activated by collagen. Mol Cell 1, 13-23

Vogel W, Aszodi A, Alves F, Pawson T (2001): Discoidin domain receptor 1 tyrosine kinase has an essential role in mammary gland development. Mol Cell Biol 21, 290617

Von der Mark K, Kirsch T, Nerlich A, Kuss A, Weseloh G, Gluckert K, Stoss H (1992): Type $X$ collagen synthesis in human osteoarthritic cartilage. Indication of chondrocyte hypertrophy. Arthritis Rheum $\underline{35}$, 806-11

Wadhwa S, Embree M Ameye L, Young MF (2005): Mice deficient in biglycan and fibromodulin as a model for temporomandibular joint osteoarthritis. Cells Tissues Organs $\underline{181}, 136-43$

Wang X, Manner PA, Horner A, Shum L, Tuan RS, Nuckolls GH (2004): Regulation of MMP-13 expression by RUNX2 and FGF2 in osteoarthritic cartilage. Osteoarthritis Cartilage 12, 963-73

Wang XD, Zhang JN, Gan YH, Zhou YH (2015): Current understanding of pathogenesis and treatment of TMJ osteoarthritis. J Dent Res $\underline{94}$, 666-73

Weiner HL, Rothman M, Miller DC, Ziff EB (1996): Pediatric brain tumors express multiple receptor tyrosine kinases including novel cell adhesion kinases. Pediatr Neurosurg 25, 64-71; discussion 71-2

Wong M, Wuethrich P, Eggli O, Hunziker E (1996): Zone-specific cell biosynthetic activity in mature bovine articular cartilage: a new method using confocal microscopic stereology and quantitative autoradiography. J Orthop Res $\underline{14}$, 424-32

Wu JJ, Eyre DR (1989) Covalent interactions of type IX collagen in cartilage. Connect Tissue Res 20, 241-6

Wu WW, Wong JP, Kast J, Molday RS (2005): RS1, a discoidin domain-containing retinal cell adhesion protein associated with $X$-linked retinoschisis, exists as a novel disulfide-linked octamer. J Biol Chem 280, 10721-30

Xu L, Flahiff CM, Waldmann BA, Wu D, Olsen BR, Setton LA, Li Y (2003):

Osteoarthritis-like changes and decreased mechanical function of articular cartilage in the joints of mice with the chondrodysplasia gene (cho). Arthritis Rheum $\underline{48}, 2509$ 18 
Xu L, Peng H, Wu D, Hu K, Goldring MB, Olsen BR, Li Y (2005): Activation of the discoidin domain receptor 2 induces expression of matrix metalloproteinase 13 associated with osteoarthritis in mice. J Biol Chem 280, 548-55

Xu L, Peng H, Glasson S, Lee PL, Hu K, ljiri K, Olsen BR, Goldring MB, Li Y (2007): Increased expression of the collagen receptor discoidin domain receptor 2 in articular cartilage as a key event in the pathogenesis of osteoarthritis. Arthritis Rheum $\underline{56}$, 2663-73

Xu L, Polur I, Lim C, Servais JM, Dobeck J, Li Y, Olsen BR (2009): Early-onset osteoarthritis of mouse temporomandibular joint induced by partial discectomy. Osteoarthritis Cartilage 17, 917-22

Xu L, Servais J, Polur I, Kim D, Lee PL, Chung K, Li Y (2010): Attenuation of osteoarthritis progression by reduction of discoidin domain receptor 2 in mice. Arthritis Rheum $\underline{62}, 2736-44$

Zamli Z, Sharif M (2011): Chondrocyte apoptosis: a cause or consequence of osteoarthritis? Int J Rheum Dis $\underline{14}, 159-66$

Zhai G, van Meurs JB, Livshits G, Meulenbelt I, Valdes AM, Soranzo N, Hart D, Zhang F, Kato BS, Richards JB, Williams FM, Inouye M, Kloppenburg M, Deloukas P, Slagboom E, Uitterlinden A, Spector TD (2009): A genome-wide association study suggests that a locus within the ataxin 2 binding protein 1 gene is associated with hand osteoarthritis: the Treat-OA consortium. J Med Genet $\underline{46}, 614-6$.

Zheng Q, Zhou G, Morello R, Chen Y, Garcia-Rojas X, Lee B (2003): Type X collagen gene regulation by Runx2 contributes directly to its hypertrophic chondrocyte-specific expression in vivo. J Cell Biol 162, 833-42

Zhou G, Zheng Q, Engin F, Munivez E, Chen Y, Sebald E, Krakow D, Lee B (2006): Dominance of SOX9 function over RUNX2 during skeletogenesis. Proc Natl Acad Sci U S A $\underline{103}, 19004-9$ 


\section{Amendment}

Zur Sicherung guter wissenschaftlicher Praxis weisen der Verfasser dieser Dissertationsschrift, Herr Leonard Hoene, und der Doktorvater Herr Prof. Dr. med. Nicolai Miosge daraufhin, dass ein bestimmter, in den Legenden genau ausgewiesener Anteil dieser Arbeit bereits publiziert wurde.

Der Name des Doktoranden (Leonard Hoene) wurde allein durch das Versäumnis des Seniorautors (Prof. Dr. med. N. Miosge) nicht in der Publikation Schminke, Muhammad et al. (2014) A discoidin domain receptor 1 knock-out mouse as a novel model for osteoarthritis of the temporomandibular joint. Cell Mol Life Sci. 71(6):1081-96) aufgeführt.

Die Promotionskommission wurde hiervon schriftlich in Kenntnis gesetzt. Die Kommission hat am 12.07.2018 festgestellt, dass Herr Leonard Hoene glaubhaft dokumentieren kann, einen signifikanten Beitrag an der Datenerstellung und auswertung geleistet zu haben und

dass ihm nach anerkannten Grundsätzen der Autorenregelung eine Koautorenschaft auf besagter Publikation zustünde.

Die Arbeit wurde am 12.07.2018 endgültig als Dissertationsleistung angenommen.

Göttingen, den

Unterschrift

(N. Miosge)
Unterschrift

(L. Hoene) 